\title{
LUCIANO BELOTTI
}

Efeitos cardiopulmonares da exposição ao material particulado fino $\left(\mathrm{MP}_{2,5}\right)$ proveniente do concentrador de partículas ambientais (CPA) na hipertrofia ventricular esquerda de ratos wistar

Dissertação apresentada à Faculdade de Medicina da Universidade de São Paulo para obtenção do título de Mestre em Ciências

Programa: Fisiopatologia Experimental

Orientador: Prof. Dr. Paulo Hilário Nascimento Saldiva

\section{SÃO PAULO}

2012 


\section{LUCIANO BELOTTI}

Efeitos cardiopulmonares da exposição ao material particulado fino $\left(\mathrm{MP}_{2,5}\right)$ proveniente do concentrador de partículas ambientais (CPA) na hipertrofia ventricular esquerda de ratos wistar

Dissertação apresentada à Faculdade de Medicina da Universidade de São Paulo para obtenção do título de Mestre em Ciências

Programa: Fisiopatologia Experimental

Orientador: Prof. Dr. Paulo Hilário Nascimento Saldiva

\section{SÃO PAULO}

2012 
Dados Internacionais de Catalogação na Publicação (CIP)

Preparada pela Biblioteca da

Faculdade de Medicina da Universidade de São Paulo

Creprodução autorizada pelo autor

Belotti, Luciano

Efeitos cardiopulmonares da exposição ao material particulado fino $\left(\mathrm{MP}_{2,5}\right)$ proveniente do concentrador de partículas ambientais (CPA) na hipertrofia ventricular esquerda de ratos wistar / Luciano Belotti. -- São Paulo, 2012.

Dissertação (mestrado)--Faculdade de Medicina da Universidade de São

Paulo.

Programa de Fisiopatologia Experimental.

Orientador: Paulo Hilário Nascimento Saldiva.

Descritores: 1.Estereologia do coração 2.Hipertrofia ventricular esquerda 3.Isoproterenol 4.Material particulado 5.Frequência cardíaca 6.Cardiomiopatia hipertrófica

USP/FM/DBD-329/12 
"A escolha certa não é necessariamente a escolha segura, confortável ou óbvia."

"Se nos deixarmos ser controlados pelo medo de tropeçar, podemos andar somente pelos caminhos mais largos e mais usados. Se nos recusarmos a aceitar que cometemos erros, então ficaremos avessos a arriscar; e se não arriscarmos, é possível que nunca encontremos nossa paixão, ou nosso verdadeiro eu."

Peter Buffet 


\section{DEDICATÓRIA}

Aos meus pais José Belotti Neto, Renato Lang, Antonio Roberto Sanches, Maria Cristina Olivarez Lang, Sonia Seixas e Joana Aparecida Sanches. Minha eterna gratidão pelos ensinamentos e o persistente apoio.

A minha irmã Cristiane Belotti e aos meus irmãos André Ricardo Sanches, Antonio Roberto Sanches Júnior e Fernando Rodrigo Sanches, exemplos de dedicação e determinação. Obrigado por me propiciarem momentos inesquecíveis.

Mãe

"Disciplina é liberdade......" (Renato Russo)

Pai

Obrigado por acreditar! 


\section{AGRADECIMENTOS}

Ao Prof. Dr. Paulo Hilário Nascimento Saldiva pela motivação e as grandes ideias que proporcionaram o desenvolvimento deste trabalho.

A Dra. Mariana Matera Veras meu imensurável agradecimento pelo acolhimento e fundamental contribuição para o desenvolvimento e desfecho deste trabalho.

A Jôse Mára de Brito pela colaboração, auxílio e amizade durante o desenvolvimento deste trabalho

A orientação da Profa. Dra. Dolores Helena Rodriguez Ferreira no inicio deste trabalho, pelo convite e oportunidade de trabalhar no LPAE.

Aos amigos Luiz Afonso Pires, Mac Gayver da Silva Castro e Robson Seriani pela amizade e companheirismo durante o todo o período de estudo e divertimento.

Ao Guilherme, Gabriel e Laís minha sincera gratidão pela ajuda e dedicação que foram oferecidas neste trabalho. 


\section{SUMÁRIO}

Lista de quadros

Lista de figuras

Lista de tabelas

Lista de siglas

Lista de símbolos

Resumo

Abstract

\section{INTRODUÇÃO}

1.1. Poluição Atmosférica

1.1.1. Histórico

1.1.2. Conceito

1.1.3. Padrões de Qualidade do ar

1.1.4. Monitoramento da Poluição Atmosférica no Estado de São Paulo e Região Metropolitana

1.1.5. Principais Medidas de Controle da Poluição Atmosférica no Estado de São Paulo

1.1.6. Material Particulado

1.2. Evidências dos efeitos adversos à saúde humana e sistema cardiopulmonar causado pela exposição ao material particulado

1.3. Cardiomiopatia hipertrófica

1.3.1. Hipertrofia Ventricular Esquerda induzida pelo isoproterenol

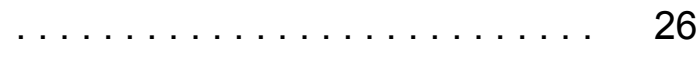

\section{JUSTIFICATIVA}

3. OBJETIVOS

4. MATERIAL E MÉTODOS 
4.4. Exposição ao material particulado concentrado

4.5. Caracterização do material particulado

4.6. Registro da frequência cardíaca, variabilidade da frequência cardíaca e pressão arterial

4.7. Hemograma

4.7.1. Coleta do sangue e processamento do hemograma

4.8. Lavado Broncoalveolar

4.9. Coleta dos órgãos

$\ldots \ldots \ldots \ldots \ldots \ldots \ldots+\cdots \ldots$

4.10. Cálculo do índice de Hipertrofia Cardíaca e estimativa da dose

4.11. Avaliação estereológica do coração

4.11.1. Amostragem

4.11.2. Volume dos ventrículos

4.11.3. Estimativa do volume individual dos ventrículos e do septo interventricular

4.11.4. Avaliação da densidade de volume de cardiomiócitos, tecido conjuntivo, capilares

4.11.5. Avaliação do diâmetro e volume ponderado dos cardiomiócitos do ventrículo esquerdo

4.12. Análise estatística

5. RESULTADOS

5.1. Composição elementar do material particulado

5.2. Peso Corporal

5.3. Peso dos órgãos - Pulmão, Fígado, Rins, Baço e de dose inalada 
5.5. Análise da inflamação pulmonar pelo lavado

5.6. Dados do Hemograma

5.7. Estudo estereológico do coração

5.7.1 Volume total (VT) e Densidade de Volume (Vv) dos principais compartimentos cardíacos

5.7.2. Espessura da parede ventricular

5.7.3. Volume total (VT) e Densidade de Volume (Vv) dos constituintes teciduais do ventrículo esquerdo

5.7.4. Diâmetro médio e volume médio ponderado dos cardiomiócitos do ventrículo esquerdo

5.8. Avaliação eletrocardiográfica

6. DISCUSSÃO

7. CONCLUSÃO

8. ANEXOS

9. REFERENCIAS BIBLIOGRÁFICA 


\section{LISTA DE QUADROS}

Quadro 1 - Relação dos Poluentes com os valores máximos e tempo de exposição de acordo com os Padrões nacionais de qualidade do

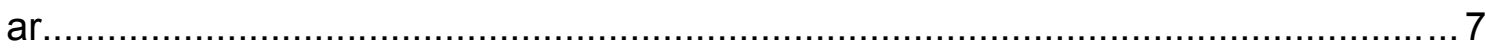

Quadro 2 - Valores recomendados segundo a revisão das Diretrizes da

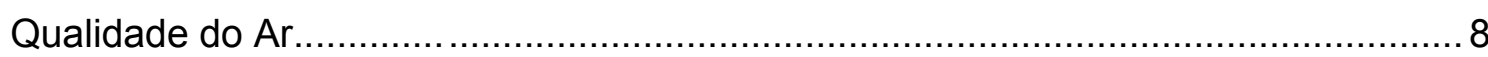

Quadro 3 - O aumento do número total de veículos durante os anos de 2007 ,

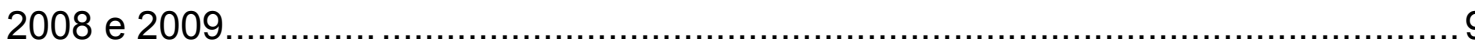




\section{LISTA DE FIGURAS}

Figura 1 - Comparação do tamanho aerodinâmico das partículas $\left(\mathrm{MP}_{2,5}-\mathrm{MP}_{10}\right)$ com outros materiais

Figura 2 - Ilustração da composição do MP produzido pela combustão do diesel.

Figura 3 - Componentes do Sarcômero. Os percentuais representam a frequência estimada com o qual uma mutação no gene correspondente atua na $\mathrm{CMH}$.......

Figura 4 - Histopatologia da $\mathrm{CMH}$. (A). Distribuição normal das miofibrilas do miocárdio ventricular saudável com alinhamento ordenado de miócitos com fibrose intersticial mínima (hematoxilina-eosina). (B) Nítido alargamento intersticial e desordem dos miócitos (vermelho) com o aumento da fibrose intersticial (azul) evidente na CMH (Tricromo de Masson).

Figura 5 - (A) Espécime patológico de um paciente que morreu subitamente com CMH (Ommen et al., 2011). (B) Coração normal, com espessura e dimensões normais do VE.

Figura 6 - $\quad$ Representação esquemática do protocolo experimental.

Figura 7 - CPA, o biotério para acomodação dos animais (Rack de manutenção dos animais), o sistema de impactadores virtuais e as câmaras onde os animais eram acomodados para as exposições

Figura 8 - Composição elementar do MP2,5 proveniente do ambiente. S, enxofre; $\mathrm{Na}$, sódio; Al, alumínio; Si, silício; Ca, cálcio; Fe, ferro; K, potássio; $\mathrm{P}$, fósforo; Zn, zinco; $\mathrm{Cu}$, cobre; Ti, titânio ; $\mathrm{Pb}$, chumbo; $\mathrm{V}$, vanádio; $\mathrm{Ni}$, níquel 
Figura 9 - Representação gráfica do peso médio dos animais aos 7, 15 e 21 dias de exposição ao $\mathrm{MP}_{2,5}$ concentrado.

Figura 10 - Representação gráfica do peso médio do fígado dos animais sadios e com $\mathrm{CMH}$ aos 7,15 e 21 dias de exposição ao $\mathrm{MP}_{2,5}$ concentrado

Figura 11 - Representação gráfica do peso médio do cérebro dos animais de cada grupo $($ ISOP $=I$ e salina $=\mathrm{S})$ CPA e AF $(7,15$ e 21 dias)

Figura 12 - Representação gráfica do peso médio dos rins nos animais sadios e com $\mathrm{CMH}$ aos 7,15 e 21 dias de exposição ao $\mathbf{M P}_{2,5}$ concentrado

Figura 13 - Representação gráfica da porcentagem média de macrófagos do LBA nos animais sadios e com $\mathrm{CMH}$ aos 7, 15 e 21 dias de exposição ao $\mathrm{MP}_{2,5}$ concentrado

Figura 14 - Representação gráfica do número total de células do LBA nos animais sadios e com $\mathrm{CMH}$ aos 7,15 e 21 dias de exposição ao $\mathrm{MP}_{2,5}$ concentrado.

Figura 15 - Representação gráfica da porcentagem média do Hematócrito nos animais sadios e com $\mathrm{CMH}$ aos 7, 15 e 21 dias de exposição ao $\mathrm{MP}_{2,5}$ concentrado

Figura 16 - Representação gráfica da média do VCM fL (fentolitros) nos animais sadios e com $\mathrm{CMH}$ aos 7,15 e 21 dias de exposição ao $\mathrm{MP}_{2,5}$ concentrado 
Figura 17 - Representação gráfica da média do HCM pg (picogramas) nos animais sadios e com $\mathrm{CMH}$ aos 7,15 e 21 dias de exposição ao $\mathrm{MP}_{2,5}$ concentrado

Figura 18 - Representação gráfica da porcentagem média da amplitude de distribuição dos eritrócitos representados como coeficiente de variação (RDW CV) nos animais sadios e com $\mathrm{CMH}$ aos 7, 15 e 21 dias de exposição ao $\mathrm{MP}_{2,5}$ concentrado 60

Figura 19 - Gráfico Box plot do volume total dos ventrículos (direito e esquerdo) nos animais normais (salina) e cardiopatas (ISOP) expostos ou não a poluição ao longo do tempo

Figura 20 - Gráfico de barras da densidade de volume média dos diferentes compartimentos cardíacos nos grupos estudados

Figura 21 - Gráfico de barras do volume total médio dos diferentes compartimentos cardíacos nos grupos estudados.

Figura 22 - Gráfico Box Plot da espessura média da parede livre do VE nos animais dos grupos experimentais.

Figura 23 - Gráfico de barras da densidade de volume totais de cardiomiócitos, tecido conjuntivo e vasos sanguíneos

Figura 24 - Gráfico de barras dos volumes totais médio de cardiomiócitos, tecido conjuntivo e vasos sanguíneos.

Figura 25 - Gráfico Box plot do diâmetro médio do cardiomiócito nos animais dos grupos experimentais

Figura 26 - Gráfico Box plot do volume individual médio do cardiomiócito nos animais dos grupos experimentais. 
Figura 27 - Gráfico Box plot representando a média do SDNN (ms) dos animais após o tratamento (ISOP e salina) durante os dias de exposição.

Figura 28 - Gráfico Box plot representando a média do RMSSD (ms) dos animais após o tratamento (ISOP e salina) durante os dias de exposição.

Figura 29 - Gráfico Box plot representando a média do $\operatorname{LF}\left(\mathrm{ms}^{2}\right)$ dos animais após o tratamento (ISOP e salina) durante os dias de exposição.......

Figura 30 - Gráfico Box plot representando a média do HF $\left(\mathrm{ms}^{2}\right)$ dos animais após o tratamento (ISOP e salina) durante os dias de exposição.

Figura 31 - Gráfico Box plot representando a média da razão LF/HF dos animais após o tratamento (ISOP e salina) durante os dias de exposição

Figura 32 - Gráfico Box plot representando a média de batimentos cardíacos dos animais após o tratamento (ISOP e salina) durante os dias de exposição.

Figura 33 - Gráfico Box plot representando a média da pressão arterial $(\mathrm{mmHg})$ dos animais após o tratamento (ISOP e salina) durante os dias de exposição 


\section{LISTA DE TABELAS}

Tabela 1 - Médias, desvio padrão (DP) e erro padrão (EP) para o peso corporal dos animais nos grupos estudados..................................................... 50

Tabela 2 - Médias, desvio padrão (DP) e erro padrão (EP) para o número total de células do LBA nos grupos estudados.

Tabela 3 - Médias, desvio padrão (DP) e erro padrão (EP) para a porcentagem de macrófagos do LBA nos grupos estudados. 


\section{LISTA DE SIGLAS}

AF

Apheis

B2

B5

Cetesb

$\mathrm{CMH}$

CONAMA

COVs

CPA

DP

EP

eNOS

ERO

EVS

FC

HF

HVE

IAG - USP

IAM

$\mathrm{IHC}$

ISOP

LBA

LF

LF/HF

MMA

MP

$\mathrm{MP}_{0,1}$

$\mathrm{MP}_{2,5}$

$\mathrm{MP}_{10}$

NAAQS

NESHAPS
Ar filtrado

Air Pollution and Health - A European Information System

$2 \%$ de biodiesel acrescido de $98 \%$ de diesel

$5 \%$ de biodiesel acrescido de $95 \%$ de diesel

Companhia de Tecnologia de Saneamento Ambiental

Cardiomiopatia hipertrófica

Conselho Nacional do Meio Ambiente

Compostos orgânicos voláteis

Concentrador de partículas ambientais

Desvio padrão

Erro padrão

Endothelial nitric oxide synthase

Espécies reativas de oxigênio

Em vias de saturação

Frequência cardíaca

high frequency

Hipertrofia ventricular esquerda

Instituto de Astronomia e Geofísica da Universidade de São

Paulo

Infarto agudo do miocárdio

Índice de Hipertrofia cardíaca

Isoproterenol

Lavado Broncoalveolar

low frequency

Razão Low frequency / High frequency

Ministério do Meio Ambiente

Material Particulado

Material particulado com diâmetro inferior a 0,1 $\mu \mathrm{m}$

Material particulado com diâmetro inferior a 2,5 $\mu \mathrm{m}$

Material particulado com diâmetro inferior a $10 \mu \mathrm{m}$

National Ambient Air Quality Standards

National Emission Standards for Hazardous Air Pollutants 


$\begin{array}{ll}\text { NSPS } & \text { New Source Performance Standards } \\ \text { PA } & \text { Pressão arterial } \\ \text { PAD } & \text { Pressão arterial diastólica } \\ \text { PBS } & \text { Phosphate Buffer Saline } \\ \text { PED } & \text { Partículas de exaustão de diesel } \\ \text { PREA } & \text { Programa de Redução de Emissões Atmosféricas } \\ \text { PROCONVE } & \text { Programa de Controle da Poluição do Ar por Veículos } \\ & \text { Automotores } \\ \text { PTS } & \text { Partículas totais em suspensão } \\ \text { RMSP } & \text { Região Metropolitana de São Paulo } \\ \text { RMSSD } & \text { Square root of mean of sum of squares of differences } \\ & \text { between adjacent NN-intervals } \\ \text { SAL } & \text { Salina } \\ \text { SDNN } & \text { Standard deviation of the normal-to-normal } \\ \text { SEBRAE } & \text { Serviço Brasileiro de Apoio às Micro e Pequenas Empresas } \\ \text { SIPs } & \text { State Implementation Plans } \\ \text { SNA } & \text { Sistema nervoso autonômico } \\ \text { SNC } & \text { Sistema nervoso central } \\ \text { TTPA } & \text { Tempo tromboplastina parcial ativada } \\ \text { VFC } & \end{array}$




\section{LISTA DE SÍMBOLOS}

\begin{tabular}{|c|c|}
\hline${ }^{\circ} \mathrm{C}$ & Graus Celsius \\
\hline$\left(\left(\mathrm{CH}_{3}\right)_{2} \mathrm{~S}\right)$ & Dimetilsulfeto \\
\hline $\mathrm{CH}_{3} \mathrm{SH}$ & Metil-mercaptana \\
\hline $\mathrm{CH}_{3} \mathrm{SSCH}_{3}$ & Dimetil-dissulfeto \\
\hline $\mathrm{CO}$ & Monóxido de carbono \\
\hline $\mathrm{CO}_{2}$ & Dióxido de carbono \\
\hline $\cos$ & Sulfeto de carbonila \\
\hline $\mathrm{fL}$ & fenolitros \\
\hline g & Gramas \\
\hline $\mathrm{h}$ & Horas \\
\hline $\mathrm{HC}$ & Hidrocarbonetos \\
\hline $\mathrm{Hg}$ & Mercúrio \\
\hline $\mathrm{H}_{2} \mathrm{O}$ & Água \\
\hline $\mathrm{H}_{2} \mathrm{O}_{2}$ & Peróxido de hidrogênio \\
\hline $\mathrm{H}_{2} \mathrm{~S}$ & Sulfeto de hidrogênio \\
\hline $\mathrm{Kg}$ & Kilograma \\
\hline $\mathrm{Km}$ & Quilômetro \\
\hline $\mathrm{m}$ & Metro \\
\hline $\min$ & Minutos \\
\hline $\mathrm{mg}$ & Miligrama \\
\hline$\mu g$ & Micrograma \\
\hline $\mathrm{ml}$ & Mililitro \\
\hline $\mathrm{mm}$ & Milímetro \\
\hline$\mu \mathrm{m}$ & Micrômetro \\
\hline $\mathrm{mM}$ & Milimolar \\
\hline $\mathrm{ms}$ & Metros por segundo \\
\hline $\mathrm{NaCl}$ & Cloreto de sódio \\
\hline $\mathrm{Na}_{3} \mathrm{C}_{6} \mathrm{H}_{5} \mathrm{O}_{7}$ & Cítrato de sódio \\
\hline $\mathrm{NO}_{x}$ & Óxidos de nitrogênio \\
\hline $\mathrm{NO}_{2}$ & Dióxido de nitrogênio \\
\hline $\mathrm{O}_{2}$ & Oxigênio \\
\hline $\mathrm{O}_{3}$ & Ozônio \\
\hline
\end{tabular}


$\mathrm{Pg}$

ppm

rpm

$\mathrm{SO}_{\mathrm{x}}$

$\mathrm{SO}_{2}$ pictogramas

Partes por milhão

Rotação por minuto

Óxido de enxofre

Dióxido de enxofre 


\section{RESUMO}

Belotti, L. Efeitos cardiopulmonares da exposição ao material particulado fino $\left(M P_{2,5}\right)$ provenientes do concentrador de partículas ambientais (CPA) na Hipertrofia Ventricular esquerda de ratos wistar [dissertação]. São Paulo: "Faculdade de Medicina, Universidade de São Paulo"; 2012.

Estudos epidemiológicos e experimentais tem mostrado consistentemente que tanto as exposições agudas e crônicas à poluição do ar estão associadas com uma variedade de doenças cardiovasculares. A poluição atmosférica é composta por uma mistura de substâncias nocivas incluindo partículas e gases. Os efeitos adversos cardiovasculares são mais comumente atribuídos às partículas e experimentos toxicológicos tem demonstrado diferentes mecanismos pelos quais a exposição às partículas pode provocar estes efeitos. Neste estudo nos investigamos os efeitos do tempo (7, 15 e 21 dias) de exposição as partículas ambientais (dose $=600 \mu \mathrm{g} / \mathrm{m}^{3}$ ) nos parâmetros funcionais e morfológicos do coração de ratos normais e ratos com hipertrofia ventricular esquerda (HVE) induzida pelo isoproterenol (agonista não seletivo $\beta$-adrenérgico de ação direta) $(1,2 \mathrm{mg} / \mathrm{kg})$. A utilização de ratos com HVE foi motivado pelo fato de que a existência de uma doença cardiovascular prévia representa um fator de risco elevado para estes indivíduos. Nossos dados mostraram que o tempo de exposição ao material particulado concentrado é um fator importante para a magnitude dos efeitos sobre a função e morfologia do coração, como mostrado pelo aumento da variabilidade da frequência cardíaca, diminuição da frequência cardíaca e aumento no volume de tecido conjuntivo no miocárdio do ventrículo esquerdo. Os ratos com HVE mostraram efeitos similares, porém mais graves sobre o coração, que incluíram diminuição da pressão arterial e aumento da hipertrofia dos cardiomiócitos em comparação com ratos com HVE não expostos. Concluindo, nossos resultados corroboram com achados anteriores que mostram que a poluição atmosférica particulada induz alterações no controle autonômico do coração e que indivíduos com doenças cardiovasculares preexistentes são mais afetados que indivíduos normais. Mostramos ainda que o material particulado concentrado é capaz de induzir alterações na microestrutura do miocárdio, dependendo da dose acumulada de exposição.

Descritores: Estereologia do coração, Hipertrofia ventricular esquerda, Isoproterenol, Material particulado, Frequência cardíaca, Cardiomiopatia hipertrófica. 


\begin{abstract}
Belotti, L. Cardiopulmonary effects of the exposure to fine particulate matter $\left(P M_{2,5}\right)$ from an ambient particle concentrator on left ventricular hypertrophy in Wistar rats [dissertation]. São Paulo: "Faculdade de Medicina, Universidade de São Paulo"; 2012.

Epidemiological and experimental studies have consistently shown that both short- and long-term exposures to air pollution are associated with a variety of cardiovascular diseases. Air pollution is composed by a mixture of noxious substance including particles and gases. The cardiovascular adverse effects are more commonly attributed to particles and toxicological experiments have demonstrated several mechanisms by which particle exposure may trigger these effects. In this study we investigated the effects of time (7, 15 and 21 days) of exposure to concentrated ambient particles (dose $=600 \mu \mathrm{g} / \mathrm{m}^{3}$ ) on morphofunctional parameters of the heart in normal and rats with left ventricular hypertrophy ( $\mathrm{LVH}$ ) induced by isoproterenol (nonselective $\beta$-adrenergic agonist with direct action) $(1.2 \mathrm{mg} / \mathrm{kg})$. The use of LVH rats was motivated by the fact that individuals with cardiovascular diseases are considered at higher risk for effect of ambient PM. Our data have shown that time is an important factor on the magnitude of the effects of concentrated ambient particles on heart function and morphology, as shown by increased HRV (heart rate variability), decreased heart rate and increased volume of connective tissue in left ventricle myocardium. LVH rats presented similar outcomes but more severe effects on the heart which included decreased blood pressure and increased cardiomyocyte hypertrophy compared to non-exposed LVH rats. In conclusion, our results corroborate with previous findings that particulate air pollution induces changes in the autonomic control of the heart and that individual with previous cardiovascular disease are more affected than normal ones. We have further shown that concentrated ambient particles are capable of inducing changes in the microstructure of the myocardium depending on accumulated dose of exposure.
\end{abstract}

Descriptors: Heart stereology, Left ventricular hypertrophy, Isoproterenol, Particulate matter, Heart rate, Hypertrophic cardiomyopathy. 


\section{INTRODUÇÃO}

Apesar dos avanços alcançados nas recentes décadas voltados a um ambiente com ar mais limpo, principalmente em países desenvolvidos, os níveis atuais demonstrados em estudos indicam que a maior parcela da população humana ainda sofre com os danos causados à saúde (Brunekreef e Holgate, 2002; Gouveia et al., 2006; Saldiva, 2008; Dockery, 2009; Sierra-Vargas e Teran, 2012). Com o aumento do crescimento populacional, a expansão urbana, o número de veículos e outras fontes, os impactos causados pela poluição atmosférica na qualidade de vida se tornam mais aparentes (Craig et al., 2008).

A Poluição atmosférica resultante da atividade humana é considerada um fator determinante na constante transformação do ambiente urbano ao longo dos séculos desde a introdução do fogo como formas de aquecimento e para cozinhar. A inalação dos produtos gerados pela queima de biomassa e combustíveis fósseis tais como as emissões de partículas e gases, tem sido reconhecida como causa de doenças e morte prematura (Ayres, 2006; Hedley, 2009). Sendo as partículas finas consideradas como um dos principais fatores de risco determinantes para 0 acometimento $e$ agravos das doenças cardiovasculares nas comunidades urbanas (Mills et al., 2009; Brook et al., 2010; Ito et al., 2011; Anderson et al., 2012; Franchini e Mannucci, 2012).

Embora o entendimento dos mecanismos patológicos responsáveis pela relação entre exposição a poluição atmosférica e as doenças cardiovasculares não esteja totalmente compreendido (Zareba et al., 2001; Brook, 2008; Shrey et al., 2011), estudos experimentais, clínicos e epidemiológicos indicam que a exposição a fração particulada fina é capaz de provocar disfunções do sistema nervoso autônomo (Pope III et al., 2004a; Rivero et al., 2005a; Adar et al., 2007; Burgan et al., 2010; jia et al., 2012), remodelamento ventricular (Wold et al., 2012) e processos inflamatórios sistêmicos comprometendo o sistema cardiovascular 
(Feng e Yang, 2012; Grahame e Schlesinger, 2012, Langrish et al., 2012).

Outros estudos também indicam que além do tipo de poluente, a concentração, o tempo de exposição, a presença de outros poluentes coexistentes (gases), a susceptibilidade individual (Kampa e Castanas, 2008), e a idade (idosos, crianças) e doenças prévias (Saldiva et al., 1994; Saldiva et al., 1995; Cançado et al., 2006; Sierra-Vargas e Teran, 2012) podem modificar, modular e mesmo agravar os efeitos da exposição. Neste cenário, a toxicidade cardiovascular decorrente da exposição a poluentes atmosféricos mostra-se como um importante fator de risco e um problema de saúde pública principalmente nos centros urbanos.

\subsection{Poluição Atmosférica}

\subsubsection{Histórico}

A Revolução Industrial teve início no final do século XVIII, na Inglaterra. A mecanização dos sistemas de produção com a utilização de carvão e caldeiras movidas a óleo em usinas, navios, locomotivas, fábricas e a introdução de máquinas a vapor em meados de 1800, tiveram como consequências intensas emissões de poluentes na atmosfera e consequentemente uma variedade de doenças humanas associadas a ela. O incentivo para a criação de agências governamentais comprometidas com o controle e limitações das emissões atmosféricas, não foram suficientes e apesar do reconhecimento dos efeitos à saúde, pouco se fez para controlar efetivamente as emissões de poluentes na atmosfera (Phalen e Phalen, 2011).

$\mathrm{Na}$ história moderna, muitos episódios críticos de poluição incentivaram ações de saúde pública para proteger as populações contra as emissões de poluentes para a atmosfera (Hedley, 2009). 
Os três principais episódios ocorreram na primeira metade do século $\mathrm{XX}$, na Europa e nos Estados Unidos. O primeiro ocorreu no leste da Bélgica no Vale do Rio Meuse, uma região fortemente industrializada, repleta de usinas de energia elétrica, fábricas e com considerável tráfego de caminhões, automóveis, ferrovias e o uso doméstico intenso de carvão. Em dezembro de 1930, um denso nevoeiro cobriu o Vale do Meuse durante um período de seis dias como consequência da combinação de baixas temperaturas, ventos de baixa velocidade e alta concentração de poluentes. Foram atribuídas ao episódio, cerca de 60 mortes, a maioria de idosos e pessoas com doenças cardíacas e pulmonares preexistentes e aproximadamente 6000 pessoas com sintomas de dor no peito, tosse, falta de ar e alguns com sinais de edema pulmonar. A causa destes efeitos a saúde foram atribuídas ás emissões de combustíveis com elevado teor de enxofre, incluindo o dióxido de enxofre e elevados níveis de partículas (Hedley, 2009; Phalen e Phalen, 2011).

O segundo episódio é um caso parecido com o ocorrido no Vale do Meuse. O principal combustível utilizado foi o carvão para fins domésticos e em processos industriais. Em outubro de 1948 em Donora no sudoeste da Pensilvânia, nos Estados Unidos, os níveis de poluição na cidade em conjunto com um fenômeno de inversão térmica causou um nevoeiro denso e com cheiro forte (por conta do dióxido de enxofre), a visibilidade ao nível do solo ficou muito baixa prejudicando o tráfego. Embora haja uma discussão sobre o número exato de pessoas afetadas, cerca de $40 \%$ dos 15.000 habitantes provavelmente foram afetados, somando 20 mortes nos três primeiros dias e mais 50 de mortes após o incidente, sendo a maioria de pessoas idosas e com doenças cardíacas e pulmonares preexistentes (Hedley, 2009; Phalen e Phalen, 2011).

O terceiro episódio aconteceu em Dezembro de 1952, sendo considerado o episódio de poluição de atmosférica de maior repercussão. A cidade de 
Londres no Reino Unido encontra-se em um amplo vale do rio Tâmisa, e tinha uma população de 8,6 milhões de pessoas. As condições meteorológicas e o uso doméstico intenso de carvão com alto teor de enxofre também tiveram grande influência neste episódio e desta vez os impactos na saúde da população foram de grandes proporções, cerca de 4.000 mortes ocorreram somente nos cinco primeiros dias com um total de 8.000 mortes. Doenças cardíacas e pulmonares preexistentes, pessoas com idade superior a 45 anos e crianças com idade inferior a 1 ano foram consideradas fatores de risco para $80 \%$ das mortes. Um surto de gripe que ocorreu na mesma época também poderia ter contribuído para o número expressivo de mortes. Este episódio incentivou a criação da British Clean Air Act em 1956 pelo parlamento do Reino Unido, visando controlar a emissão de poluentes na atmosfera, principalmente limitando a utilização de carvão para aquecimento de casas. Essa medida influenciou outros países, entre eles os Estado Unidos com a criação do National Clean Air Act em 1963 (Hedley, 2009; Phalen e Phalen, 2011). Em 1967 os estudos das emissões de poluentes atmosféricos, monitoramento e inspeções ambientais de fontes fixas foram ampliados. A publicação do National Clean Air Act em 1970 regulamenta programas que estabelecem limites para as emissões das fontes estacionárias (industrial) e móveis (automóveis). Quatro grandes programas regulatórios para fontes estacionárias foram iniciados (The National Ambient Air Quality Standards (NAAQS), State Implementation Plans (SIPS), New Source Performance Standards (NSPS), and National Emission Standards for Hazardous Air Pollutants (NESHAPs)) e ao mesmo tempo, em 02 de Dezembro de 1970, estabeleceu a criação da U.S. Environmental Protection Agency (EPA), um órgão com objetivos de comprometimento com atividades em pesquisa, monitoramento, fiscalização e execução de normas para assegurar a proteção ambiental (EPA, 2012). 


\subsubsection{Conceito}

A poluição atmosférica pode ser definida como a contaminação do ambiente interior ou exterior, por qualquer agente químico, físico ou biológico que modifica as características naturais da atmosfera (WHO, 2011). Com relação a sua origem, os poluentes podem ser classificados como Primários (emitidos diretamente pelas fontes de emissão) e Secundários (aqueles formados na atmosfera através da reação química entre poluentes ou constituintes naturais na atmosfera) (Cetesb, 2010).

A poluição atmosférica é quantificada quanto à presença de poluentes no ar relacionados à atividade humana ou de processos naturais, considerando as possíveis concentrações que interfiram na saúde e bem estar dos seres vivos. $O$ grau de concentração de determinado poluente indicará a exposição dos receptores (ser humano, animais, plantas e materiais), sendo identificado pelo processo de lançamento deste poluente por fontes emissoras e na interação com a atmosfera (Rivero, 2005; Cançado et al., 2006).

As consequências à exposição aos poluentes atmosféricos vão além dos agravos que ocorrem no sistema respiratório, pois a interação dos pulmões com o sistema circulatório pode causar interferências no funcionamento fisiológico normal do indivíduo (Kinney, 2008), nos sistemas cardiovascular (Rivero et al., 2005a; Schulz et al., 2005; Cançado et al., 2006; Mills et al., 2009; Brito et al., 2010), nervoso (van Berlo et al., 2010; Zanchi et al., 2010), endócrino (Wang et al., 2005; Brook, 2008) e reprodutivo (Lichtenfels et al., 2007; Veras, 2008).

Segundo Martins et al. (2004) e Wong et al. (2008), os casos de morbidade e mortalidade pela frequente exposição à poluentes atmosféricos indicam uma relação entre os níveis socioeconômico e cultural, por consequência da industrialização e das demandas aumentadas para a energia e os automóveis 
(Kampa e Castanas, 2008).

A queima de combustíveis fósseis causa prejuízos em vários níveis, o gás natural pode ser considerado uma exceção, ainda que a sua utilização pareça ser menos prejudicial, gerando menos emissões que o petróleo e o carvão, estes influenciam no bem estar e saúde dos receptores e na manutenção e equilíbrio do planeta Terra. Os principais poluentes lançados na atmosfera pela combustão dos combustíveis fósseis compreendem as emissões de monóxido de carbono (CO), hidrocarbonetos $(\mathrm{HC})$, óxidos de nitrogênio $\left(\mathrm{NO}_{\mathrm{x}}\right)$, material particulado (MP) e óxidos de enxofre $\left(\mathrm{SO}_{x}\right)$ que levam a alteração da qualidade do ar (Azevedo e Chasin, 2003; Rivero, 2005; Kinney, 2008; Cetesb, 2008b). Existem ainda poluentes emitidos na atmosfera que não estão sobregulamentação como aldeídos, amônia, benzeno, cianetos, tolueno e hidrocarbonetos policíclicos aromáticos (HPAs) (Braun et al., 2003, Caplain et al., 2006).

\subsubsection{Padrões de Qualidade do Ar}

Os padrões de qualidade do ar são divididos em primários e secundários. Os padrões primários de qualidade do ar revelam-se pelas concentrações de poluentes que quando ultrapassadas, poderão afetar a saúde da população. Podem ser entendidos como níveis máximos toleráveis de concentração de poluentes atmosféricos, constituindo-se em metas de curto e médio prazo. São padrões secundários de qualidade do ar, as concentrações de poluentes atmosféricos inferiores das quais se prevê o mínimo efeito adverso sobre o bem estar da população, assim como o mínimo dano à fauna e à flora, aos materiais e ao meio ambiente em geral (Cetesb, 2008b). O estabelecimento de padrões secundários tem como objetivo criar uma base para uma política de prevenção da 
degradação da qualidade do ar. Os padrões secundários são aplicados às áreas de preservação (parques nacionais, áreas de proteção ambiental, estâncias turísticas, etc.). Não se aplicam, pelo menos em curto prazo, a áreas de desenvolvimento, onde devem ser aplicados os padrões primários. Se determinada área não possuir ainda uma classificação, os padrões aplicáveis serão os primários (Cetesb, 2010). Os valores dos padrões primário e secundário, além de critérios para episódios agudos de poluição do ar são estabelecidos na Resolução CONAMA no 3 (1990). O Art. $3^{\circ}$ desta Resolução estabelece os padrões de qualidade do ar para os seguintes poluentes (Quadro 1): partículas totais em suspensão (PTS), fumaça, $\mathrm{MP}, \mathrm{CO}$, dióxido de enxofre $\left(\mathrm{SO}_{2}\right)$, ozônio $\left(\mathrm{O}_{3}\right)$ e dióxido de nitrogênio $\left(\mathrm{NO}_{2}\right)$.

Quadro 1 - Relação dos Poluentes com os valores máximos e tempo de exposição de acordo com os Padrões nacionais de qualidade do ar

\begin{tabular}{|c|c|c|c|}
\hline Poluente & $\begin{array}{c}\text { Período de } \\
\text { Tempo }\end{array}$ & $\begin{array}{c}\text { Padrão } \\
\text { Primário } \\
\left(\mu \mathrm{m} / \mathrm{m}^{3}\right)\end{array}$ & $\begin{array}{l}\text { Padrão } \\
\text { Secundário } \\
\left(\mu \mathrm{m} / \mathrm{m}^{3}\right)\end{array}$ \\
\hline PTS & $\begin{array}{l}24 \text { horas } \\
\text { Média anual }\end{array}$ & $\begin{array}{c}240 \\
80\end{array}$ & $\begin{array}{c}150 \\
60\end{array}$ \\
\hline MP & $\begin{array}{l}24 \text { horas } \\
\text { Média anual }\end{array}$ & $\begin{array}{c}150 \\
50\end{array}$ & $\begin{array}{c}150 \\
50\end{array}$ \\
\hline Fumaça & $\begin{array}{l}24 \text { horas } \\
\text { Média anual }\end{array}$ & $\begin{array}{c}150 \\
60\end{array}$ & $\begin{array}{c}100 \\
40\end{array}$ \\
\hline $\mathrm{SO}_{2}$ & $\begin{array}{l}24 \text { horas } \\
\text { Média anual }\end{array}$ & $\begin{array}{c}365 \\
80\end{array}$ & $\begin{array}{c}100 \\
40\end{array}$ \\
\hline $\mathrm{NO}_{2}$ & $\begin{array}{c}1 \text { hora } \\
\text { Média anual }\end{array}$ & $\begin{array}{l}320 \\
100\end{array}$ & $\begin{array}{l}190 \\
100\end{array}$ \\
\hline $\mathrm{CO}$ & $\begin{array}{l}1 \text { hora } \\
8 \text { horas }\end{array}$ & $\begin{array}{c}40.000 \\
35 \mathrm{ppm} \\
10.000 \\
9 \mathrm{ppm}\end{array}$ & $\begin{array}{c}40.000 \\
35 \mathrm{ppm} \\
10.000 \\
9 \mathrm{ppm}\end{array}$ \\
\hline $\mathrm{O}_{3}$ & 1 hora & 160 & 160 \\
\hline
\end{tabular}

Fonte: adaptado de Cetesb, 2010 
Segundo as diretrizes de qualidade do ar (WHO, 2005), com base em estudos da relação entre a concentração dos poluentes monitorados na atmosfera e agravos à saúde humana, os padrões de qualidade do ar dos seguintes poluentes atmosféricos $\left(\mathrm{CO}, \mathrm{SO}_{2}, \mathrm{O}_{3}, \mathrm{NO}_{2}\right)$ (Quadro 2) foram revistos e definidos os valores máximos para o material particulado inalável $\left(\mathrm{MP}_{10}\right)$ e o material particulado fino $\left(\mathrm{MP}_{2,5}\right)$.

Quadro 2 - Valores recomendados segundo a revisão das Diretrizes da Qualidade do $\mathrm{Ar}$

\begin{tabular}{|c|c|c|c|c|}
\hline \multicolumn{5}{|c|}{ Diretrizes da qualidade do ar } \\
\hline $\mathrm{MP}_{10}$ & $\mathrm{MP}_{2.5}$ & $\mathrm{O}_{3}$ & $\mathrm{NO}_{2}$ & $\mathrm{SO}_{2}$ \\
\hline $\begin{array}{c}20 \mu \mathrm{m} / \mathrm{m}^{3} \\
\text { (média anual) }\end{array}$ & $\begin{array}{c}10 \mu \mathrm{m} / \mathrm{m}^{3} \\
\text { (média anual) }\end{array}$ & $\begin{array}{c}100 \mu \mathrm{m} / \mathrm{m}^{3} \\
\text { (média } 8 \text { horas) }\end{array}$ & $\begin{array}{c}40 \mu \mathrm{m} / \mathrm{m}^{3} \\
\text { (média anual) }\end{array}$ & $\begin{array}{c}20 \mu \mathrm{m} / \mathrm{m}^{3} \\
\text { (média anual) }\end{array}$ \\
\hline $\begin{array}{l}50 \mu \mathrm{m} / \mathrm{m}^{3} \\
\text { (média } 24 \text { horas) }\end{array}$ & $\begin{array}{l}25 \mu \mathrm{m} / \mathrm{m}^{3} \\
\text { (média } 24 \text { horas) }\end{array}$ & & $\begin{array}{c}200 \mu \mathrm{m} / \mathrm{m}^{3} \\
\text { (média } 1 \text { hora) }\end{array}$ & $\begin{array}{c}500 \mu \mathrm{m} / \mathrm{m}^{3} \\
\text { (média } 10 \text { minutos) } \\
\end{array}$ \\
\hline
\end{tabular}

Fonte: adaptado de WHO, 2005

\subsubsection{Monitoramento da Poluição Atmosférica no Estado de São} Paulo e Região Metropolitana

Localizado na região sudeste do Brasil, o Estado de São Paulo possui uma área de aproximadamente de $249.000 \mathrm{~km}^{2}$, que corresponde a $2,9 \%$ do território nacional. É o Estado brasileiro de maior ocupação territorial, maior contingente populacional (em torno de 42 milhões de habitantes) e maior desenvolvimento econômico (agrícola - principalmente a atividade sucroalcooleira responsável pela queima de palha da cana, industrial e serviços) e maior frota automotiva (Cetesb, 2012). Segundo relatório da Cetesb (2008b), o Estado de São Paulo no ano de 2007, representava cerca de $40 \%$ da frota automotiva do país com aproximadamente 17 milhões de veículos, no ano de 2008 no relatório Cetesb (2009) este número aumentou para 18,3 milhões de veículos, no relatório Cetesb (2010) no ano 2009 foi registrada a maior frota 
automotiva com 19,9 milhões de veículos automotores (Quadro 3), composta por 1,2 milhões de veículos movidos a diesel, 3,7 milhões motocicletas e 14,6 milhões de veículos do ciclo Otto - gasolina, álcool e gás.

Quadro 3 - O aumento do número total de veículos durante os anos de 2007, 2008 e 2009

\begin{tabular}{ccc}
\hline $\begin{array}{c}\text { Ano Publicação Relatórios } \\
\text { Cetesb }\end{array}$ & $\begin{array}{c}\text { Ano de } \\
\text { referência }\end{array}$ & $\begin{array}{c}\text { Total de Veículos } \\
\text { (milhões) }\end{array}$ \\
\hline 2008 & 2007 & 17,0 \\
2009 & 2008 & 18,3 \\
2010 & 2009 & 19,9 \\
\hline
\end{tabular}

Fonte: Cetesb, 2008b, 2009 e 2010

A partir do relatório Cetesb (2011), a estimativa da frota do Estado de São Paulo passou a ser calculada de acordo com a nova metodologia baseada no $1^{\circ}$ Inventário Nacional de Fontes Móveis do Ministério do Meio Ambiente (MMA). Os relatórios Cetesb (2011 e 2012) mostram uma estimativa da frota circulante do Estado de São Paulo totalizando quase 13 milhões de veículos.

Segundo relatório Cetesb (2010), a contribuição automotiva para a emissão de MP é de $40 \%$, sendo $38,6 \%$ de veículos pesados com motores a diesel e somente $1,4 \%$ de veículos leves motores do ciclo Otto.

O Estado de São Paulo apresenta áreas com características distintas que necessitam de diferentes formas de monitoramento e controle da poluição. A Cetesb mantém redes de monitoramento da qualidade do ar desde a década de 70 para avaliar os níveis de poluição atmosférica. O monitoramento era efetuado exclusivamente por estações manuais, que ainda hoje são utilizadas em vários municípios. Em 1981, foi iniciado o monitoramento automático que, além de ampliar o número de poluentes medidos, permitiu o acompanhamento dos resultados em tempo real. Em 2008, houve uma expansão significativa da rede 
automática que contou em 2011, com 42 estações fixas localizadas em 28 municípios (Cetesb, 2012).

Além dos poluentes estabelecidos em legislação como o $\mathrm{MP}_{10}$ e Fumaça, PTS, $\mathrm{SO}_{2}, \mathrm{NO}_{2}, \mathrm{CO}$ e $\mathrm{O}_{3}$ e monitoramento das condições meteorológicas, atualmente a Cetesb (2010) monitora outros poluentes que não possuem padrão de qualidade determinados na legislação nacional como o $\mathrm{MP}_{2,5}$ e os compostos de enxofre reduzido (sulfeto de hidrogênio $\left(\mathrm{H}_{2} \mathrm{~S}\right)$, metil-mercaptana $\left(\mathrm{CH}_{3} \mathrm{SH}\right)$, dimetilsulfeto $\left(\left(\mathrm{CH}_{3}\right)_{2} \mathrm{~S}\right)$, dimetil-dissulfeto $\left(\mathrm{CH}_{3} \mathrm{SSCH}_{3}\right)$ e sulfeto de carbonila (COS)). Os compostos de enxofre reduzidos são gerados pela degradação microbiológica de matéria orgânica contendo sulfato em condições anaeróbias e como resultado da decomposição bacteriológica de proteínas. São também emitidos em processos industriais como a fabricação de papel e produção de rayon viscose e de celofane (Cetesb, 2010).

As concentrações mais altas dos poluentes primários no Estado de São Paulo ocorrem entre os meses de Maio e Setembro, devido à maior ocorrência de inversões térmicas, ventos fracos e baixos índices pluviométricos. Os níveis de maior concentração de poluentes secundários, principalmente o $\mathrm{O}_{3}$, ocorrem com maior frequência entre o período de Setembro a Março, que normalmente são meses considerados relativamente quentes e com maior incidência de radiação solar. Nos meses mais quentes (Janeiro e Fevereiro), a concentração é menor devido a um aumento na nebulosidade diminuindo à quantidade de radiação solar incidente. No Entanto, o maior número de ocorrências de alta concentração de $\mathrm{O}_{3}$ é registrado nos períodos de mudança entre períodos seco e chuvoso na região sudeste (Cetesb, 2008b). 


\subsubsection{Principais Medidas de Controle da Poluição Atmosférica no} Estado de São Paulo

A busca de alternativas energéticas renováveis de menor custo e maior diversidade de matérias-primas foi incentivada pelas crises do petróleo das décadas de 70 e 80 por conflitos no Oriente Médio, provocando insegurança e elevação nos preços do barril do petróleo. A considerável dependência das importações de petróleo nesse período estimulou o Brasil a iniciar de forma pioneira o programa de produção de álcool combustível, o Programa Nacional do Álcool - Proálcool em 1975. O Proálcool tinha como objetivo substituir parte da frota nacional de veículos movidos a gasolina pelo álcool e utilizar o álcool como aditivo à gasolina (álcool anidro), tornando menos poluente a sua combustão. No mesmo período surgiram algumas experiências voltadas à produção de biodiesel com as matérias-primas provenientes das culturas de mamona e de soja que acabaram não evoluindo. Somente em 2005, através da lei $n^{\circ} 11.097$, o biodiesel foi introduzido na matriz energética brasileira com a intenção de gerar outro tipo de energia que pudesse substituir parcial ou totalmente o combustível de origem fóssil e estabelecer metas percentuais mínimas de mistura de biodiesel ao diesel de 2005 a 2007 autorizando a mistura de 2\% de biodiesel (B2); a partir de 2008 até 2012 será obrigatória a mistura de 2\% de biodiesel (B2) e de 2013 em diante, será obrigatória a mistura de 5\% de biodiesel (B5) (SEBRAE, 2007).

O Programa de Controle da Poluição do Ar por Veículos Automotores (PROCONVE) estabelecido pela Resolução CONAMA No 18 (1986), previsto para todo o Brasil, atribui para a região metropolitana de São Paulo um programa de fiscalização da fumaça preta em veículos a diesel, onde a frota é composta basicamente por caminhões, vans e ônibus. O programa conta com inspeções, treinamento e orientação aos responsáveis dos veículos, além da aplicação de 
multas aos veículos considerados inadequados, de acordo com os padrões da emissão de poluentes estabelecidos.

O rodízio municipal de veículos em São Paulo estabelecido pela Lei Municipal 12.490 (1997) e regulamentado pelo Decreto 37.085 (1997), determina a restrição da circulação dos veículos automotores na cidade de São Paulo. Implantado desde 1997 com o objetivo de melhorar as condições ambientais através da redução da carga de poluentes na atmosfera, logo esta restrição acabou refletindo posteriormente no congestionamento nas principais vias da cidade, principalmente nos horários de maior movimento. No entanto, os congestionamentos da cidade estão cada vez maiores pelo ininterrupto crescimento da frota veicular, por consequência do crescimento descontrolado da cidade e pela fácil aquisição de um ou mais automóveis, fato este observado nos dados publicados nos relatórios pela Cetesb anualmente.

Conforme descrito no relatório Cetesb (2011), o Estado de São Paulo apresenta diferentes formas de monitoramento e controle da poluição devido às suas características distintas, segundo Decreto Estadual nº 50.753 (2006), foi criado o Programa de Redução de Emissões Atmosféricas (PREA) para fortalecer o gerenciamento das áreas consideradas saturadas ou em vias de saturação para poluentes atmosféricos e já em 2002 o Decreto Estadual n 47.397 estabelece prazos de validade para as Licenças de Operação. A determinação de um conjunto de ações para incentivar reduções de emissões de poluentes atmosféricos nos empreendimentos instalados em sub-regiões saturadas (SAT) e em vias de saturação (EVS) deve compor os parâmetros para o processo de renovação de Licença de Operação das fontes de poluição consideradas existentes e novas no Estado de São Paulo.

O Programa de Inspeção e Manutenção de Veículos em vigor foi estabelecido pelas Leis Municipais $n^{\circ} 11.733$ de 27 de março de $1995, n^{\circ} 12.157$ 
de 09 de agosto de 1996 e $n^{\circ} 14.717$ de 17 de abril de 2008 e pela Resolução CONAMA n 418 (2009) e está previsto no Artigo 104 do Código de Trânsito Brasileiro. Segundo a concessionária Controlar, responsável pelas inspeções, o Programa de Inspeção e Manutenção de Veículos é realizado desde 2008, ano este que iniciou o serviço com inspeções apenas na frota a diesel. Somente em 2009 carros fabricados entre 2003 e 2008 e motos foram incluídos na vistoria. Atualmente, todos os veículos registrados no Município de São Paulo devem ser submetidos à inspeção e avaliados obrigatoriamente. O objetivo é reduzir a poluição do ar e assim melhorar a qualidade de vida da população. O Programa mede nos automóveis e motocicletas os níveis de $\mathrm{CO}$, dióxido de carbono $\left(\mathrm{CO}_{2}\right)$ e $\mathrm{HC}$ e nos veículos a diesel mede os valores de opacidade, MP e níveis de ruídos emitidos pelo funcionamento do veículo. Atualmente, apenas as cidades de São Paulo e Rio de Janeiro realizam a inspeção de maneira obrigatória. A Resolução CONAMA n 418 (2009) impede a realização do licenciamento dos automóveis que não forem submetidos à inspeção ou reprovados com relação aos níveis de poluentes emitidos e ruído (Controlar, 2010).

\subsubsection{Material Particulado}

A poluição pelo MP refere-se à mistura de partículas sólidas ou líquidas suspensas no ar, que variam em sua forma, composição e origem. As partículas podem ser classificadas em primária ou secundária, dependendo do seu mecanismo de formação. As partículas primárias são emitidas diretamente na atmosfera por processos antropogênicos (combustíveis fósseis, desgaste de pneus e freios, construção civil) e naturais (vulcões, poeiras do solo). As partículas secundárias são formadas na atmosfera normalmente por reações químicas dos poluentes gasosos e são principalmente produtos da transformação do $\mathrm{NO}_{x}$ na atmosfera (emitidos pelo tráfego e alguns processos 
industriais) $\mathrm{SO}_{2}$ (queima de combustíveis com elevado teor de enxofre). A fração fina do MP é composta principalmente de partículas secundárias (WHO, 2005a). MP possui tamanho heterogêneo e pode ser classificado através de seu diâmetro aerodinâmico (Figura 1). Em geral, quanto menor a partícula, maior o seu potencial impacto na saúde humana, podendo ser mais facilmente inalada (EPA, 2011). As partículas ultrafinas são definidas pelo diâmetro inferior a 0,1 $\mu \mathrm{m}\left(\mathrm{MP}_{0,1}\right)$, as partículas finas são definidas pelo diâmetro inferior a 2,5 $\mu \mathrm{m}$ $\left(\mathrm{MP}_{2,5}\right)$, as partículas grossas (inaláveis) são definidas pelo diâmetro inferior a 10 $\mu \mathrm{m}\left(\mathrm{MP}_{10}\right)$, e partículas totais em suspensão (PTS) com diâmetro inferior a 100 $\mu \mathrm{m}$ e superior a $10 \mu \mathrm{m}$. A composição do MP (principalmente $\mathrm{MP}_{10}$ ) pode apresentar variabilidade de substâncias adsorvidas como metais de transição e compostos orgânicos e inorgânicos (Cetesb, 2008b; Courtois et al., 2008); os principais componentes são o sulfato, nitratos, amónia, cloreto de sódio, pó de carvão mineral, e água (WHO, 2005a).

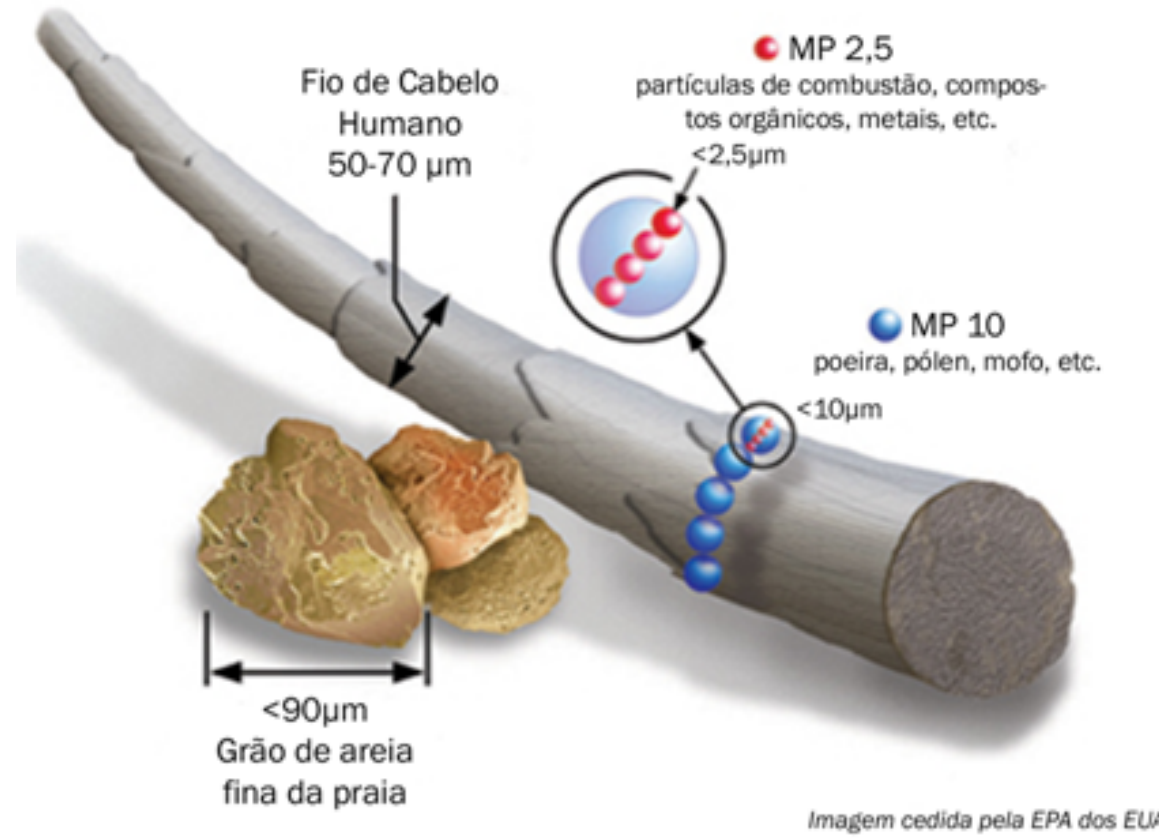

Fonte: adaptado de EPA, 2011

Figura 1 - Comparação do tamanho aerodinâmico das partículas $\left(\mathrm{MP}_{2,5}-\mathrm{MP}_{10}\right)$ com outros materiais 
As partículas mais grossas, de diâmetro entre $2,5 \mu \mathrm{m}$ e $30 \mu \mathrm{m}$, são emitidas através de combustão descontrolada, dispersão mecânica do solo, além de outros materiais como grãos de pólen, esporos e outros materiais biológicos (Cançado et al., 2006). Segundo Li et al. (2009), partículas de diâmetro até 0,1 $\mu \mathrm{m}$ são lançadas principalmente por automóveis movidos pela combustão do diesel, e quando inaladas podem chegar aos alvéolos alcançando a circulação, causando efeitos cardiovasculares tóxicos (Mills et al., 2009). As partículas de tamanho maior se depositam principalmente nas vias respiratórias superiores podendo ser removidas pelo sistema mucociliar e então serem deglutidas ou expectoradas (Oberdörster et al., 2005). As partículas inaláveis finas são produzidas principalmente a partir de emissão direta nos processos de combustão de automóveis, incineradores, termoelétricas e também a partir dos gases precursores emitidos como $\mathrm{SO}_{2}, \mathrm{NO}_{\mathrm{x}}$ e compostos orgânicos voláteis (COVs) que reagem na atmosfera (Cetesb, 2008b). A fração fina é composta tipicamente de nitrato, sulfato, amônio, material carbonáceo e metais. Por possuírem menor tamanho e maior acidez, ocorre maior possibilidade de atingirem as porções inferiores do trato respiratório como brônquios, bronquíolos, alvéolos. Partículas grossas como $0 \mathrm{MP}_{10}$ caracterizam-se por atingirem as porções superiores do trato respiratório, mas também podem atingir as vias respiratórias inferiores (independente de sua característica e composição química), possuindo a facilidade de transportar gases adsorvidos para as porções onde ocorre a hematose (Cançado et al., 2006).

Estudos de análise elementar do MP, mostraram que existe relação na formação de MP no escapamento de veículos dependente da queima do combustível e de óleo lubrificante, assim como o desgaste de rolamentos, materiais dos motores (Cadle et al., 1997), desgaste dos freios, desgaste dos pneus, desgaste da superfície da estrada e ressuspensão na região de passagem 
do tráfego, consideradas potenciais fontes de MP (Thorpe e Harrison, 2008). Entretanto, a emissão veicular evidencia-se como principal fonte de poluição nas grandes cidades (Grahame e Schlesinger, 2007). Os veículos movidos por motores a diesel são considerados os principais responsáveis pela emissão de MP, sendo muito pequena a contribuição dos motores do ciclo Otto (Wichmann, 2007; Cetesb, 2011).

A composição do MP produzido pela combustão do diesel (partículas de exaustão de diesel) (Figura 2) é constituída de aglomerados de núcleos de carbono, aos quais se adsorvem hidrocarbonetos e sulfatos resultantes da combustão incompleta do óleo diesel formando partículas secundárias que se aglomeram dando origem ao MP (Braun et al., 2003).

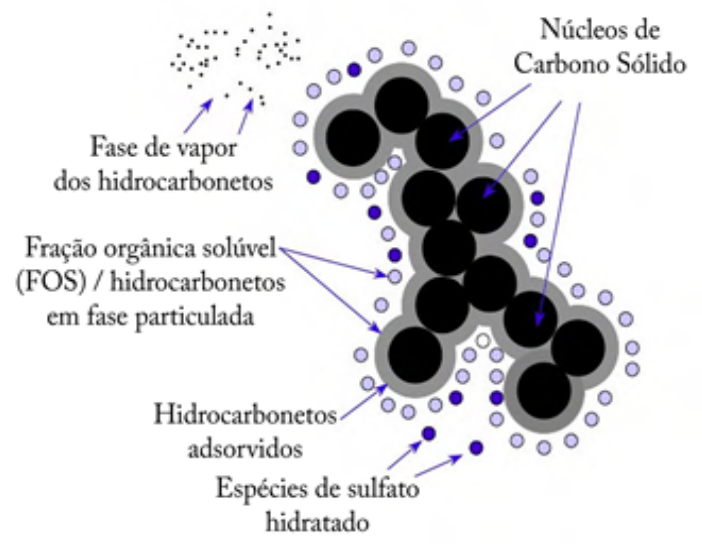

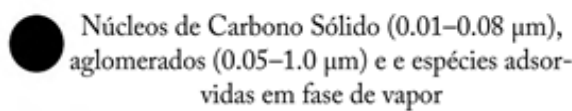
vidas em fase de vapor

Hidrocarbonetos adsorvidos

- Partículas de hidrocarbonetos líquidas condensadas

- Espécies de sulfato hidratado

Fonte: adaptado de Twigg e Phillips, 2009

Figura 2 - llustração da composição do MP produzido pela combustão do diesel 
1.2. Evidências dos efeitos adversos à saúde humana e sistema cardiopulmonar causados pela exposição ao Material Particulado

Segundo estudo de Danielsen et al. (2008), a inalação de partículas de exaustão de diesel (PED) é prejudicial para o fígado e pulmão; o estudo mostrou que as PED mesmo quando removidas pelo sistema mucociliar, podem estimular o estresse oxidativo, genotoxicidade e prejudicar os sistemas antioxidante e DNA de reparo. Segundo estudo desenvolvido por Nemmar et al. (2007), 24 horas após a administração das PED na circulação em ratos, a pressão sanguínea, frequência cardíaca (FC) e a hemostasia são afetadas e a presença das partículas na circulação pode causar edema e inflamação pulmonar. Swanson et al. (2007) afirmam que as PED quando inalado ainda pode causar inflamações sistêmicas e específicas no tecido, causando prejuízos no sistema cardiopulmonar, agravando doenças alérgicas. Estudo realizado por Laks et al. (2008) demonstrou que baixas doses de partículas de diesel por instilação nasal (15 $\mu \mathrm{g}$ de diesel em $10 \mu \mathrm{l}$ de solução salina - 0,9\% $\mathrm{NaCl}$ ) são suficientes para causar toxicidade pulmonar em ratos.

Normalmente a poluição do ar é composta por concentrações significantes de PED e está relacionada aos casos de morbidade e mortalidade respiratória e cardiovascular (Pope III, 2002; Nemmar et al., 2007; Peretz et al., 2008; Laumbach et al., 2009). De acordo com Datasus (2007), os índices de morbidade e mortalidade por doenças cardiovasculares em pessoas com 65 anos de idade ou mais, são de $28 \%$ e 40,5\% respectivamente. Esses índices são os mais elevados em comparação às doenças totais, superando até mesmo as taxas referentes à morbidade em doenças respiratórias $(12,9 \%)$ e mortalidade em doenças neoplásicas (tumores) $(19,7 \%)$. O perfil das mortes apresentado nos índices do Datasus (2007) na cidade de São Paulo não é recente, 
sendo observado em estudos realizados por Saldiva et al. (1995) e por Gouveia et al. (2006): ambos estudos foram realizados no Município de São Paulo nos períodos de 1990 à 1991 e 1996 à 2000 respectivamente. Estes autores concluíram que as internações hospitalares por doenças circulatórias ocorreram mais em idosos e as doenças respiratórias ocorreram mais em crianças. De acordo com Braga et al. (2007), os poluentes gasosos e o $\mathrm{MP}_{10}$ estão relacionados com agravos ao sistema respiratório de crianças e adolescentes, com aumento de internações hospitalares após 3 dias do pico de poluição. No entanto, em idosos, houve maior número de internações hospitalares por complicações no sistema cardiovascular de maneira aguda, ou seja, após 1 dia do pico de poluição. Como citado acima, as mortalidades cardiovasculares apresentam magnitude superior aquelas observadas em doenças respiratórias além de indicar efeito mais agudo, como observado também no estudo de Braga et al. (2001) que demonstrou que um aumento de $10 \mu \mathrm{g} / \mathrm{m}^{3}$ no $\mathrm{MP}_{10}$ foi associado com mortalidade cardiovascular no mesmo dia do evento da poluição.

O trabalho de Ballester et al. (2008) em 26 cidades europeias, através de dados obtidos pelo grupo Apheis (Air Pollution and Health - A European Information System), demonstrou associação e estimativas na redução de mortalidade a partir de uma redução nos níveis ambientais anuais de $\mathrm{MP}_{2,5}$ entre as pessoas com 30 de idade. A redução de mortes prematuras poderia ser 4 vezes maior se houvesse uma redução na concentração de $\mathrm{MP}_{2,5}$ para $15 \mu \mathrm{g} / \mathrm{m}^{3}$ comparado com $25 \mu \mathrm{g} / \mathrm{m}^{3}$. Segundo Mills et al. (2009) as consequências relacionadas aos eventos cardiovasculares adversos por conta da exposição ao MP, compreendem admissões hospitalares como a angina, infarto agudo do miocárdio (IAM), morte súbita, e principalmente a associação entre a exposição ao $\mathrm{MP}_{2,5}$ e o controle do sistema nervoso autonômico (SNA) da FC e ritmo cardíaco. 
As inervações simpática e parassimpática compõem o SNA exercendo funções antagonistas no controle da FC. O estímulo simpático provoca um aumento da FC em resposta ao exercício, estresse e cardiopatias, aumentando a frequência de disparo das células (na variação das baixas frequências) no nódulo sinoatrial do coração. O estímulo parassimpático (vagal) promove um balanço regulatório na função autonômica fisiológica, diminuindo a frequência de disparo das células (na variação das altas frequências) no nódulo sinoatrial do coração. A variabilidade da frequência cardíaca (VFC) corresponde às oscilações dos intervalos R-R entre os batimentos cardíacos consecutivos. O intervalo entre os picos $\mathrm{R}$ de dois complexos QRS consecutivos representam os batimentos normais cardíacos, também chamados intervalos N-N. (Zareba et al., 2001; Achten e Jeukendrup, 2003; Acharya et al., 2006; Rowan III et al., 2007). A VFC analisada pelo domínio do tempo na variabilidade (ms) e domínio da frequência em potência espectral $(\mathrm{Hz})$ e valores absolutos $\left(\mathrm{ms}^{2}\right)$ são as duas abordagens mais comuns para esse tipo de estudo. Os parâmetros de domínio do tempo são avaliados estatisticamente em cada intervalo $\mathrm{N}-\mathrm{N}$ durante determinado intervalo de tempo, esses parâmetros incluem SDNN (standard deviation of the NN interval), RMSSD (root mean square of successive diferences in NN intervals) e indicam a influência parassimpática no coração. Picos nas diferentes frequências refletem diferentes influencias do sistema nervoso simpático e parassimpático nos parâmetros de domínio da frequência no intervalo $\mathrm{N}-\mathrm{N}$, esses parâmetros incluem HF (high frequency) (controle parassimpático), LF (Iow frequency) (controle simpático) e LF/HF (razão low frequency/high frequency) reflete o balanço simpato-vagal e valores altos indicam uma predominância do sistema simpático no controle da função cardíaca (Vanderlei et al., 2009; Farraj et al., 2011).

A Diminuição da VFC está associada ao risco aumentado de mortalidade 
na população em geral e do desenvolvimento de eventos cardíacos não fatais (Dekker et al., 1997). De acordo com Fang et al. (2010), estudos mostram evidências de associação entre exposições agudas ocupacionais ao MP e diminuição da VFC, um fator de risco de mortalidade nas doenças cardiovasculares, podendo mostrar-se como um potencial mecanismo de eventos cardiovasculares adversos, assim como a inflamação sistêmica e doenças isquêmicas do coração associados ao MP.

A exposição crônica por $\mathrm{MP}_{2,5}$ e $\mathrm{SO}_{x}$ é um fator de risco importante nos casos de mortalidade por doenças cardiopulmonares e câncer no pulmão (Enomoto et al., 2008). Mesmo se a inalação de $\mathrm{MP}_{2,5}$ ocorra durante alguns minutos ou horas, existe a possibilidade de IAM, isquemia cardíaca, arritmias, insuficiência cardíaca e morte súbita (Brook, 2008). A exposição crônica também pode estar associada à diminuição nos índices da VFC (de Hartog et al., 2009). Estudo crônico realizado em ratos Wistar utilizando o concentrador de partículas de combustão de diesel, Anselme et al. (2007) observaram que a exposição às PED $\left(\mathrm{MP}_{10}-0.5 \mu \mathrm{g} / \mathrm{m}^{3}\right)$ resultou em uma marcante diminuição na VFC. Estudos verificaram que a exposição aguda ao $\mathrm{MP}_{10}$ também influencia na diminuição da VFC em adultos com asma (Yeatts et al., 2007) e idosos (Chang et al., 2007).

Estudo realizado em Boston, nos Estados Unidos, em homens com 70 anos de idade em média, divididos em diabéticos, hipertensos e indivíduos com isquemia cardíaca, sugere que a exposição ao $\mathrm{MP}_{2,5} \mathrm{em}$ um curto período é um fator prognóstico das alterações na função autonômica cardíaca medida pela VFC entre homens idosos (Park et al., 2005). Outro estudo realizado nos Estados Unidos em 3 regiões do estado de Utah, indica associação relevante do $\mathrm{MP}_{2,5}$ com VFC e Proteína C-reativa, sugerindo uma possível contribuição no surgimento das alterações nas funções autonômicas cardíacas e inflamação pulmonar sistêmica (Pope III et al., 2004a). No estudo realizado em ratos wistar 
por Rivero et al. (2005a), foi observada diminuição da VFC após 60 minutos de exposição ao $\mathrm{MP}_{2,5}$ da cidade de São Paulo.

Segundo estudo com dados obtidos do Brigham and Women's Hospital em Boston, observou-se que a exposição ao $\mathrm{MP}_{2,5}$ pode levar ao aumento da pressão arterial (PA) em pacientes com doenças cardiovasculares em repouso e em pacientes com elevada FC, a PA eleva-se ainda mais durante o exercício (Zanobetti et al., 2004). Segundo estudo realizado por Urch et al. (2005), o aumento significante $(6 \mathrm{mmHg})$ na pressão arterial diastólica (PAD) está relacionado à exposição a $\mathrm{MP}_{2,5}$ e $\mathrm{O}_{3}$, peculiarmente devido ao carbono existente na composição do $\mathrm{MP}_{2,5}$. $\mathrm{O}$ estudo realizado em veias e artérias de camundongos C57BL/6 expostos às PED, indicou que veias podem manifestar uma resposta tóxica maior que artérias, e que a disfunção endotelial nas veias ocorre provavelmente pelo desacoplamento da eNOS (Endothelial nitric oxide synthase) e a consequente diminuição na produção de óxido nítrico favorecendo o efeito constritor pela endotelina-1. (Knuckles et al., 2008).

A exposição às PED pode estimular estresse oxidativo no parênquima cerebral, causando prejuízos no Sistema Nervoso Central (SNC) (Hartz et al., 2008). Mills et al. (2009) concluíram que a potencialização dos efeitos vasculares adversos e aterogênese parecem ser mediados por vias pro- inflamatórias e oxidativas decorrentes da inalação do MP. As PED quando inaladas também podem induzir a expressão gênica associada ao estresse oxidativo mitocondrial nos ventrículos em ratos saudáveis (Gottipolu et al., 2009). Dados obtidos nos estudos de Møller et al. (2008) mostraram que os modelos experimentais animais de modo geral, expostos ao PED apresentam níveis elevados de oxidação de guaninas em tecidos, como no epitélio do colon, fígado e pulmão; estudos de biomonitoramento de indivíduos expostos à poluição atmosférica demonstram a existência de níveis elevados de oxidação de guaninas no sangue. 
Estudos com cultura de células endoteliais aórticas humanas expostas a PED mostraram indução ao estresse oxidativo vascular via c-Jun $\mathrm{N}$-terminal kinase (JNK) e disfunção endotelial (Li et al., 2009). Cultura primária de cardiomiócitos ventriculares de ratos wistar expostos a PED subcronicamente (24 e 48 horas) e agudamente (1, 2, 4 e 8 horas), mostrou a indução citotóxica nos cardiomiócitos devido às espécies reativas de oxigênio (ERO) $\left(\mathrm{OH} ; \mathrm{H}_{2} \mathrm{O}_{2}\right.$ e $\left.\mathrm{O}_{2}\right)$, indicando a inviabilidade desses cardiomiócitos e sugerindo possível relação entre esse estudo in vitro com as doenças cardiovasculares in vivo (Okayama et al., 2006).

\subsection{Cardiomiopatia hipertrófica}

O termo Cardiomiopatia hipertrófica $(\mathrm{CMH})$ é o mais adotado, pois descreve precisamente a característica predominante da doença (o aumento da massa muscular ventricular) que tem sido conhecida por uma gama confusa de nomes, refletindo sua heterogeneidade clínica e muitas vezes tornando-se um dilema, podendo induzir inicialmente a uma interpretação clínica distorcida (Bohachick e Rongaus, 1984; Maron, 1997; Maron, 2002). Existem evidências clínicas e experimentais que relacionam quantitativamente sobrecarga hemodinâmica crônica com o grau de hipertrofia (Leenen et al., 2001; Samesina e Amodeo, 2001; Carmo et al., 2003); independentemente de qualquer sobrecarga hemodinâmica identificável, a CMH pode ser de causa hereditária (genética), no entanto, fatores de natureza neural, autócrina/parácrina (sistema reninaangiotensina) e hormonal podem contribuir para o desenvolvimento da hipertrofia cardíaca (Franchini, 2001).

As evidências morfológicas da doença são encontradas em cerca de um quarto dos parentes de primeiro grau de um paciente com $\mathrm{CMH}$ (Braunwald et al., 
2005). CMH possui característica mendeliana com um padrão de herança autossômica dominante, que em grande parte é causada por uma variedade de mutações em genes que codificam proteínas do sarcômero (Figura 3) ( $\beta$-miosina de cadeia pesada, Troponina cardíaca T, $\alpha$-Tropomiosina, Proteína $C$ de ligação à miosina e na cadeia leve de miosina ocorre mais raramente) (Maron, 2002; Spirito et al., 1997), caracterizada pelo envolvimento do ventrículo esquerdo (VE) simétrico (concêntrica) ou assimétrico (septal, medioventricular, apical, lateral e posterior) (Albanesi, 1996), hipertrofiado não dilatado com desarranjo miofibrilar e evidente fibrose intersticial e perivascular (Figura 4) no miocárdio (Maron, 1997; Murad et al., 2001; Hu et al., 2003; Ommen e Nishimura, 2004; Poliac et al., 2006; Harvey e Leinwand, 2011), tendo aumento das dimensões dos cardiomiócitos (Franchini, 2001) e muitas vezes ocorrendo em especial no septo interventricular (Seidman e Seidman, 2001). Com o tempo, a massa muscular miocárdica ventricular aumentada reduz a complacência e o tamanho da cavidade ventricular esquerda (Figura 5), prejudicando ainda mais o relaxamento diastólico e intensificando a contração sistólica. O VE normalmente está mais envolvido que o direito, mas o envolvimento também no lado direito pode ser observado (Bohachick e Rongaus, 1984; Maron, 2002). 


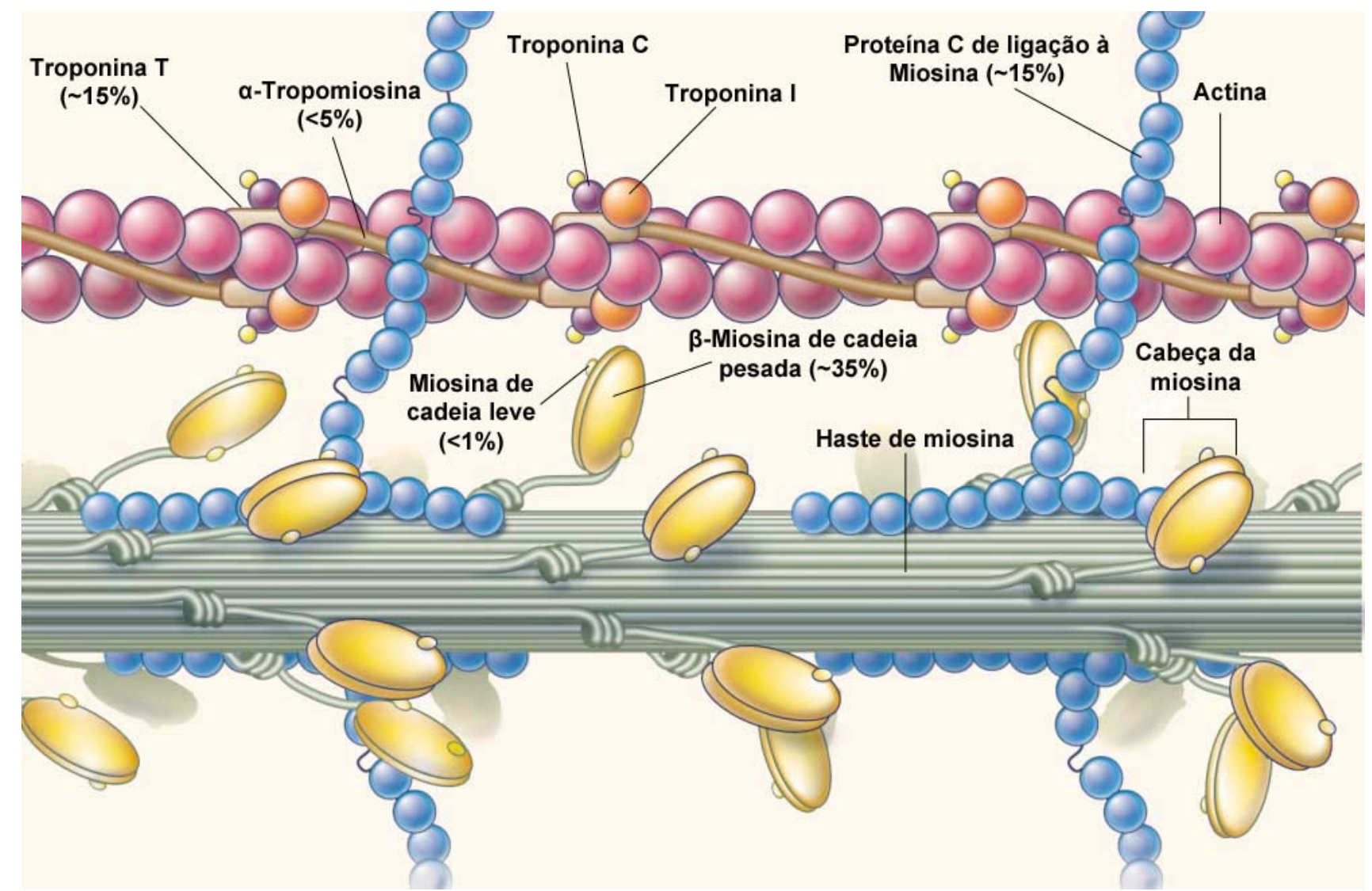

Fonte: adaptado de Spirito et al., 1997; Braunwald et al., 2005

Figura 3 - Componentes do Sarcômero. Os percentuais representam a frequência estimada com o qual uma mutação no gene correspondente atua na $\mathrm{CMH}$
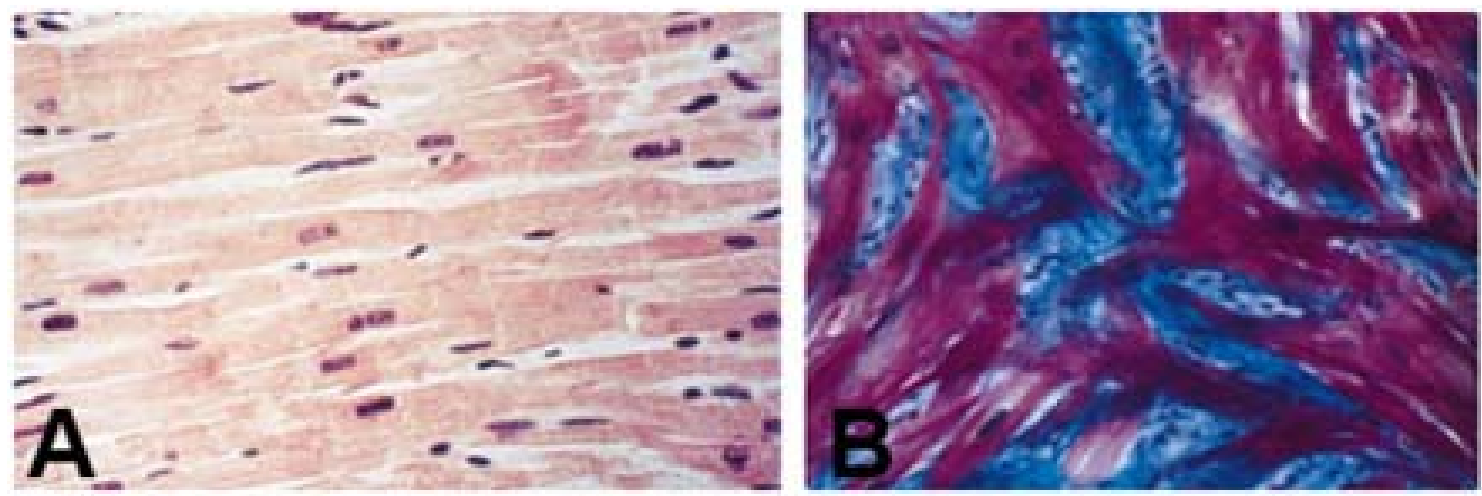

Fonte: adaptado de Seidman e Seidman, 2001

Figura 4 - Histopatologia da $\mathrm{CMH}$. (A). Distribuição normal das miofibrilas do miocárdio ventricular saudável com alinhamento ordenado de miócitos com fibrose intersticial mínima (hematoxilina-eosina). (B) Nítido alargamento intersticial e desordem dos miócitos (vermelho) com o aumento da fibrose intersticial (azul) evidente na $\mathrm{CMH}$ (Tricromo de Masson) 

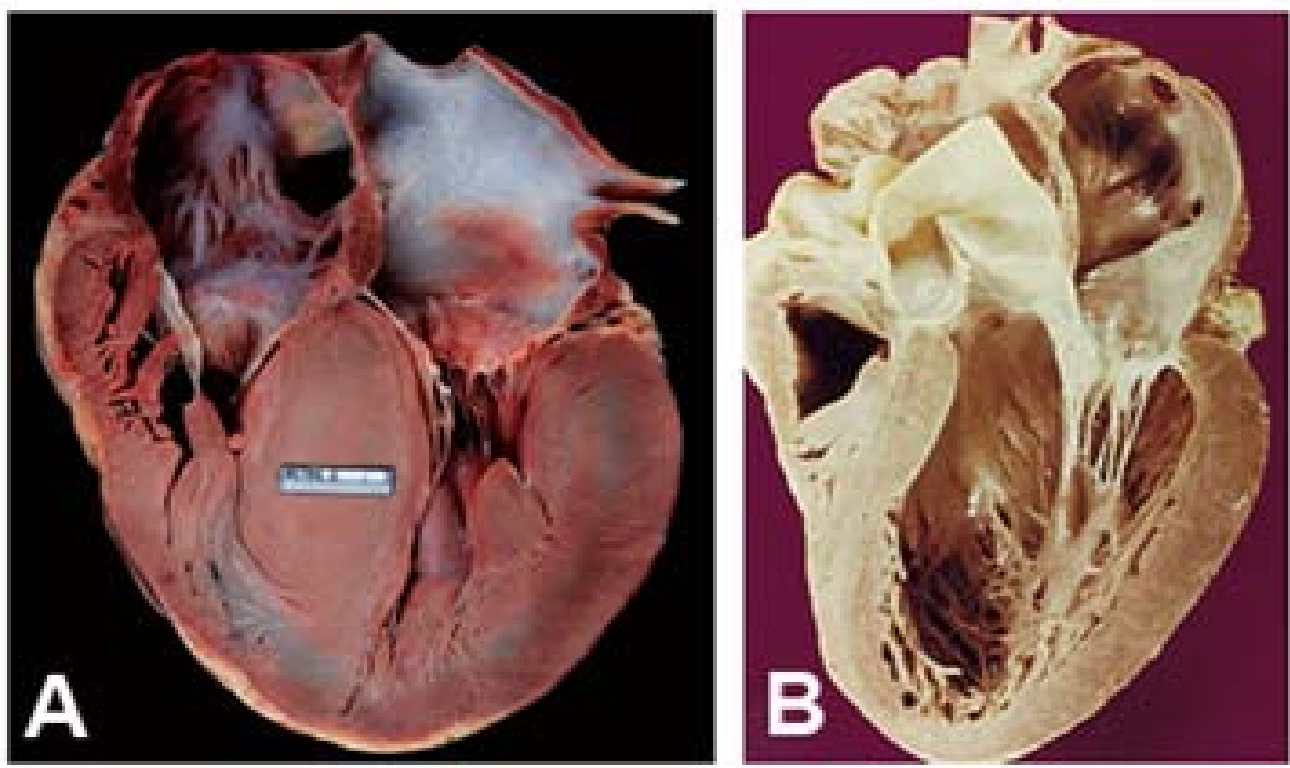

Fonte: adaptado de Seidman e Seidman, 2001

Figura 5 - (A) Espécime patológico de um paciente que morreu subitamente com $\mathrm{CMH}$ (Ommen et al., 2011). (B) Coração normal, com espessura e dimensões normais do VE

Do ponto de vista hemodinâmico, as $\mathrm{CMH}$ são divididas em obstrutivas (septal assimétrica e medioventricular) e não obstrutivas (septal assimétrica, concêntrica, apical, lateral e/ou látero-posterior) (Albanesi, 1996). O abaulamento do septo na cavidade ventricular esquerda diminui a via de saída do VE e contribui para obstrução (Soor et al., 2008). A obstrução causa um aumento na pressão sistólica do VE, ocorrendo prolongamento do relaxamento ventricular, elevação da PAD do VE, regurgitação mitral, isquemia miocárdica, e uma diminuição do débito cardíaco (Ommen et al., 2011). A fisiopatologia da $\mathrm{CMH}$ é complexa e consiste em várias anormalidades inter-relacionadas, incluindo disfunção diastólica do VE (devido à grande massa muscular), obstrução da via de saída do VE, pode haver insuficiência cardíaca progressiva por falência sistólica, regurgitação mitral, isquemia miocárdica (podendo evoluir para IAM) e arritmias (podendo acarretar morte súbita) (Brasileiro Filho e Bogliolo, 2011; Ommen et al., 2011). 


\subsubsection{Hipertrofia Ventricular Esquerda induzida pelo isoproterenol}

As catecolaminas são compostas por um catecol (diidroxibenzeno - anel benzênico com dois grupos hidroxila adjacentes) e uma cadeia lateral amina que interagem de forma agonista (ativando) com os receptores adrenérgicos ( $\alpha$ e $\beta$ ) divididos em classes $\left(\alpha_{1}\right.$ e $\left.\alpha_{2}\right)\left(\beta_{1}, \beta_{2}\right.$ e $\left.\beta_{3}\right)$. Do ponto de vista farmacológico, são destacadas: norepinefrina, epinefrina, dopamina e isoproterenol. Os agonistas agem de forma hierárquica nos receptores $\beta$ adrenérgicos (isoproterenol > epinefrina $\geq$ norepinefrina) e receptores a adrenérgicos (epinefrina $\geq$ norepinefrina $>$ isoproterenol). Os receptores $\beta$ regulam muitas respostas funcionais, destacam-se a frequência e contratilidade cardíaca $\left(\beta_{1}\right)$, relaxamento do músculo liso $\left(\beta_{2}\right)$, dilatação de vasos e brônquios (broncodilatador) $\left(\beta_{2}\right)$ e lipólise $\left(\beta_{3}\right)$. As catecolaminas sintéticas exercem poderoso efeito estimulante no funciomento cardíaco reduzindo sua eficência, resultantes de um aumento significativo do débito cardíaco, em consequência dos efeitos inotrópicos e cronotrópicos positivos e consumo de oxigênio pelo miocárdio. O isoproterenol é uma catecolamina sintética, de estrutura semelhante à adrenalina. É um potente agonista não seletivo $\beta$-adrenérgico de ação direta, com afinidade muito baixa pelos receptores $\alpha$, exercendo efeitos potentes no sistema cardiovascular (aumento da contratilidade, FC e velocidade de condução do estímulo elétrico cardíaco). A administração de grandes doses pode causar necrose do miocárdio em animais (Rang et al., 2007; Brunton et al., 2010).

Conforme descrito anteriormente, a $\mathrm{CMH}$ é uma doença cardíaca caracterizada por hipertrofia ventricular esquerda (HVE) e baseia-se na identificação do aumento de peso do coração determinada principalmente pelo aumento de tamanho dos cardiomiócitos (Escudero e Pinilla, 2007). O estudo realizado por Takeshita et al. (2008) com HVE induzida pelo isoproterenol, 
demonstrou que na relação peso do VE/ peso corpóreo em ratos, houve aumento significativo do coração com aumento da rigidez da parede do miocárdio, característico da HVE. Assim como o MP está relacionado com injúrias cardiovasculares significantes como IAM, arritmias, disfunção diastólica e morte súbita, neste cenário, o processo que antecede 0 mecanismo de desenvolvimento destas patologias pode estar associado à instalação da $\mathrm{CMH}$ como fator primário de lesão (Soor et al., 2008).

Yan et al. (2008), demonstrou comprometimento significativo na função ventricular esquerda através de avaliação ecocardiográfica na exposição aguda às PED e maior comprometimento nos ratos que receberam doses de isoproterenol, capaz de induzir hipertrofia ventricular sem comprometimento da pressão arterial (Taylor e Tang, 1984; Costa et al., 1997). A HVE causa remodelamento elétrico do coração (Charpentier et al., 1991; Swynghedauw et al., 1997a), através da resposta exacerbada do sistema nervoso simpático, causando um aumento na frequência da ocorrência de morte súbita (Levy et al., 1987) em idosos hipertensos (Mammarella et al., 2000). Sabendo que o desbalanço autonômico do coração, com alterações da VFC pode desencadear morte súbita, torna-se importante e justificável empregar a análise da VFC (domínio de tempo e domínio de frequência) na HVE. Este fato pode ser comprovado pelo estudo de Nishimura et al. (2010) que demonstrou alterações da razão LF/HF (índices de análise de VFC) em pacientes dependentes de hemodiálise com HVE esquerda. 


\section{JUSTIFICATIVA}

Considerando que:

(1) A cidade de São Paulo apresenta uma qualidade do ar deteriorada pelas emissões de origem veicular decorrente de uma gigantesca frota de veículos leves e pesados.

(2) estudos epidemiológicos e experimentais conduzidos em São Paulo e em outras cidades do mundo mostram que a exposição crônica ou aguda está associada a um comprometimento tanto da função respiratória quanto cardíaca em indivíduos normais jovens.

(3) Indivíduos com doenças preexistentes e idosos são mais sensíveis aos efeitos negativos da exposição à poluição do ar nas grandes cidades.

(4) Apesar da exposição à poluição do ar nas grandes cidades ser consistentemente associada a doenças cardiovasculares ainda não são bem conhecidos os mecanismos que geram esta associação em doenças cardiovasculares específicas tais como infarto do miocárdio e insuficiência cardíaca.

(5) Evidências recentes mostram que a poluição particulada de origem veicular é capaz de aumentar o numero de internações, infarto agudo do miocárdio e a mortalidade em indivíduos com insuficiência cardíaca, porém ainda não se sabe ao certo se a exposição à poluição do ar está associada ao desenvolvimento da insuficiência cardíaca. 
Este trabalho propõe um estudo do sistema cardíaco em animais normais e cardiopatas (hipertrofia ventricular induzida por isoproterenol) expostos sub cronicamente à poluição particulada do ar da cidade de São Paulo visando avaliar se a exposição por si só é capaz de alterar morfofuncionalmente ou agravar uma cardiopatia preexistente. 


\section{OBJETIVOS}

\section{Objetivo Geral}

Avaliar os efeitos morfofuncionais da exposição à poluição particulada de origem veicular sobre o sistema cardíaco de ratos normais e cardiopatas (hipertrofia ventricular esquerda induzida por isoproterenol).

\section{Objetivos Específicos}

\section{Função cardíaca}

- Avaliar a função cardíaca através dos parâmetros obtidos de frequência cardíaca (FC) e variabilidade da frequência cardíaca (VFC).

- SDNN (ms)

- RMSSD (ms)

$-\mathrm{HF}\left(m \mathrm{~s}^{2}\right)$

$-\operatorname{LF}\left(\mathrm{ms}^{2}\right)$

- LF/HF

- FC (bpm)

- Avaliar a pressão arterial

\section{Morfologia}

- Avaliar por meio de métodos estereológicos se há alterações morfológicas no estrutura macro e microscópica do coração.

- volume do coração

- volume dos ventrículos esquerdo e direito

- espessura da parede ventricular

- volume de cardiomiocítos no ventrículo esquerdo

- volume de tecido conjuntivo no ventrículo esquerdo 
- volume de vasos sanguíneos

- diâmetro dos cardiomiócitos

- volume médio dos cardiomiócitos

- Avaliar alterações hematológicas via hemograma e fatores de coagulação

- $\quad$ Análise do lavado broncoalveolar (LBA) 


\section{MATERIAL E MÉTODOS}

Neste estudo foram utilizados como modelo experimental ratos wistar machos jovens obtidos junto ao Biotério Central da Faculdade de Medicina da Universidade de São Paulo. O Protocolo de Pesquisa foi aprovado pela Comissão de Ética para Análise de Projetos de Pesquisa (CAPPesq) sob o número 0839/09. Os animais foram tratados humanamente e todo cuidado foi tido para aliviar o desconforto, dor e estresse.

Tendo em vista nosso objetivo de avaliar os efeitos da exposição ao $\mathrm{MP}_{2,5}$ de origem veicular da cidade de São Paulo sobre a função e morfologia cardíaca em indivíduos normais ou com $\mathrm{CMH}$, utilizamos injeções diárias de isoproterenol como agente indutor da doença. Nos animais sadios foi injetado solução salina $(0,9 \% \mathrm{NaCl})$.

Resumidamente, os animais jovens, sadios (S) e doentes (I) foram divididos em dois grandes grupo e expostos a poluição particulada (CPA) ou ar filtrado (AF) formando 4 grupos (S-AF, S-CPA, I-AF e I-CPA). Os animais foram expostos diariamente a uma concentração média de $600 \mu \mathrm{g} / \mathrm{m}^{3}$, as coletas dos dados eletrocardiográficos foram realizadas previamente e a cada 3 dias após o término das injeções de isoproterenol (a partir do $8^{\circ}$ dia de exposição). E a cada 7 dias um lote de animais de cada grupo $(7,15,21$ dias) foi eutanasiado para realização das avaliações morfológicas do coração, coleta de sangue e LBA.

\subsection{Animais}

Foi utilizado um total de 96 ratos wistar machos com idade aproximada de 3 meses (peso 250-300g) divididos em 8 indivíduos por grupo. Fora dos períodos de exposição os animais foram mantidos em caixas apropriadas com no 
máximo 5 animais por caixa em um "rack" ventilado/ estante ventilada recebendo ar filtrado (HEPA). Água e ração foram fornecidos ad libitum.

\subsection{Indução da hipertrofia cardíaca por isoproterenol}

Em nosso estudo a hipertrofia cardíaca foi induzida pela injeção subcutânea de isoproterenol (Sigma Co.) na dose de 1,2 mg/kg (Takeshita et al., 2008; Nakajima-Takenaka et al., 2009) suspendidos em $1 \mathrm{ml}$ de solução salina 0,9 $\%(\mathrm{NaCl})$. Nos animais sadios foi injetado $(1 \mathrm{ml})$ apenas o veículo, ou seja, solução salina $0,9 \%(\mathrm{NaCl})$.

\subsection{Grupos experimentais}

No desenho experimental deste estudo contamos com dois grandes grupos de animais subdivididos de acordo com a exposição ou não ao $\mathrm{MP}_{2,5}$ e o tempo de exposição.

As exposições ocorreram por 7, 15 e 21 dias. A seguir (Figura 6) está representado o desenho do estudo e a seguir a descrição do procedimento para cada um dos 12 grupos deste estudo: 

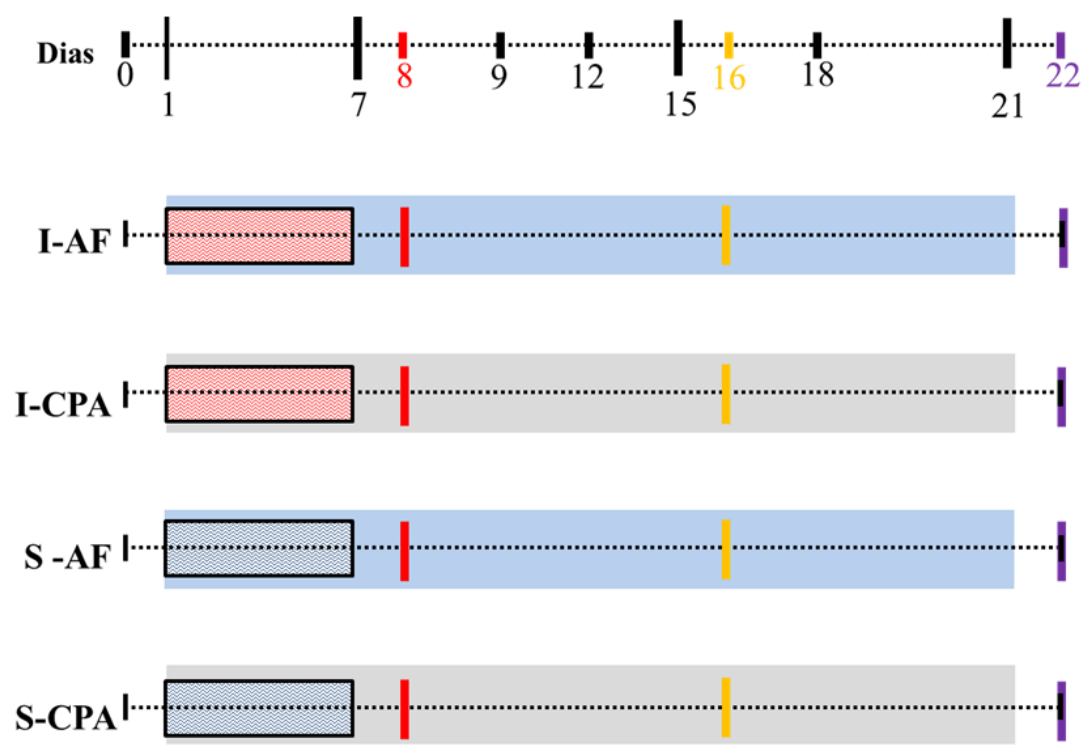

$\square$ Salina $(0,9 \% \mathrm{NaCl}) \quad \square$ Isoproterenol $(1,2 \mathrm{mg} / \mathrm{kg}) \quad$ |VFC $\quad$ EUTANASIA

Figura 6 - Representação esquemática do protocolo experimental

Descrição dos grupos experimentais:

I-AF-7 - ratos submetidos a injeções de isoproterenol e exposições ao ar filtrado durante 7 dias.

I-AF-15 - ratos submetidos a injeções de isoproterenol e exposições ao ar filtrado durante 15 dias.

I-AF-21 - ratos submetidos a injeções de isoproterenol e exposições ao ar filtrado durante 21 dias.

S-AF-7 - ratos submetidos a injeções de solução de salina e exposições ao ar filtrado durante 7 dias.

S-AF-15 - ratos submetidos a injeções de solução salina e exposições ao 
ar filtrado durante 15 dias.

S-AF-21 - ratos submetidos a injeções de solução salina e exposições ao ar filtrado durante 21 dias.

I-CPA-7 - ratos submetidos a injeções de isoproterenol e exposições ao CPA durante 7 dias.

I-CPA-15 - ratos submetidos a injeções de isoproterenol e exposições ao CPA durante 15 dias.

I-CPA-21 - ratos submetidos a injeções de isoproterenol e exposições ao CPA durante 21 dias.

S-CPA-7 - ratos submetidos a injeções de solução salina e exposições ao CPA durante 7 dias.

S-CPA-15 - ratos submetidos a injeções de solução salina e exposições ao CPA durante 15 dias.

S-CPA-21 - ratos submetidos a injeções de solução salina e exposições ao CPA durante 21 dias. 


\subsection{Exposição ao material particulado concentrado}

As exposições foram realizadas diariamente com auxílio de um CPA (Figura 7). Este equipamento está alocado no jardim da Faculdade de Medicina da Universidade de São Paulo na região central da cidade de São Paulo, SP, Brasil.

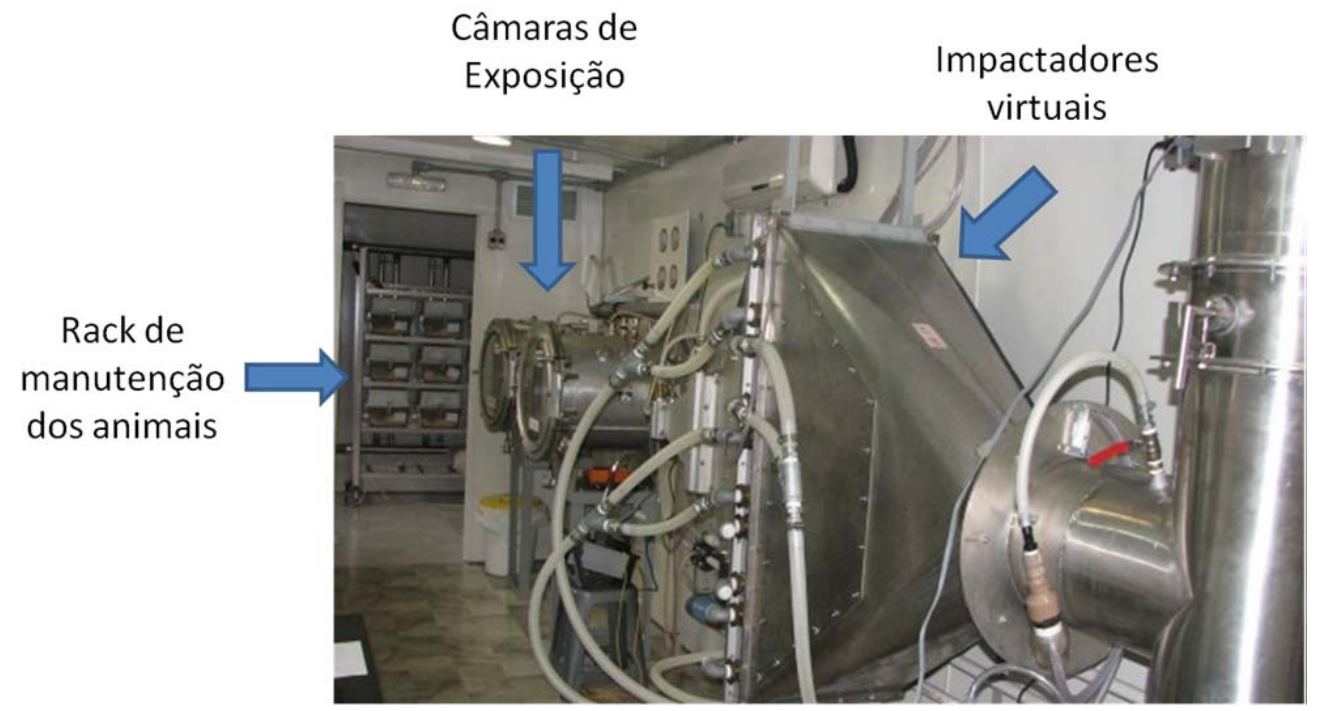

Figura 7 - CPA, o biotério para acomodação dos animais (Rack de manutenção dos animais), o sistema de impactadores virtuais e as câmaras onde os animais eram acomodados para as exposições

O CPA é um equipamento que nos permite realizar exposições controladas com relação a dose de exposição a poluição particulada do ar. Ele foi desenvolvido pela Universidade de Harvard e é capaz de concentrar cerca de 27 vezes os níveis ambientais de $\mathrm{MP}_{2,5}$. Este sistema utiliza a tecnologia de impactadores virtuais que permite que o MP suspenso na atmosfera não sofra modificações químico-físicas, mantendo assim suas características e composição. Este sistema alimenta duas câmaras, onde os animais são acomodados, uma que recebe ar filtrado e outra o ar carregado de partículas (Figura 7). As exposições foram do tipo corpo inteiro (whole body exposure), ficando os animais livres durante todo tempo. 
A dose de exposição foi escolhida tendo como referencia a dose de exposição a qual pessoas vivendo na cidade de São Paulo estão expostas. A média diária anual na cidade é de $25 \mu \mathrm{g} / \mathrm{m}^{3}$ de $\mathrm{MP}_{2,5}$ (Cetesb, 2008a). Assim, em $24 \mathrm{~h}$ a uma concentração de $25 \mu \mathrm{g} / \mathrm{m}^{3}$ temos uma dose de $600 \mu \mathrm{g} / \mathrm{m}^{3}$. Portanto, neste estudo os animais receberam diariamente $600 \mu \mathrm{g} / \mathrm{m}^{3}$ de $\mathrm{MP}_{2,5}$. As exposições foram realizadas sempre no período da manhã entre 8:00-10:00.

\subsection{Caracterização do Material Particulado}

Logo após as exposições e em dias alternados, os filtros para coleta do $\mathrm{MP}_{2,5}$ foram ligados apropriadamente ao sistema para caracterização elementar. Esta análise foi realizada com auxilio de um espectrômetro de fluorescência de raio-X (modelo EDX 700 HS, da Shimadzu Corporation, Japão) em parceria com o Laboratório do Instituto de Astronomia e Geofísica da Universidade de São Paulo (IAG) - USP. Os resultados da análise estão apresentados como média do percentual de cada elemento.

\subsection{Registro da frequência cardíaca, variabilidade da frequência} cardíaca e pressão arterial

Para o registro eletrocardiográfico, os animais foram previamente sedados por injeção intraperitoneal da associação de Rompum® (xilasina) (9 $\mathrm{mg} / \mathrm{Kg}$ ) e Ketamina-S(+)® (Cloridrato de Ketamina) $(42 \mathrm{mg} / \mathrm{Kg})$. As avaliações foram realizadas a cada 3 dias durante todo o período do estudo e no dia anterior a eutanásia. Um registro prévio ao tratamento foi realizado para avaliação dos animais experimentais. 
Para o exame foi adaptado um cuff com transdutor de pulso específico para ratos ajustado na base da cauda, e acoplado via conector BNC (Bayonet Neill-Concelman) ao sistema digital de aquisição de dados NIBP (noninvasive blood Pressure) system (ML125/R PowerLab System; ADInstruments, Mountain View, CA) usado em conjunto com o sistema Powerlab (ADInstruments) para o registro da FC, VFC e PA.

A VFC foi avaliada no domínio de tempo através do SDNN e RMSSD e no domínio da frequência através da HF, LF e LF/HF. Na figura 6 podem ser verificados os dias de registro para todos os grupos.

\subsection{Hemograma}

No hemograma completo inclui o estudo da série vermelha, série branca, contagem das plaquetas e reticulócitos, e os índices hematológicos (Vallada, 2003).

Os índices hematológicos são determinados a partir da contagem global dos eritrócitos, taxa de hemoglobina e determinação do hematócrito. O hematócrito representa a quantidade de glóbulos vermelhos existentes em determinada quantidade de sangue total. Os valores aumentam quando há número muito alto de células vermelhas no sangue, na diminuição da tensão de oxigênio no sangue, desidratações em geral (cirurgia, queimaduras, diarreias, vômitos, etc.). As diminuições ocorrem com a redução do número de eritrócitos (anemias), descompensações cardíacas, gravidez e administração excessiva de líquidos que acarretam hemodiluição. Os valores absolutos obtidos em relação ao sangue são determinados através do cálculo dos índices eritrocitários (HCM Hemoglobina corpuscular média, expressa a quantidade média de hemoglobina que existe dentro de uma hemácia; $\mathrm{CHCM}$ - Concentração hemoglobínica 
corpuscular média, expressa a quantidade de hemoglobina presente num determinado volume de sangue; VCM - Volume corpuscular médio, que determina o volume médio de cada eritrócito) (Vallada, 2002; Lorenzi, 2006).

Os índices da amplitude de distribuição dos eritrócitos (RDW) indicam o grau de variação do tamanho dos eritrócitos e são determinados através de dois parâmetros: RDW-CV (amplitude de distribuição dos eritrócitos representados como coeficiente de variação) e RDW-SD (amplitude de distribuição dos eritrócitos representados como desvio padrão), que são calculados a partir do VCM. (Lorenzi, 2006; Monteiro, 2010).

A contagem global e diferencial (específica) dos leucócitos compreende a leucometria e os estudos quantitativo e qualitativo dos glóbulos brancos. Podem ser divididos em granulócitos (Neutrófilos, Eosinófilos e Basófilos), linfócitos e monócitos. Os neutrófilos são as células mais numerosas entre os leucócitos, especializados em fagocitar pequenas partículas e bactérias. Os neutrófilos segmentados são neutrófilos maduros, encontrados geralmente no sangue periférico e em maior quantidade que os neutrófilos mais jovens (bastonetes). Os neutrófilos bastonetes possuem o núcleo não amadurecido por completo, permanecendo na medula óssea e raramente são vistos na circulação sanguínea. Os eosinófilos estão associados à defesa do organismo exercendo ações tóxicas contra parasitas e algumas células tumorais. As funções dos eosinófilos são muito discutidas e ainda que os eosinófilos sejam capazes de fagocitar, acreditase que esta não seja sua principal função. Os basófilos são encontrados em pequenas quantidades no sangue periférico, acompanhando as modificações quantitativas dos eosinófilos, estão envolvidos principalmente nas reações alérgicas e normalmente ausentes nos processos infecciosos agudos. (Oliveira, 1998; Vallada, 2002; Lorenzi, 2006).

Os linfócitos são células desprovidas de granulações citoplasmáticas, 
estão presentes na circulação e órgão linfoides, se locomovem após serem estimulados e podem penetrar entre as células endoteliais dos vasos, mudando sua morfologia para uma forma alongada e atingir pontos situados além desta barreira em resposta a agentes estimulantes secretados por outros linfócitos ou por macrófagos. Os subtipos de linfócitos T e B se diferenciam basicamente em função do tipo de resposta imune, os linfócitos B se diferenciam em plasmócitos e fazem uma resposta imune humoral envolvendo imunoglobulinas. Os receptores formados e aderidos (membrana) nos linfócitos $\mathrm{T}$ fazem uma resposta imune celular. Os monócitos são elementos constates na circulação sanguínea que não estão em função fagocitária, os monócitos quando emigram da corrente sanguínea para se fixarem nos tecidos se transformam em macrófagos. Os Reticulócitos são hemácias jovens, sofrem um período inicial de maturação dentro da medula óssea e são liberados no sangue periférico se transformando em hemácia madura. As plaquetas são células incompletas anucleadas originárias da fragmentação citoplasmática do megacariócito e estão envolvidas no processo de hemostasia primária e coagulação. O mecanismo de coagulação consiste em várias reações que tem por finalidade a transformação do fibrinogênio (Fator I) em fibrina por clivagem da trombina. (Oliveira, 1998; Lorenzi, 2006). O fator VIII (globulina anti-hemofílica) sintetizado no endotélio vascular é um cofator importante no processo de formação da trombina (Hoyer, 1981).

\subsubsection{Coleta do sangue e processamento do hemograma}

A eutanásia dos animais ocorreu 24 horas após o último dia de exposição e foi realizada overdose de anestésico via injeção intraperitoneal da associação de Rompum ${ }^{\circledR}$ (xilasina) $(15 \mathrm{mg} / \mathrm{Kg})$ e Ketamina-S(+)® (Cloridrato de Ketamina) (75 mg/Kg). 
A coleta do sangue foi realizada através de punção da artéria aorta abdominal. O sangue foi colocado em frascos EDTA K3 para análise do hemograma: eritrograma (Eritrócitos, Hemoglobina, Hematócrito, $\mathrm{HCM}, \mathrm{CHCM}$, VCM, RDW CV, RDW SD, contagem de reticulócitos) e Leucograma (Leucócitos, Neutrófilos, Neutrófilos Bastonetes, Neutrófilos Segmentados, Eosinófilos, Basófilos, Linfócitos, Monócitos). O material coletado foi encaminhado ao Serviço de Hematologia do Laboratório Central do Hospital das Clínicas da Faculdade de Medicina da Universidade de São Paulo para análise.

A análise hematológica foi realizada através do equipamento Pentra 120 da ABX Diagnósticos (Montpellier, França). O principio da contagem de plaquetas e eritrócitos foi feito por impedância elétrica, e, para a classificação do tamanho e complexidade dos leucócitos, usou-se dispersão a laser associada a citoquímica. Para a avaliação dos reticulócitos, a citometria de fluxo foi usada associada à coloração fluorescente. A contagem diferencial de leucócitos foi feita através de microscópio ótico em aumento de 1000 x, em lâminas coradas com Romanowsky.

Os marcadores de hemostasia (Plaquetas) foram determinados em plasma citratado mensurados em equipamento Thrombolyzerb Rack Rotor (Behnk Elektronik® - Organon Tekinica®) automatizado. Amostras adicionais de sangue foram acondicionadas em citrato de sódio $\left(\mathrm{Na}_{3} \mathrm{C}_{6} \mathrm{H}_{5} \mathrm{O}_{7}\right)$ para análise de fibrinogênio e fator VIII. Os níveis de fibrinogênio foram determinados pela metodologia coagulométrica (método Clauss modificado). Os níveis de fator VIII foram determinados pelo tempo de tromboplastina parcial ativada (TTPA). 


\subsection{Lavado Broncoalveolar}

Após a coleta do sangue, procedeu-se a toracotomia para retirada dos pulmões em bloco (traqueia, pulmão e coração); o coração foi isolado do bloco, seguidamente a traqueia e os pulmões foram pesados e colocados em uma placa embebida com tampão fosfato de sódio (PBS, pH 7,4). Um cateter foi inserido na traqueia, fixado, e com auxílio de uma seringa acoplada foram feitas 3 lavagens com cerca de $2,5 \mathrm{ml}$ de PBS totalizando um volume de $7,5 \mathrm{ml}$ que foram acondicionados em tubos cônicos de $15 \mathrm{ml}$.

O volume recuperado foi centrifugado a $1810 \mathrm{rpm}$, a $5^{\circ} \mathrm{C}$ por 10 minutos. O sobrenadante foi acondicionado em tubos Eppendorf e congelado em freezer $70^{\circ} \mathrm{C}$. O pellet foi ressuspendido em $1000 \mu \mathrm{l}$ de PBS. $100 \mu \mathrm{l}$ do pellet ressuspendido foi retirado e colocado em um eppendorf com $400 \mu$ de PBS. $10 \mu \mathrm{l}$ do LBA foram acondicionados no hemocitômetro de Neubauer para a contagem total de células por microscopia ótica em aumento de 400x.

Para a contagem diferencial, $100 \mu \mathrm{l}$ do LBA foram adicionados em centrífuga cytospin (Cytospin 3 - Shandon) e citocentrifugados a 450 rpm por 6 minutos. O material depositado na lâmina do cytospin foi corado com Diff Quick (Baxter Dade, Dudingen, Suiça) para contagem diferencial das células inflamatórias: macrófagos, neutrófilos, linfócitos, eosinófilos em microscópio óptico com objetiva de imersão e aumento de 1000 x.

\subsection{Coleta dos órgãos}

Após a pesagem dos pulmões e coleta do LBA, procedeu-se a retirada dos órgãos de interesse de todos os animais (fígado, rins, baço, cérebro) para avaliação do peso entre os grupos. 


\subsection{Cálculos do Índice de Hipertrofia Cardíaca e estimativa da dose} inalada

Depois de isolar o coração do bloco, os átrios foram retirados e os ventrículos foram pesados (fresh weight). $\mathrm{O}$ índice de hipertrofia cardíaca foi calculado dividindo-se a média da massa dos ventrículos pela média da massa corporal dos ratos de cada grupo (IHC $=\mathrm{mg}$ ventrículos $/ \mathrm{g}$ corporal) $(\mathrm{Hu}$ et al., 2003).

A dose de $\mathrm{MP}_{2.5}$ que cada rato inalou durante o período de exposição a cada dia, foi estimada utilizando-se a seguinte fórmula:

\section{Dose $=\begin{gathered}\text { Taxa total de } \\ \text { ventilação média }\end{gathered} \times \underset{(\mu \mathrm{g} / \mathrm{L})}{\text { Concentração }} \times \begin{gathered}\text { Período de } \\ \text { exposição/dia }(\mathrm{min})\end{gathered}$ $\exp \quad(\mathrm{L} / \mathrm{min})$}

Onde a taxa total de ventilação média considerada para cada rato foi de 0,12 L/min (Davies e Morris, 1993), a concentração média e o período de exposição por dia foram considerados respectivamente: 0,6 $\mu \mathrm{g} / \mathrm{L}$ e $120 \mathrm{~min}$.

\subsection{Avaliação estereológica do coração}

A estereologia é um conjunto de métodos desenvolvidos para garantir uma rigorosa análise quantitativa do tamanho, forma é numero de objetos. Quando aplicada de forma apropriada, a estereologia desempenha um papel importante na validação ou rejeição de hipóteses experimentais em estudos biológicos. Sua utilização produz resultados acurados que facilitam a interpretação e estabelecimento de correlações entre a estrutura e função (Muhlfeld et al., 2010). 


\subsubsection{Amostragem}

Após as avaliações funcionais nos períodos estabelecidos no protocolo descrito nas seções 4.3 e 4.6, coleta do sangue, LBA, isolamento e pesagem dos ventrículos, o procedimento de amostragem do coração foi realizado de maneira sistemática, randômica e uniforme (SUR sampling) levando em consideração o princípio do "fractionator" (Gundersen, 1986) de maneira que todo o tecido tenha a mesma chance de ser amostrado e a amostra selecionada para análise seja representativa do todo. Para tanto os ventrículos foram sobrepostos sobre um sistema guia de linhas e fatias de $2 \mathrm{~mm}$ ortogonais ao maior eixo do órgão foram produzidas. As fatias foram então separadas, a fração de $1 / 2$ selecionada foi fixada por imersão em paraformaldeído tamponado (PBS 0,1 M, pH 7,0) por 24hs e transferidos para álcool etílico $70 \%$ até o momento da análise. As demais fatias foram separadas e congeladas a $-80^{\circ} \mathrm{C}$ para análise futura.

\subsubsection{Volume dos ventrículos}

Os volume total dos ventrículos foram obtidos dividindo-se o peso ("fresh weight", g) dos ventrículos (Vvent) pela densidade específica do tecido, neste caso considerada 1,06 g/cm³ (Brüel et al., 2002).

\subsubsection{Estimativa do volume individual dos ventrículos e do septo} interventricular

As fatias produzidas foram então processadas rotineiramente para inclusão em parafina. As fatias foram incluídas de forma a obtermos cortes histológicos ortogonais ao maior eixo do órgão. Estes cortes foram corados (H\&E, 
hematoxilina eosina) e utilizados para estimarmos as frações de volume (Vv) dos ventrículos direito (VD) e esquerdo (VE), do septo ventricular (SEP) pelo método de contagem de pontos (Howard e Reed, 2005).

Resumidamente, os cortes foram escaneados, e fotos de pequeno aumento de cada fatia foram produzidas utilizando o software Pannoramic ${ }^{\mathrm{TM}}$ Viewer v. 1.15 desenvolvido pela 3DHISTECH Ltd. (Budapest, Hungary). As imagens foram então analisadas com auxílio do software Image $J$ (http://rsb.info.nih.gov/ij) com o qual um sistema teste de pontos foi sobreposto a imagem e os pontos incidentes sobre cada região de interesse contados.

Este método nos permite obter uma estimativa do volume de estruturas. Os pontos incidentes (pt) sobre o VD, VE e SEP em todas as fatias foram somados e a fração de volume de cada compartimento obtida aplicando-se a seguinte fórmula:

\section{$\mathrm{Vv} \mathrm{VE}=\sum \mathrm{ptVE} / \sum \mathrm{pt}$ totais}

Onde $\sum$ pt totais refere-se a soma de todos os pontos incidentes sobre o VE, Vd e SEP.

As frações de volume de cada compartimento foram convertidas em volume total multiplicando-se o $\mathrm{V} v$ de cada compartimento pelo volume total dos ventrículos.

\subsubsection{Avaliação da densidade de volume de cardiomiócitos, tecido} conjuntivo, capilares

A densidade de volume $(\mathrm{Vv})$ de cada compartimento (cardiomiócitos, Mioc; tecido conjuntivo, Conj; capilares, Cap) foi estimada pelo método de 
contagem de pontos (Brüel et al., 2005). Para isso os cortes serão fotografados utilizando-se uma objetiva de médio aumento $(20 x)$ e sobre as imagens $(n=20$ por bloco) um sistema teste de pontos [a(p) $54 \mu \mathrm{m}$ ] foi aplicado. O número de pontos incidentes sobre os compartimentos de interesse (Mioc, Conj, Cap) foram contados e a fração de volume ( $\mathrm{V} v)$ determinada segundo a formula:

\section{$\mathrm{Vv}=\sum$ pt Comp / $\sum$ pt VE}

onde $\sum$ pt Comp é a somatória de pontos incidentes sobre Mioc, Conj ou Cap e $\sum$ pt VE é a soma de pontos incidentes sobre VE como um todo.

As densidades de volume foram convertidas em volumes absolutos multiplicando-se pelo volume total do VE. Aproximadamente 20 campos selecionados randomicamente por bloco foram analisados. O Programa Image $\mathrm{J}$ (http://rsb.info.nih.gov/ij) foi utilizado para realização das contagens e geração dos sistemas teste.

\subsubsection{Avaliação do diâmetro e volume ponderado dos} cardiomiócitos do ventrículo esquerdo

A estimativa do diâmetro e do volume médio ponderado dos cardimiócitos foi realizada utilizando-se as mesmas imagens obtidas para a análise da fração de volume de cardiomiócitos.

O volume médio ponderado dos cardiomiócitos foi obtido pelo método PSI (point sample intercept). Este é um método eficiente de se medir o volume médio ponderado de uma partícula. Este método é realizado em duas etapas (Howard e Reed, 2005): 
1) amostragem das partículas a serem medidas: isto é realizado aplicando-se um sistema teste de pontos, e os cardiomiócitos sobre os quais um ponto incide são avaliados

2) estimativa do volume de cada partícula: realizada medindo-se o comprimento de uma linha isotrópica que atravessa o ponto de amostragem que esta dentro do transecto da partícula. Então, se fazendo uma série de medidas o volume ponderado pode ser obtido aplicando-se a seguinte fórmula:

\section{VponN $=[\pi /(3 * n)] * \sum \mathrm{I}^{3}$}

onde n é o numero de medidas realizadas para uma mesma partícula, no caso um cardiomiócito, e $\sum$ l é a somatória dos comprimentos medidos elevados a terceira potencia.

O diâmetro do cardiomiócito foi avaliado de acordo com métodos morfométricos. Os cardiomiócitos que apareciam em corte transversal foram selecionados aleatoriamente e seu maior e menor diâmetro foram medidos

diretamente. A média das duas medidas foi então considerada como o diâmetro do cardiomiócito.

\subsection{Análise estatística}

A análise estatística foi realizada utilizando-se o software estatístico SPSS 17. Médias (M), desvios (DP) e erros padrões (EP) foram calculados para cada grupo e parâmetro.

Análises multivariadas (1-way e 3-way) foram utilizadas para comparar os desfechos nos diferentes grupos e os efeitos do tratamento, exposição e tempo. Quando revelou diferença estatisticamente significativa, a análise foi 
complementada com pós-teste de Student Newman Keuls. Hipótese nula foi rejeitada ao nível de probabilidade de $P<0,05$. Foram realizadas análises descritivas para todas as variáveis avaliadas nesse estudo que estão apresentadas como tabelas na seção de Anexos. 


\section{RESULTADOS}

Os principais resultados estão descritos e apresentados a seguir sob a forma de gráficos. Médias, desvios padrão e erros padrão de alguns parâmetros avaliados nos grupos estudados podem ser encontrados nos anexos. Para as análises propostas para este trabalho, exceto os parâmetros eletrocardiográficos (VFC, FC e PA), somente foram possíveis conduzir em 11 dos 12 grupos propostos para compor os resultados. Os animais do grupo I-CPA-7 morreram ou foram eutanasiados por estarem moribundos em consequência da indução de hipertrofia miocárdica por isoproterenol, não sendo possível a repetição deste grupo por conta de tempo hábil e disponibilidade de uso do CPA.

\subsection{Composição elementar do material particulado}

A avaliação da composição elementar do $\mathrm{MP}_{2,5}$ mostrou que $97 \%$ da massa é composta por carbono elementar e os demais $3 \%$ estão distribuídos entre diferentes elementos apresentados na figura 8 a seguir:

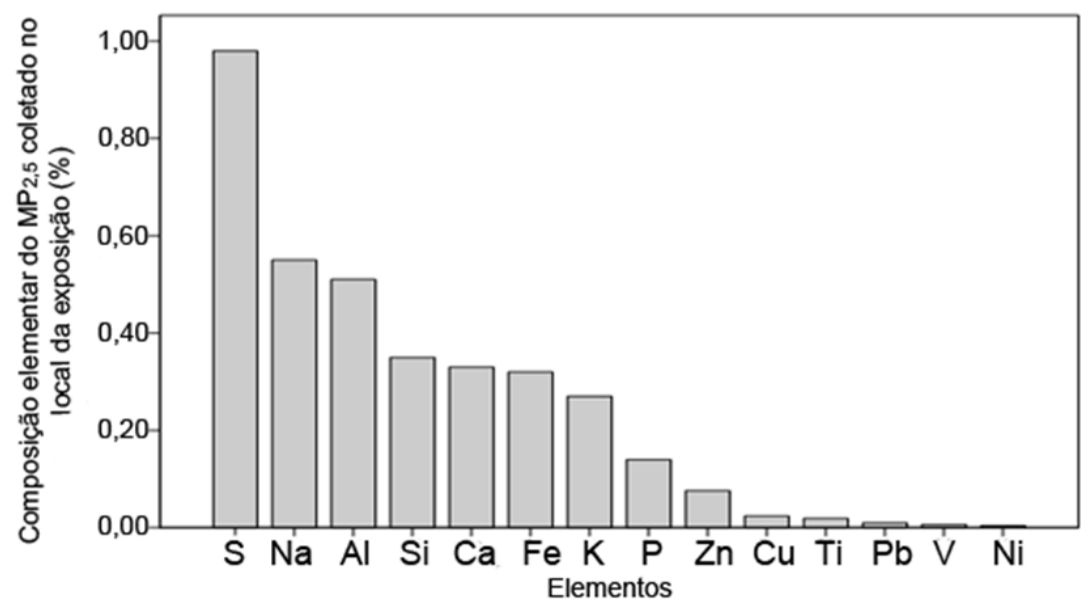

Figura 8 - Composição elementar do $\mathrm{MP}_{2,5}$ proveniente do ambiente. S, enxofre; $\mathrm{Na}$, sódio; $\mathrm{Al}$, alumínio; Si, silício; $\mathrm{Ca}$, cálcio; Fe, ferro; $\mathrm{K}$, potássio; $\mathrm{P}$, fósforo; $\mathrm{Zn}$, zinco; $\mathrm{Cu}$, cobre; Ti, titânio ; $\mathrm{Pb}$, chumbo; $\mathrm{V}$, vanádio; $\mathrm{Ni}$, níquel 


\subsection{Peso Corporal}

A avaliação do peso corporal dos animas no $15^{\circ}$ dia indica que tanto a exposição ao CPA $(p=0,006)$ bem como o tratamento com isoproterenol por 7 dias para indução de uma $\mathrm{CMH}(\mathrm{p}=0,009)$ provocam uma redução no peso dos animais quando comparado aos animais controle. A redução mostra-se mais acentuada quando os dois fatores estão combinados. A reavaliação no $21^{\circ}$ dia mostra uma clara recuperação no peso corporal, porém nos animais que receberam as injeções e foram continuamente expostos ao CPA está recuperação é menor. Nos animais dos grupos 7 dias houve um aumento de peso ao longo do tempo independente do tratamento (ISOP ou salina), esse ganho de peso é menor nos animais que receberam isoproterenol e nos animais que foram somente expostos ao CPA (Figura 9). Os resultados estão apresentados na Tabela 1.

Tabela 1 - Médias, desvio padrão (DP) e erro padrão (EP) para o peso corporal dos animais nos grupos estudados

\begin{tabular}{llrrrrr}
\hline Parâmetro & Grupo & N & Média & DP & EP & ANOVA p \\
\hline Peso corporal (g) & I-AF-7 & 6 & 291,00 & 22,970 & 9,377 & \\
& S-AF-7 & 6 & 330,67 & 13,307 & 5,432 & \\
& S-CPA-7 & 5 & 346,00 & 32,588 & 14,574 & \\
& I-AF-15 & 4 & 322,50 & 13,404 & 6,702 & 0.01 \\
& I-CPA-15 & 6 & 320,33 & 14,109 & 5,760 & \\
S-AF-15 & 5 & 356,80 & 19,728 & 8,823 & \\
& S-CPA-15 & 7 & 351,71 & 27,627 & 10,442 & \\
& I-AF-21 & 5 & 362,80 & 36,348 & 16,255 & \\
& I-CPA-21 & 6 & 344,00 & 25,235 & 10,302 & \\
S-AF-21 & 5 & 385,20 & 30,483 & 13,632 & \\
S-CPA-21 & 5 & 355,20 & 17,470 & 7,813 &
\end{tabular}




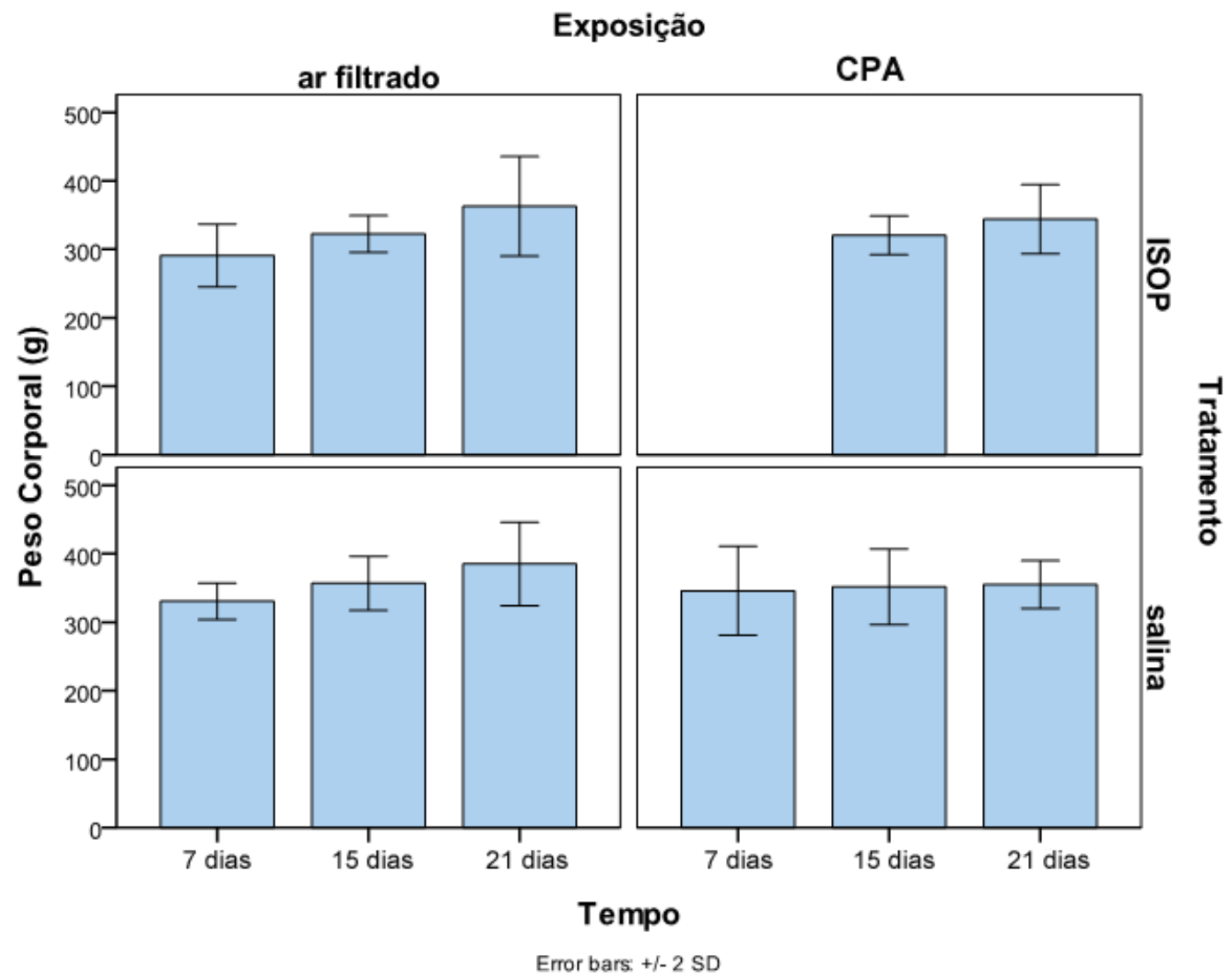

Figura 9 - Representação gráfica do peso médio dos animais aos 7, 15 e 21 dias de exposição ao $\mathrm{MP}_{2,5}$ concentrado

\subsection{Peso dos órgãos - Pulmão, Fígado, Rins, Baço e Cérebro}

O peso do baço bem como dos pulmões não variou devido ao tratamento com isoproterenol e com a exposição continuada ao $\mathrm{MP}_{2,5}$ concentrado. Entretanto o peso do fígado, rins e do cérebro forma afetados. A indução de hipertrofia ventricular por isoproterenol somada à exposição ao CPA $(p=0,02)$ está associada a uma diminuição do peso do fígado quando comparado aos animais sadios não expostos ao CPA (Figura 10). 


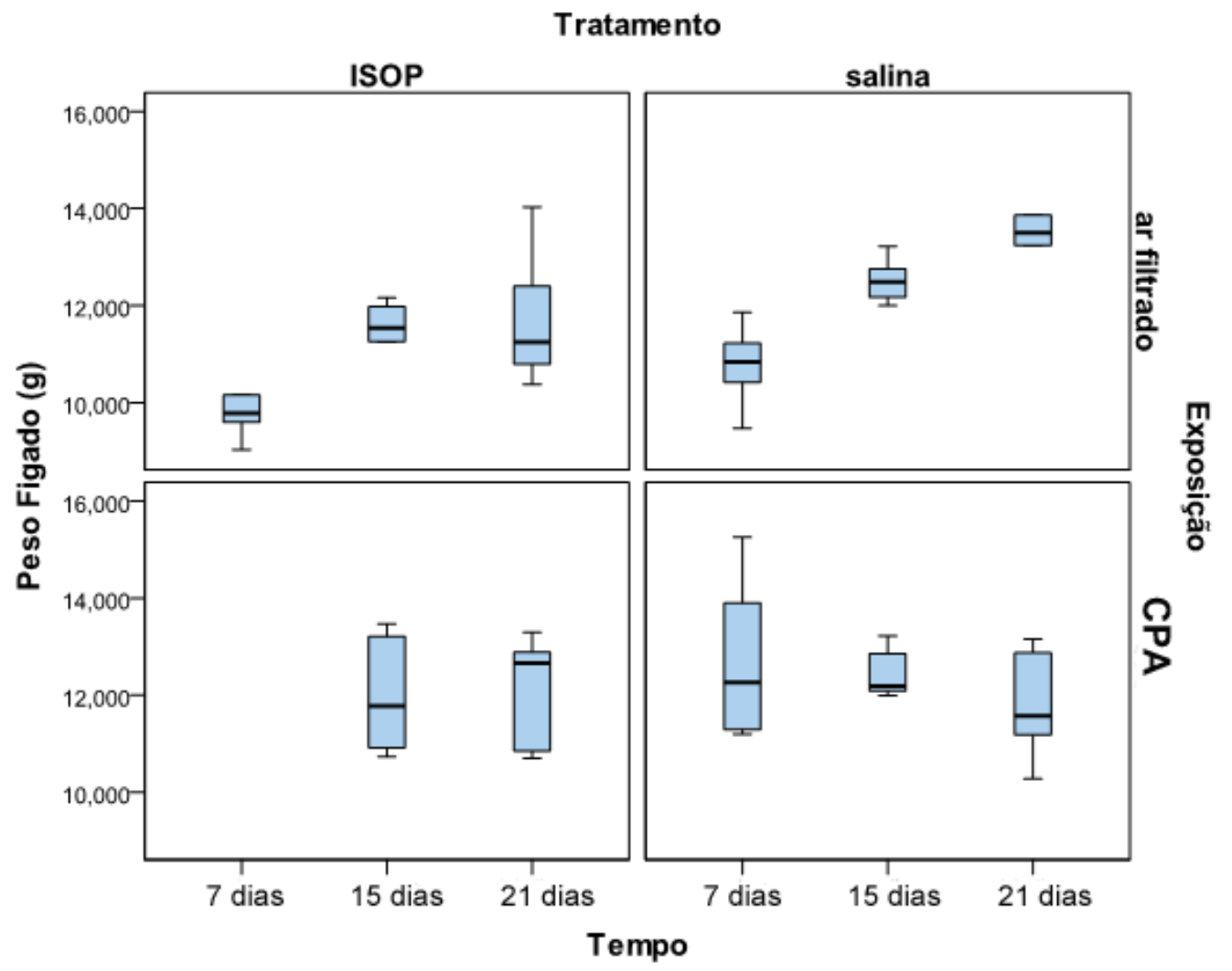

Figura 10 - Representação gráfica do peso médio do fígado dos animais sadios e com $\mathrm{CMH}$ aos 7, 15 e 21 dias de exposição ao $\mathrm{MP}_{2,5}$ concentrado

Não há interação entre os fatores para o aumento no peso do cérebro, o aumento é observado somente por conta do tempo $(p=0,02)$ e provavelmente se relaciona ao crescimento do animal (Figura 11). 


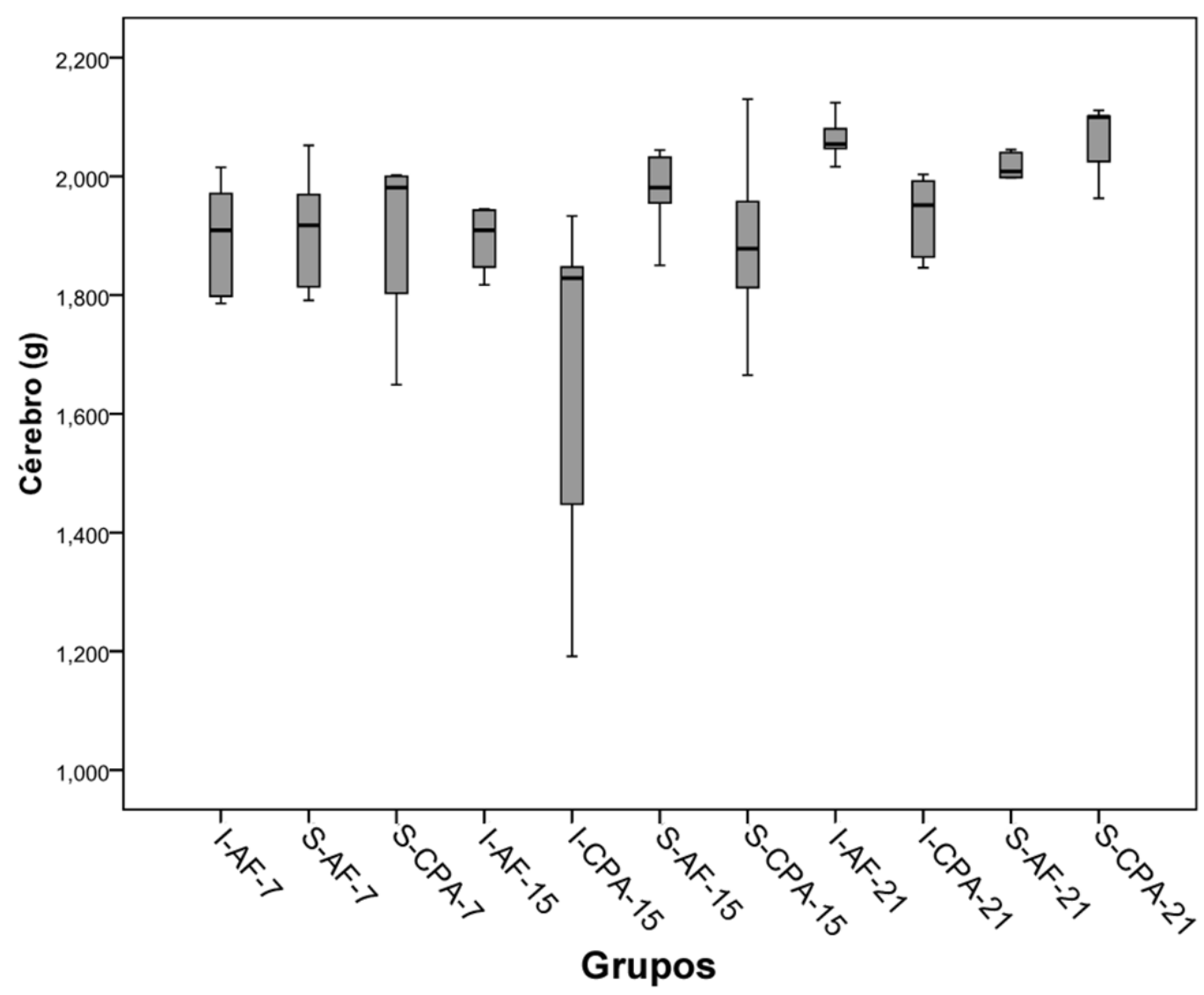

Figura 11 - Representação gráfica do peso médio do cérebro dos animais de cada grupo (ISOP = I e salina = S) CPA e AF (7, 15 e 21 dias)

O peso renal (Figura 12) parece ser afetado pelo tratamento do isoproterenol. Os resultados apontam que há uma redução no peso médio dos rins quando os animais que receberam doses de isoproterenol e não foram expostos ao CPA são comparados aos grupos controle (salina + ar filtrado). Já nos animais em que houve somente a exposição ao CPA o peso renal se manteve igual ao longo do tempo. Nos grupos expostos ao CPA e que receberam isoproterenol o peso renal reduzido é mantido ao longo do tempo. Como se tratam de animais jovens e que ainda podem apresentar crescimento, esta manutenção do peso pode caracterizar-se como um prejuízo de desenvolvimento. 


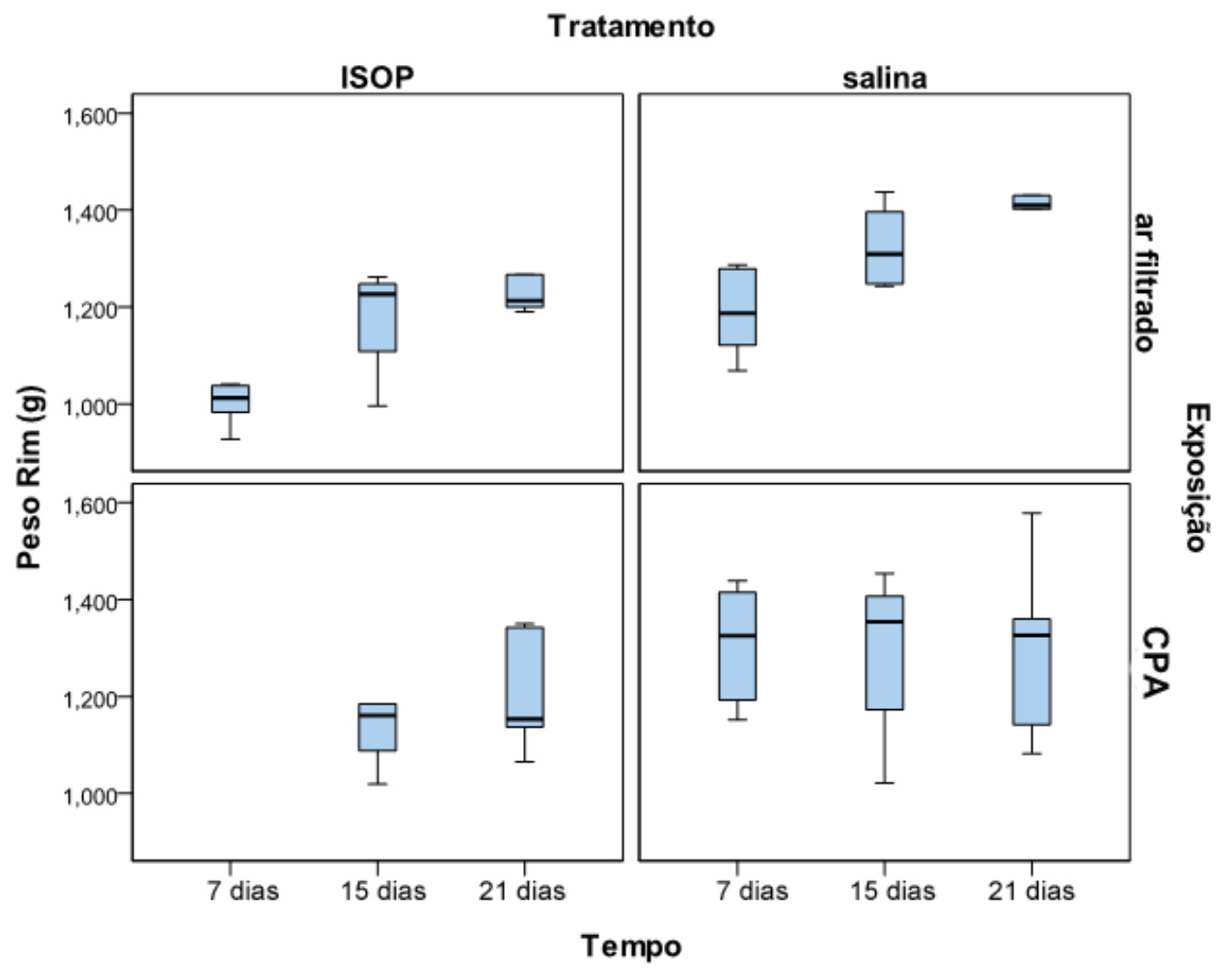

Figura 12 - Representação gráfica do peso médio dos rins nos animais sadios e com $\mathrm{CMH}$ aos 7,15 e 21 dias de exposição ao $\mathrm{MP}_{2,5}$ concentrado

5.4. Análise do Índice de Hipertrofia Cardíaca e estimatitaiva de dose inalada

Os animais tratados com o Isoproterenol (ISOP) obtiveram um maior aumento da massa cardíaca $(\mathrm{IHC})(3,34 ; 0,35 \mathrm{mg} / \mathrm{g})$, em relação aos animais tratados com solução salina $(2,83 ; 0,20 \mathrm{mg} / \mathrm{g} ; \mathrm{p}=0,021)$, independente do tempo de exposição. Não houve interação entre exposição (AF ou CPA) quanto ao índice de hipertrofia cardíaca $(p>0,05)$. 
O cálculo da dose estimada de $\mathrm{MP}_{2.5}$ que cada rato inalou durante o período de exposição a cada dia foi:

$$
\begin{gathered}
\text { Dose }_{\text {exp }}=0,12 \mathrm{~L} / \mathrm{min} \times 0,6 \mu \mathrm{g} / \mathrm{L} \times 120 \mathrm{~min} \\
\text { Dose }_{\exp }=8,64 \mu \mathrm{g} / \mathrm{dia}
\end{gathered}
$$

\subsection{Análise da inflamação pulmonar pelo lavado broncoalveolar}

A avaliação do LBA mostra que apenas o número de macrófagos e consequentemente o número de células totais $(p<0.001$, ANOVA) apresentam diferenças estatísticas entre os grupos avaliados. Os animais expostos ao CPA apresentaram valores maior número de células totais e macrófagos $(p<0,05)$ quando comparados aos animais que receberam AF. O número de macrófagos no LBA é influenciado pela exposição ao CPA $(p=0,002)$ e pelo tempo $(p=0,002)$ que esta exposição ocorreu. Na figura 13 podemos observar que há um aumento nos primeiros 15 dias de exposição ao CPA e depois com a continuação desta exposição parece haver uma diminuição indicando uma interação entre estes dois fatores $(p=0,01)$. A indução da cardiomiopatia não influenciou o número de macrófagos e o número de células totais presentes no LBA, percebe-se apenas que está resposta está diminuída nos animais do grupo que recebeu as injeções de isoproterenol e foi exposto ao CPA (Figura 13 e 14). Os resultados estão apresentados nas Tabelas 2 e 3. 
Tabela 2 - Médias, desvio padrão (DP) e erro padrão (EP) para o número total de células do LBA nos grupos estudados

\begin{tabular}{clcccc}
\hline Parâmetro & Grupo & N & Média & DP & EP \\
\hline Número Total de & I-AF-7 & 6 & 5,467 & 2,8479 & 1,1627 \\
células (Cel/mL x & S-AF-7 & 6 & 5,071 & 2,4222 & 0,9888 \\
$10^{4}$ ) & S-CPA-7 & 5 & 27,840 & 20,0860 & 8,9827 \\
& I-AF-15 & 4 & 6,256 & 2,7868 & 1,3934 \\
& I-CPA-15 & 5 & 12,125 & 1,8368 & 0,8214 \\
& S-AF-15 & 5 & 10,430 & 2,6238 & 1,1734 \\
& S-CPA-15 & 7 & 38,400 & 13,5922 & 5,1374 \\
& I-AF-21 & 5 & 13,200 & 4,7334 & 2,1168 \\
& I-CPA-21 & 6 & 15,750 & 7,5680 & 3,0896 \\
& S-AF-21 & 5 & 13,100 & 5,5929 & 2,5012 \\
& S-CPA-21 & 5 & 17,440 & 12,6217 & 5,6446 \\
\hline
\end{tabular}

Tabela 3 - Médias, desvio padrão (DP) e erro padrão (EP) para a porcentagem de macrófagos do LBA nos grupos estudados

\begin{tabular}{lllccc}
\hline \multirow{2}{*}{ Parâmetro } & Grupo & N & Média & DP & EP \\
\hline Macrófafos (\%) & I-AF-7 & 6 & 81,4444 & 21,19399 & 8,65241 \\
& S-AF-7 & 6 & 90,9444 & 6,51295 & 2,65890 \\
& S-CPA-7 & 5 & 91,4000 & 3,75204 & 1,67796 \\
& I-AF-15 & 3 & 86,3333 & 11,59023 & 6,69162 \\
& I-CPA-15 & 5 & 85,9333 & 11,86358 & 5,30555 \\
& S-AF-15 & 5 & 87,5333 & 2,29250 & 1,02524 \\
S-CPA-15 & 7 & 92,1429 & 5,66293 & 2,14039 \\
& I-AF-21 & 5 & 87,7333 & 10,98332 & 4,91189 \\
& I-CPA-21 & 6 & 78,7778 & 14,71608 & 6,00781 \\
S-AF-21 & 3 & 77,5556 & 7,16731 & 4,13805 \\
S-CPA-21 & 5 & 89,6000 & 4,99667 & 2,23458 \\
\hline
\end{tabular}




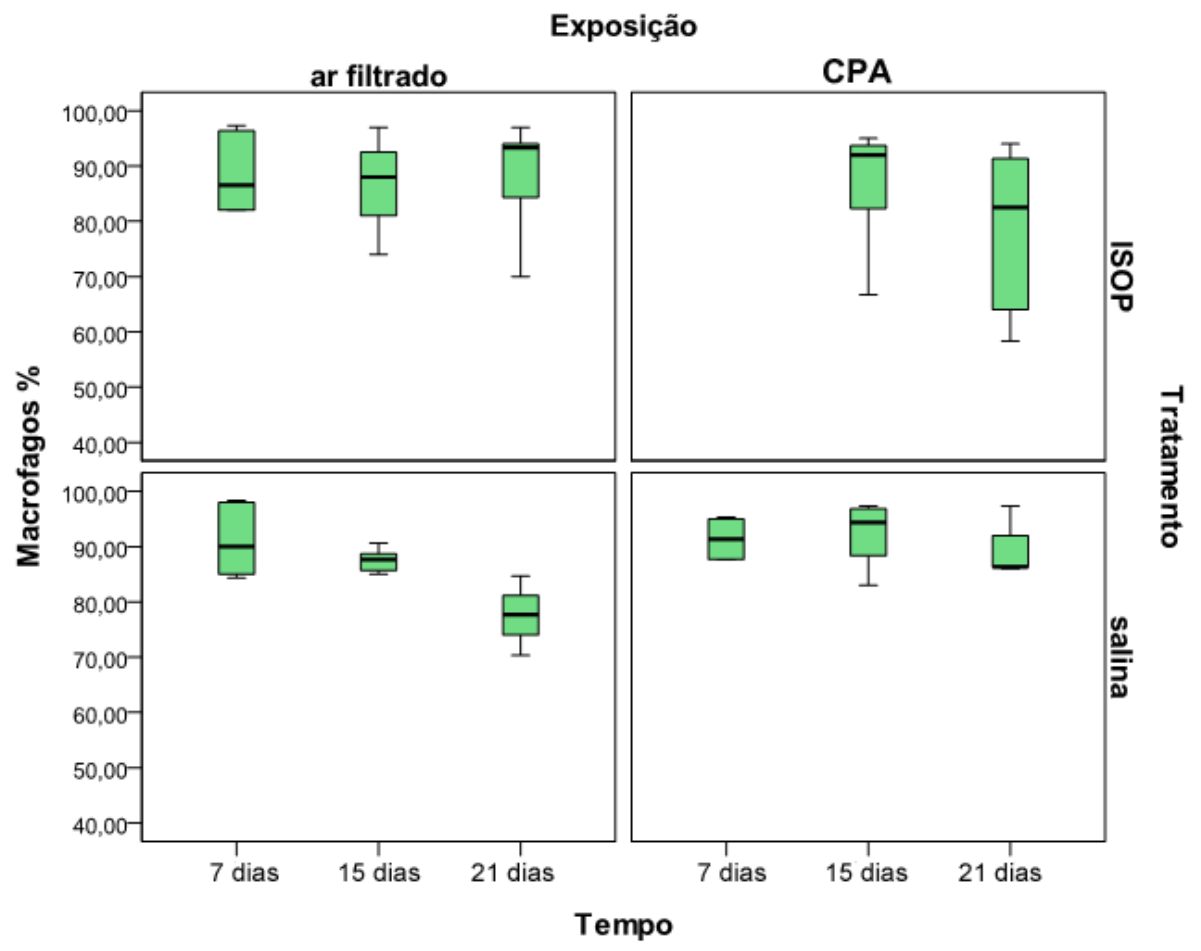

Figura 13 - Representação gráfica da porcentagem média de macrófagos do LBA nos animais sadios e com $\mathrm{CMH}$ aos 7, 15 e 21 dias de exposição ao $\mathrm{MP}_{2,5}$ concentrado

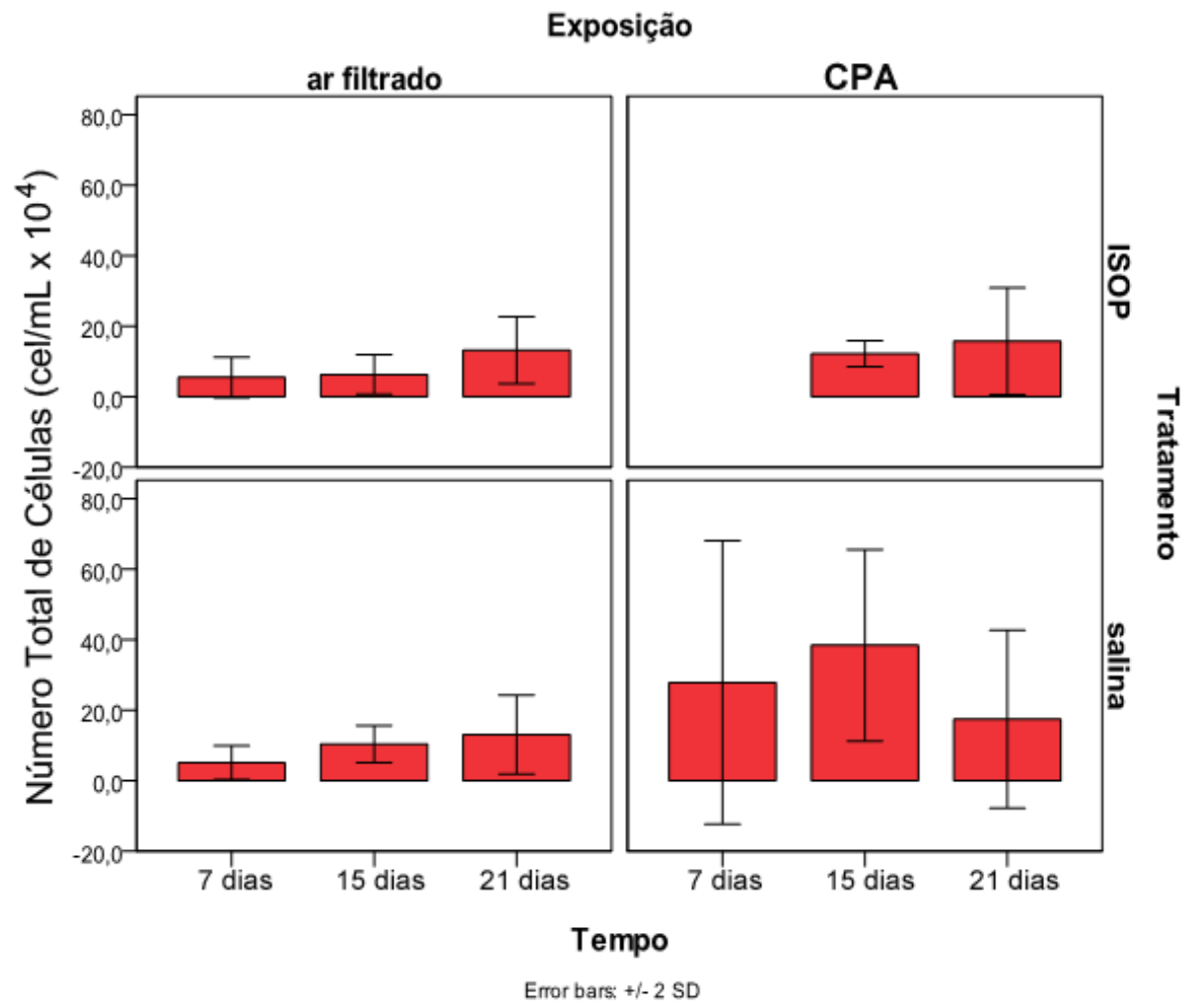

Figura 14 - Representação gráfica do número total de células do LBA nos animais sadios e com $\mathrm{CMH}$ aos 7, 15 e 21 dias de exposição ao $\mathrm{MP}_{2,5}$ concentrado 


\subsection{Dados do Hemograma}

Não foram observadas diferenças significativas nos parâmetros avaliados no exame do sangue dos animais estudados. Somente foram encontradas diferenças nos seguintes parâmetros:

A exposição a poluição do ar não interferiu no hematócrito, ou seja, na porcentagem de células vermelhas, entretanto a indução da $\mathrm{CMH}$ associada ao tempo provocou uma diminuição do hematócrito nos animais ( $p=0,02$, Figura 15). O mesmo ocorreu para o tamanho médio dos eritrócitos (VCM) que tendem a apresentar um tamanho menor com o passar do tempo $(p=0,002$, ANOVA) (Figura 16). A concentração de hemoglobina (HCM) só se mostra alterada quando os seguintes fatores tratamento com isoproterenol e tempo estão combinados ( $p=0,01$, Figura 17). Quando avaliada a concentração média de hemoglobina o tratamento com isoprotrenol é determinante para o desfecho observado $(0,01)$. O coeficiente de variação do diâmetro dos eritrócitos (RDWCV) também se apresenta alterado e é influenciado pelo tratamento e pelo tempo $(p=0,04$ - 3-WAY ANOVA), sendo maior nos animais tratados com isoproterenol o que é indicativo de uma variação em seu tamanho (Figura 18). 


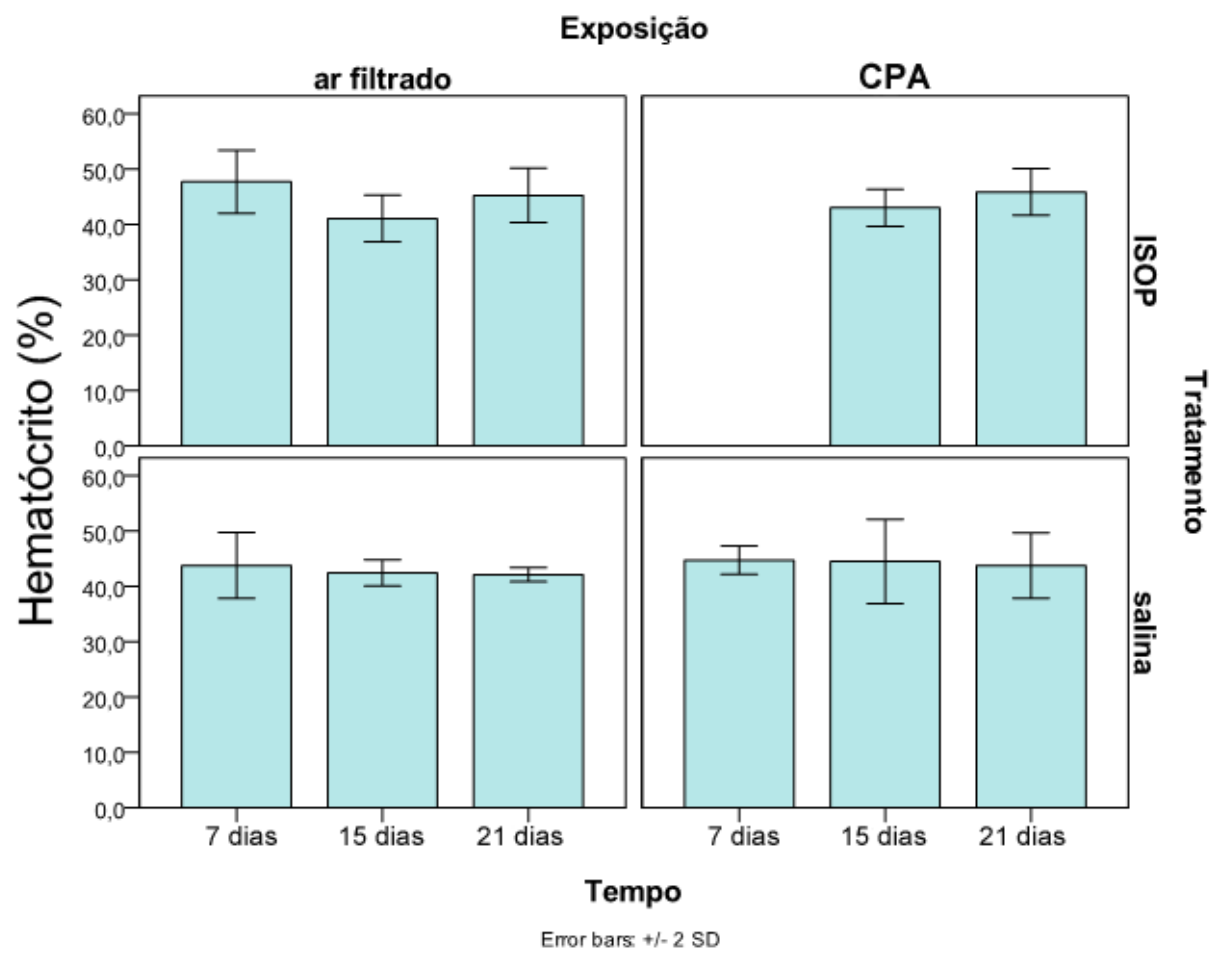

Figura 15 - Representação gráfica da porcentagem média do Hematócrito nos animais sadios e com $\mathrm{CMH}$ aos 7, 15 e 21 dias de exposição ao $\mathrm{MP}_{2,5}$ concentrado

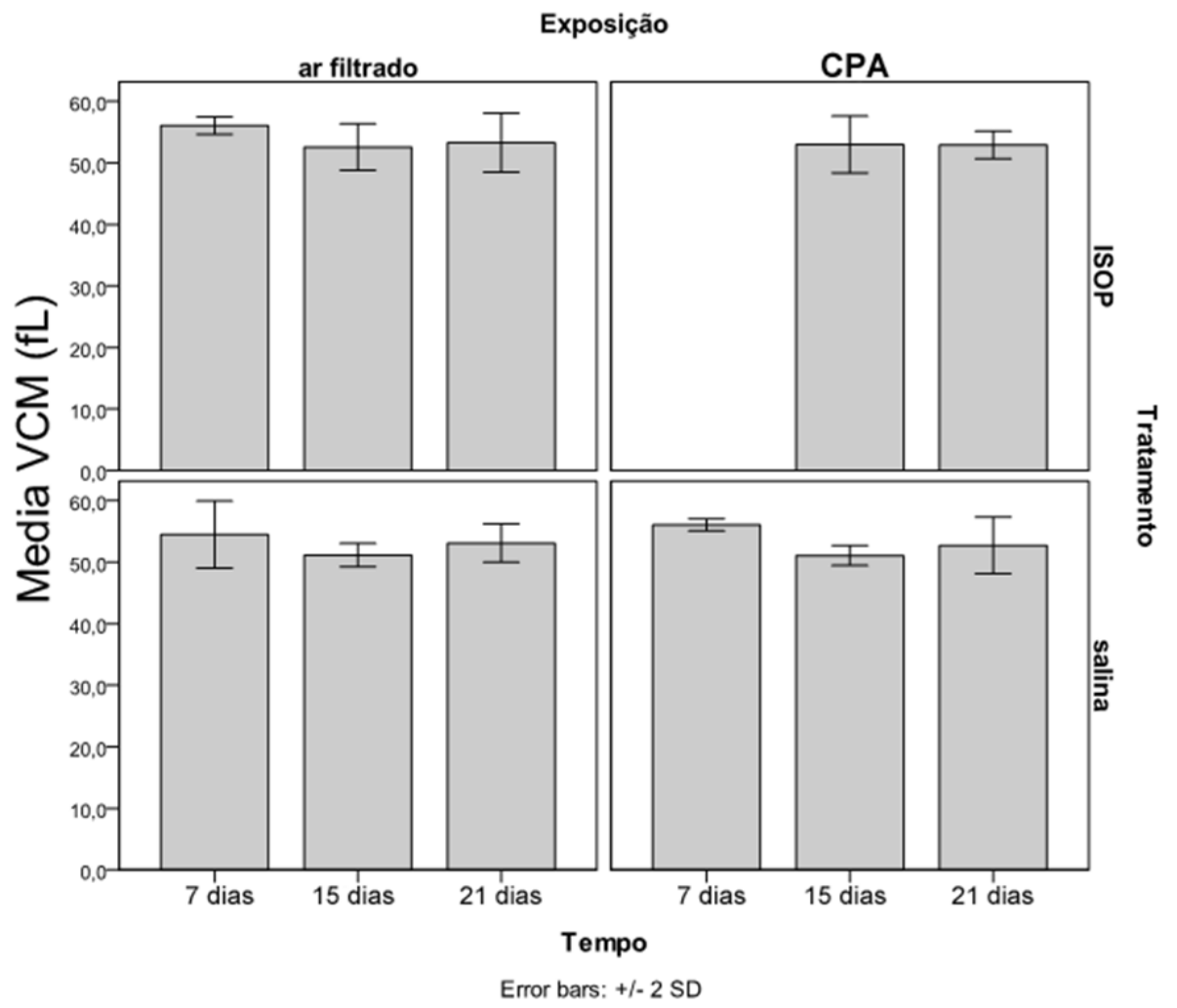

Figura 16 - Representação gráfica da média do VCM fL (fentolitros) nos animais sadios e com $\mathrm{CMH}$ aos 7, 15 e 21 dias de exposição ao $\mathrm{MP}_{2,5}$ concentrado 


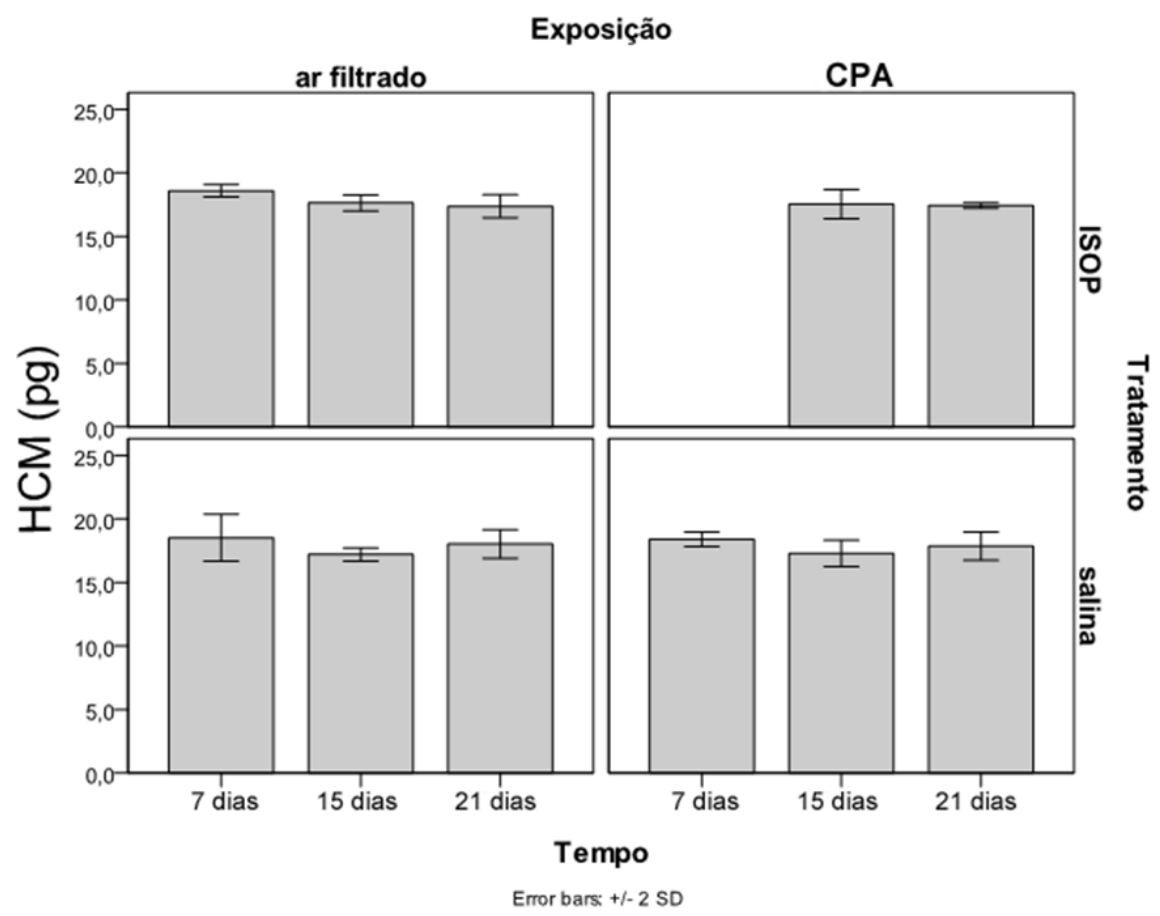

Figura 17 - Representação gráfica da média do HCM pg (picogramas) nos animais sadios e com $\mathrm{CMH}$ aos 7, 15 e 21 dias de exposição ao $\mathrm{MP}_{2,5}$ concentrado

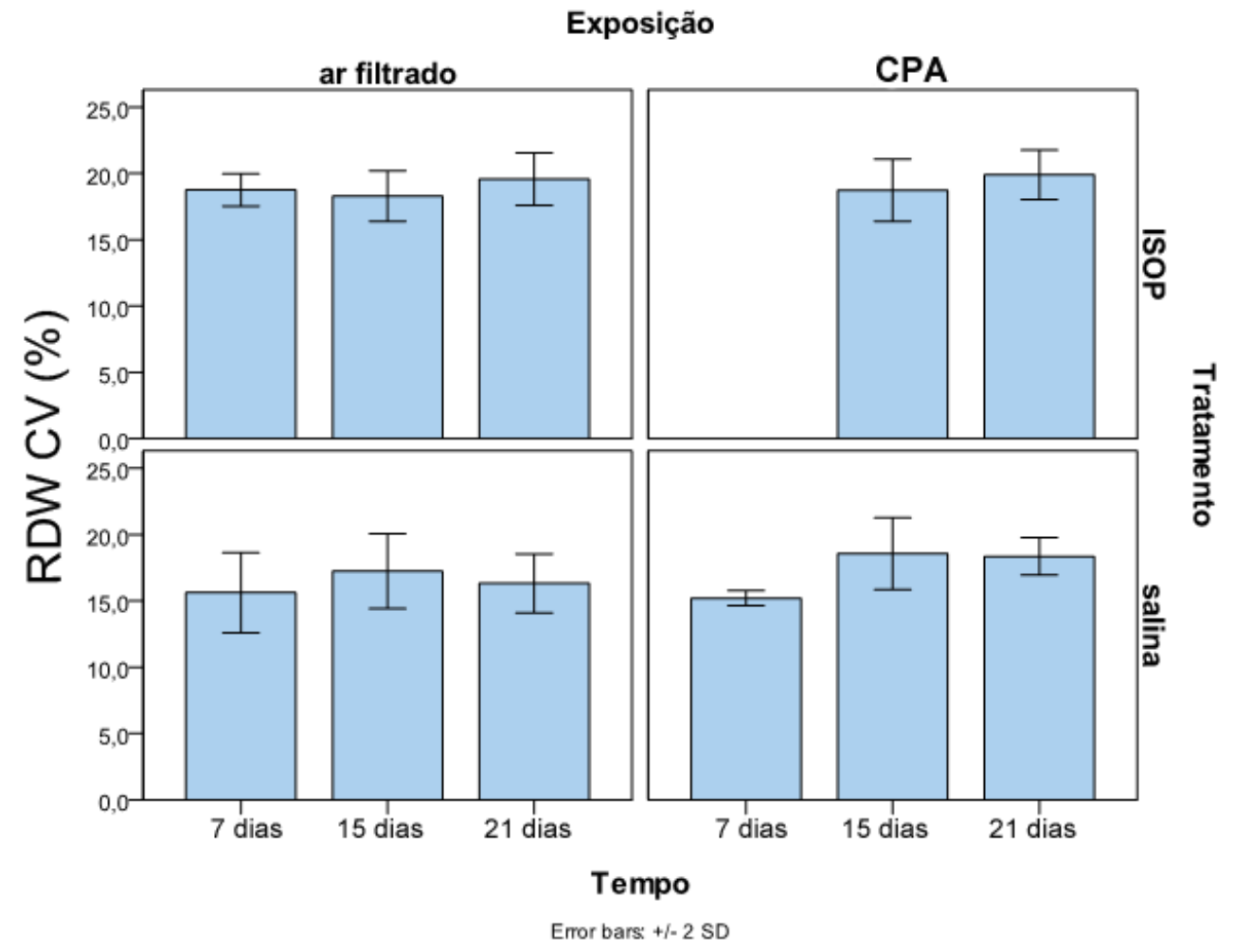

Figura 18 - Representação gráfica da porcentagem média da amplitude de distribuição dos eritrócitos representados como coeficiente de variação (RDW CV) nos animais sadios e com $\mathrm{CMH}$ aos 7, 15 e 21 dias de exposição ao $\mathrm{MP}_{2,5}$ concentrado 


\subsection{Estudo estereológico do coração}

As análises estatísticas foram conduzidas considerando-se dois conjuntos de resultados baseados na indução da hipertrofia do miocárdio por isoproterenol ou sem a indução da cardiopatia, ou seja, sadios (salina).

\subsubsection{Volume total (VT) e Densidade de Volume (Vv) dos principais} compartimentos cardíacos

Os resultados (Figura 19) mostram que não houve alteração do volume total dos ventrículos, considerando-se o direito e esquerdo juntos, em consequência da exposição à poluição do ar ao longo do tempo $(p=0,7)$. Também não foram observadas diferenças no volume total dos ventrículos nos animais nos quais foi induzida a hipertrofia cardíaca $(p=0,3)$. 


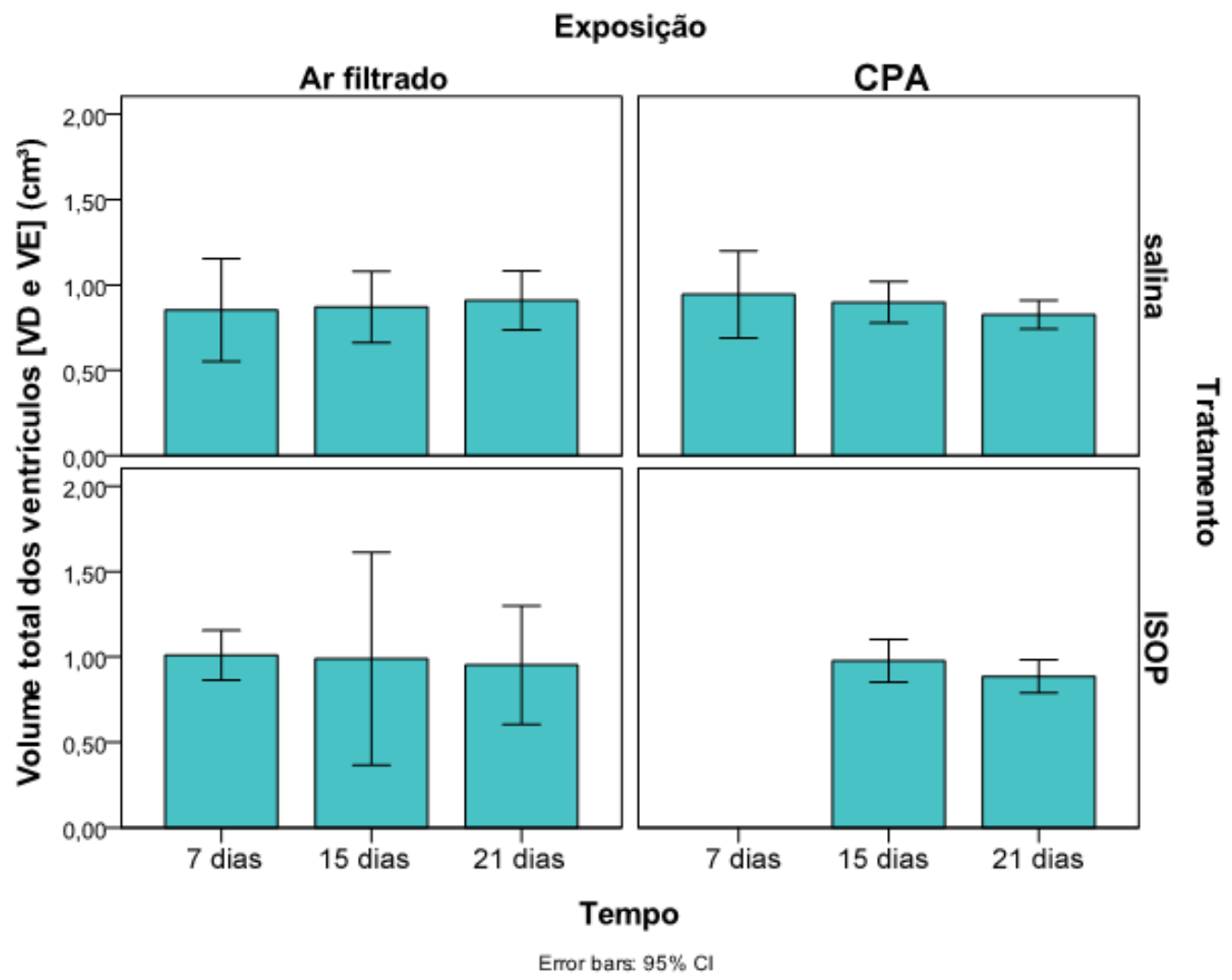

Figura 19 - Gráfico Box plot do volume total dos ventrículos (direito e esquerdo) nos animais normais (salina) e cardiopatas (ISOP) expostos ou não a poluição ao longo do tempo

Já os resultados da avaliação da densidade de volume e volume total dos principais compartimentos cardíacos (ventrículo esquerdo [VE], ventrículo direito [VD], luz do ventrículo esquerdo [LVE] e septo ventricular [SEP]) indicam que tanto o tratamento quanto a exposição ao CPA são capazes de provocar alterações morfológicas na estrutura cardíaca.

A figura 20 representa um gráfico de barras da densidade de volume dos compartimentos avaliados do coração nos diferentes grupos experimentais. 


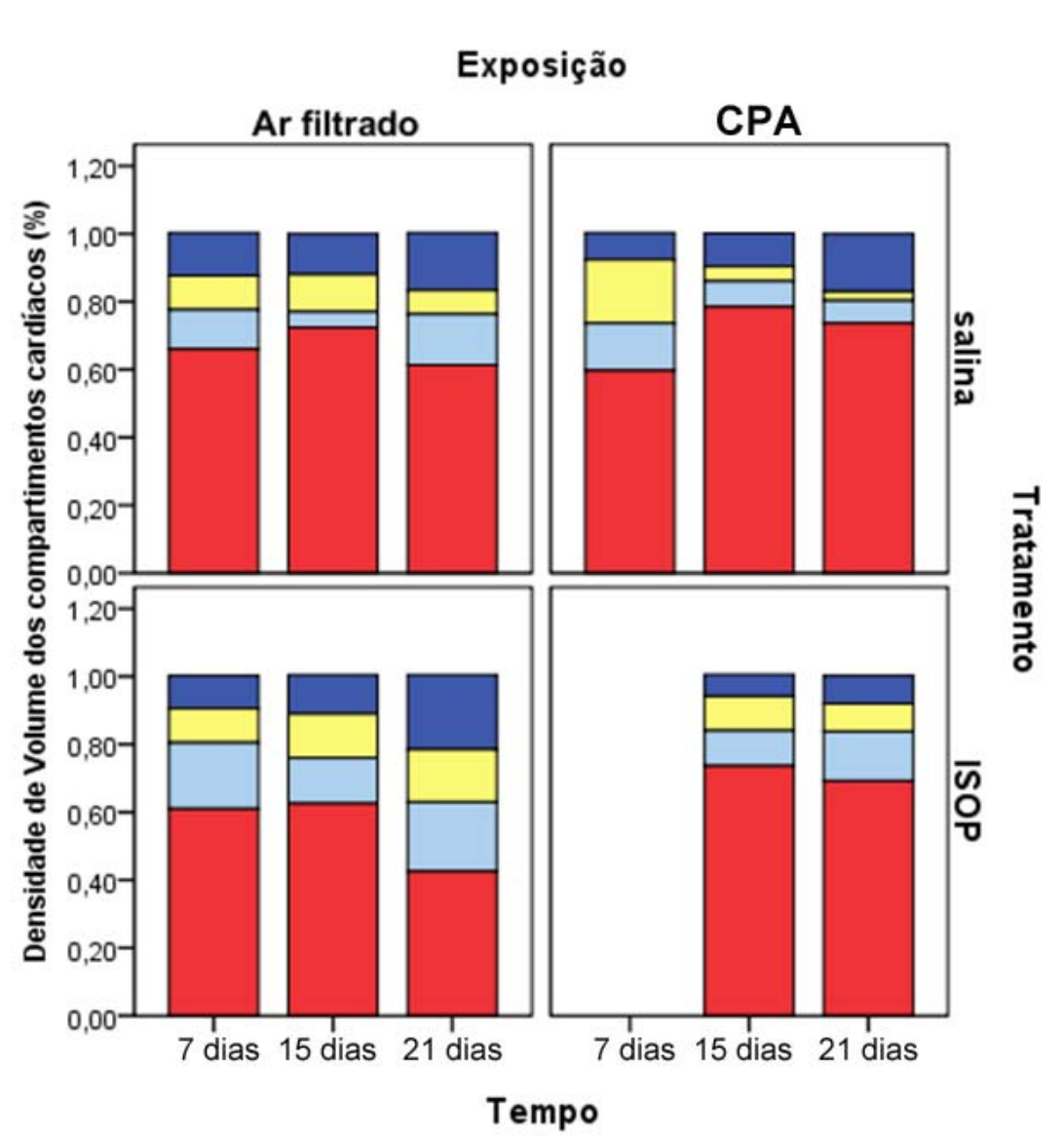

Figura 20 - Gráfico de barras da densidade de volume média dos diferentes compartimentos cardíacos nos grupos estudados

Os animais sadios (salina) quando expostos a poluição apresentam uma densidade de volume maior do VE a partir do $15^{\circ}$ dia de exposição $(p=0,02)$ quando comparado aos animais não expostos ao CPA (Vv VE= M +l- EP: S-AF$\mathbf{1 5}=0,72+/-0,07 ;$ S-AF-21 $=0,061+/-0,06$; S-CPA- 15=0,78 +/-0,05; S-CPA-21= $0,73+/-0,07)$.

A fração de volume do septo interventricular também apresentou diferenças. A exposição ao CPA provocou uma redução do volume do septo interventricular nos animais sadios expostos, sendo que esta diminuição foi acentuando-se com a progressão da exposição (Vv SEP = M +l- EP: S-CPA- 7= $0,18+/-0,05 ;$ S-CPA- 15=0,04 +/-0,02; S-CPA-21=0,026 +/-0,02). 
Não foram observadas diferenças significativas na densidade de volume da luz do VE e do ventrículo direito. Entretanto observa-se uma tendência de aumento da luz do VE e diminuição na densidade de volume do ventrículo direito.

Já os animais que sofreram $\mathrm{CMH}$ induzida por isoprotrenol, não foram observadas diferenças significativas em nenhum dos parâmetros avaliados provavelmente devido a grande variabilidade entre indivíduos. Porém, é possível perceber uma tendência de aumento da fração de volume do VE com o progresso na exposição ao CPA (Figura 20).

Quando transformadas em volumes absolutos (Figura 21) as diferenças permanecem para alguns parâmetros e em certos casos os resultados se apresentam de forma inversa.

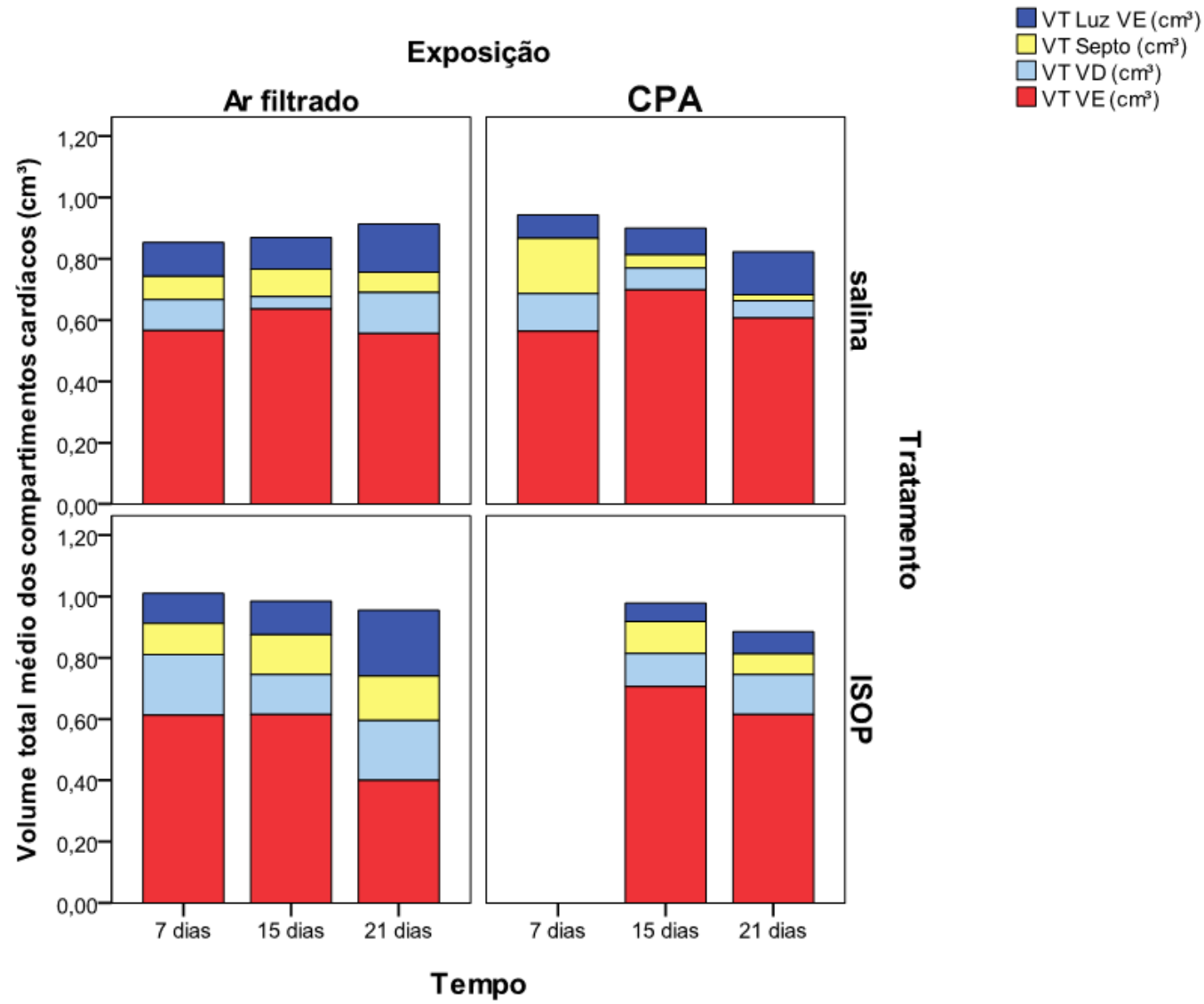

Figura 21 - Gráfico de barras do volume total médio dos diferentes compartimentos cardíacos nos grupos estudados 
No caso do grupo sadio (salina) somente as diferenças quanto ao volume do septo interventricular permaneceram (VT SEP $=$ M +l- EP: S-CPA- 7= 0,18 +/0,6; S-CPA- 15=0,06 +/-0,02; S-CPA-21=0,02 +/-0,02, $p=0,01)$.

Nos animais que receberam isoproterenol observam-se diferenças no volume total da luz quando comparados os animais que foram expostos apenas ao AF e os animais após 21 dias de exposição ao CPA (VT luz VE = M +l- EP: IAF-21 $=0,21+/-0,11 ;$ I-CPA-21=0,07+/- 0,02)

\subsubsection{Espessura da parede ventricular}

A avaliação da espessura média da parede livre do VE indicou diferenças significativas entre os grupos avaliados. Quando analisados separadamente observamos que nos animais sadios a exposição à poluição do ar por períodos de 7 e 15 dias parece estar associada a um aumento $(p=0,03)$, porém após 21

dias esta diferença desaparece (Figura 22). Já nos animais que receberam isoproterenol a exposição a poluição do ar e o tempo não parecem provocar alteração neste parâmetro. 


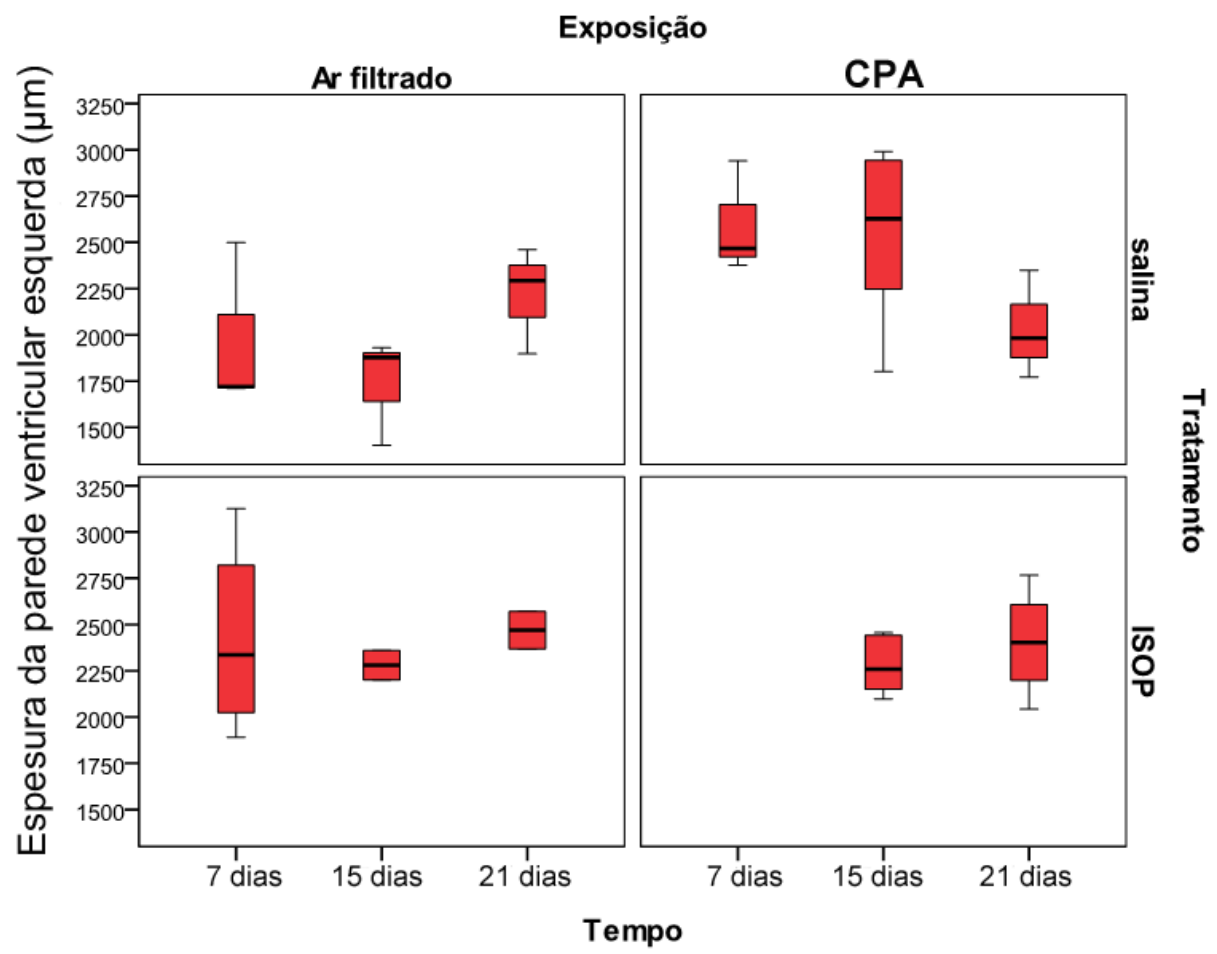

Figura 22 - Gráfico Box Plot da espessura média da parede livre do VE nos animais dos grupos experimentais

\subsubsection{Volume total (VT) e Densidade de Volume (Vv) dos} constituintes teciduais do ventrículo esquerdo

A exposição ao $\mathrm{MP}_{2,5}$ concentrado por si só está associada a alterações na distribuição e no volume total dos constituintes teciduais do VE.

As Figuras 23 e 24 apresentam gráficos da densidade de volume e volume totais de cardiomiócitos, tecido conjuntivo e vasos sanguíneos, respectivamente.

Os gráficos mostram claramente que a exposição a poluição do ar (CPA) está associada a um aumento na densidade de volume de tecido conjuntivo no VE de animais sadios (salina) quando comparado aos animais sadios não expostos $(p=0,04)$. A proporção média de tecido conjuntivo nos animais dos grupos S-CPA-7, S-CPA-15, S-CPA-21 é de 6\% $16 \%$ e 13\%, respectivamente. 
Nos grupos expostos apenas ao AF esta proporção não ultrapassa 3\%. Também se observam reduções na fração de volume dos cardiomiócitos nos animais sadios expostos ao CPA $(p=0,04)$. Os dados referentes à média, desvio e erro padrão estão apresentados na tabela do anexo B.

Quando as densidades de volume são transformadas em valores reais de volume estas diferenças se mantêm apenas para o volume total de tecido conjuntivo.

Como esperado, nos animais que receberam injeções de isoproterenol há um aumento na proporção de tecido conjuntivo, porém a diferença não foi estatisticamente significativa. Nos animais que receberam as injeções por 7 dias e não foram expostos ao CPA parece haver uma redução nesta proporção ao longo do tempo. Nos animais que receberam as injeções e foram expostos ao CPA o cenário é um pouco diferente, pois não parece haver uma redução na quantidade de tecido conjuntivo, e sim uma manutenção.

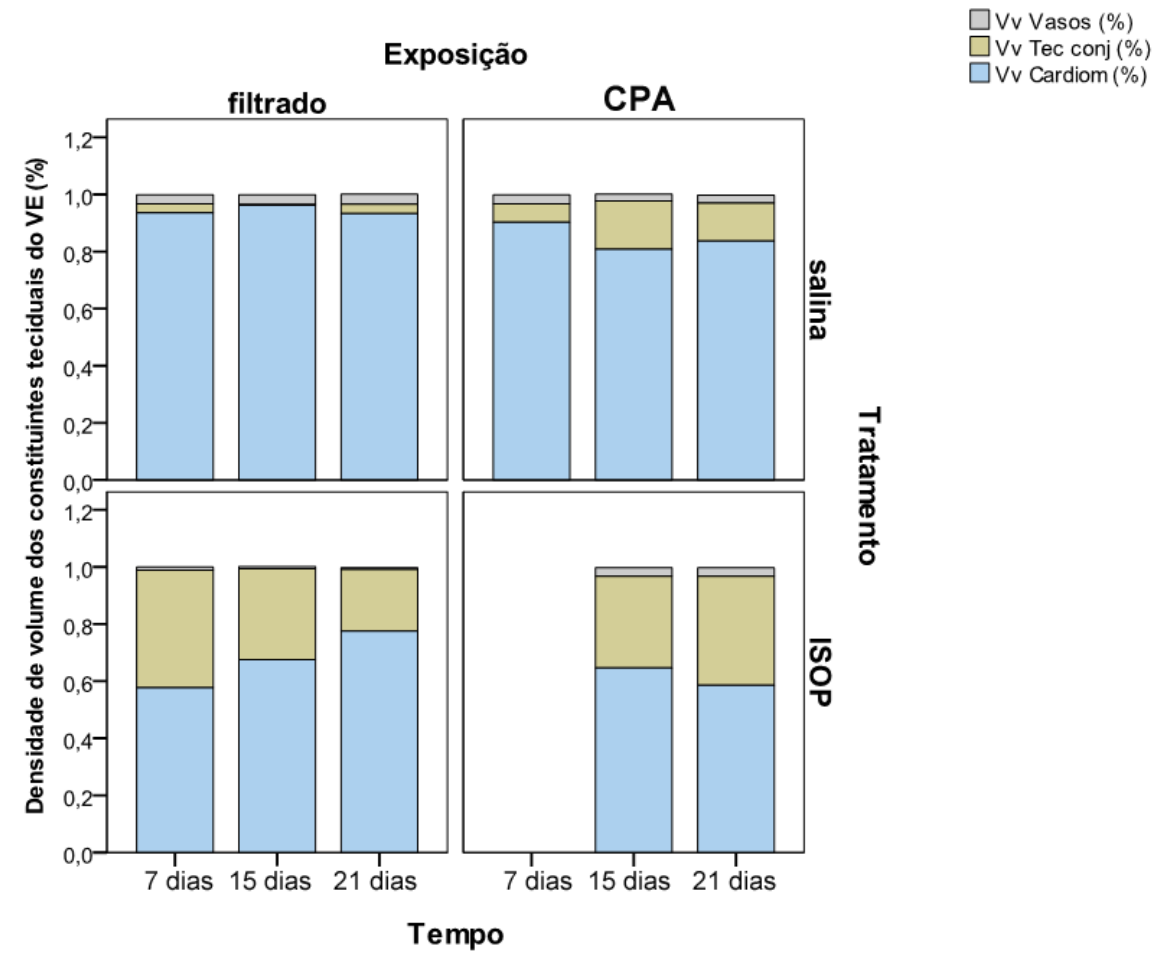

Figura 23 - Gráfico de barras da densidade de volume totais de cardiomiócitos, tecido conjuntivo e vasos sanguíneos 


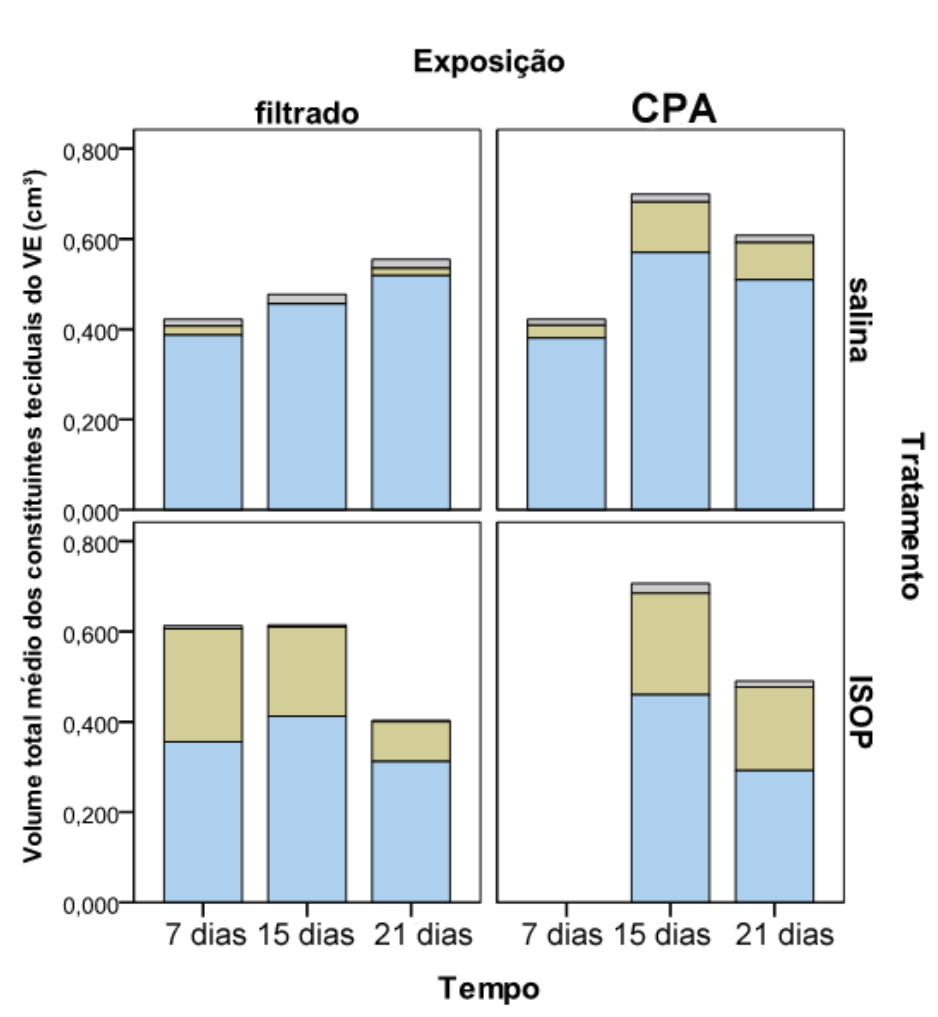

Figura 24 - Gráfico de barras dos volumes totais médio de cardiomiócitos, tecido conjuntivo e vasos sanguíneos

5.7.4. Diâmetro médio e volume médio ponderado dos cardiomiócitos do ventrículo esquerdo

O diâmetro bem como o volume médio ponderado dos cardiomiócitos não apresentaram diferenças nos grupos de animais sadios com relação a exposição ao CPA ao longo do tempo (Figuras 25 e 26). Nos animais sadios expostos ao CPA nota-se um discreto aumento no diâmetro dos cardiomiócitos com a progressão da exposição, entretanto a diferença não atingiu significância (Diam = M +l- EP: S-CPA-15 = 13,8 +/- 0,4; S-CPA-21= 17,0 +/- 0,6).

Porém nos animais com $\mathrm{CMH}$ induzida por isoproterenol, tanto o diâmetro $(p=0,02)$ quanto o volume médio ponderado $(p=0,02)$ apresentam diferenças significativas. O diâmetro dos cardiomiócitos nos animais que receberam isoproterenol mostra-se aumentado no $7^{\circ}$ e $15^{\circ}$ dia nos animais que não foram 
expostos a poluição particulada, este aumento tende a diminuir no $21^{\circ}$ dia. Nos animais tratados com isoproterenol e expostos a poluição este aumento no diâmetro é mais moderado, porém tende a aumentar com a medida que as exposições continuam. O volume dos cardiomiócitos se comporta de maneira semelhante como pode ser observado na Figura 26.

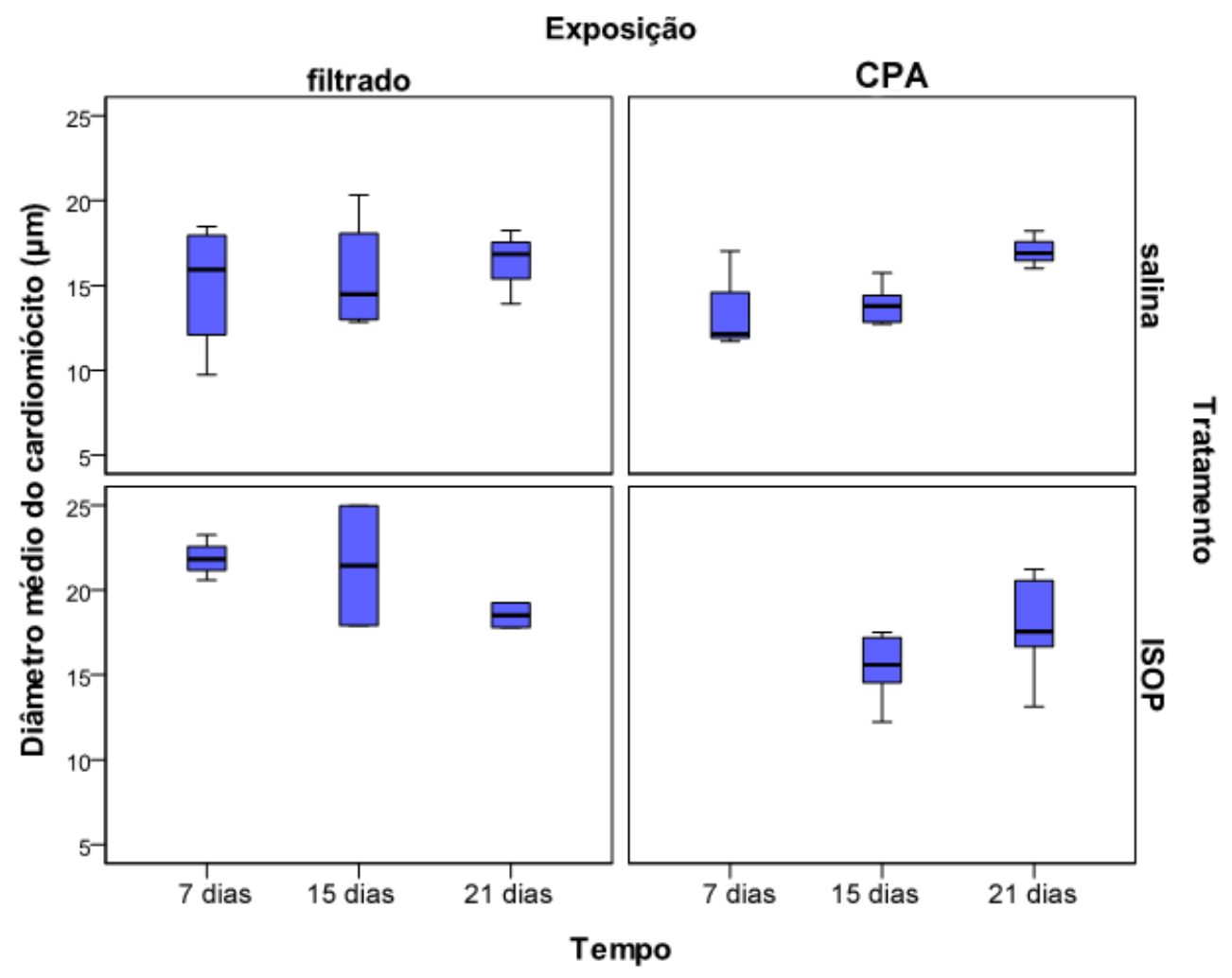

Figura 25 - Gráfico Box plot do diâmetro médio do cardiomiócito nos animais dos grupos experimentais 


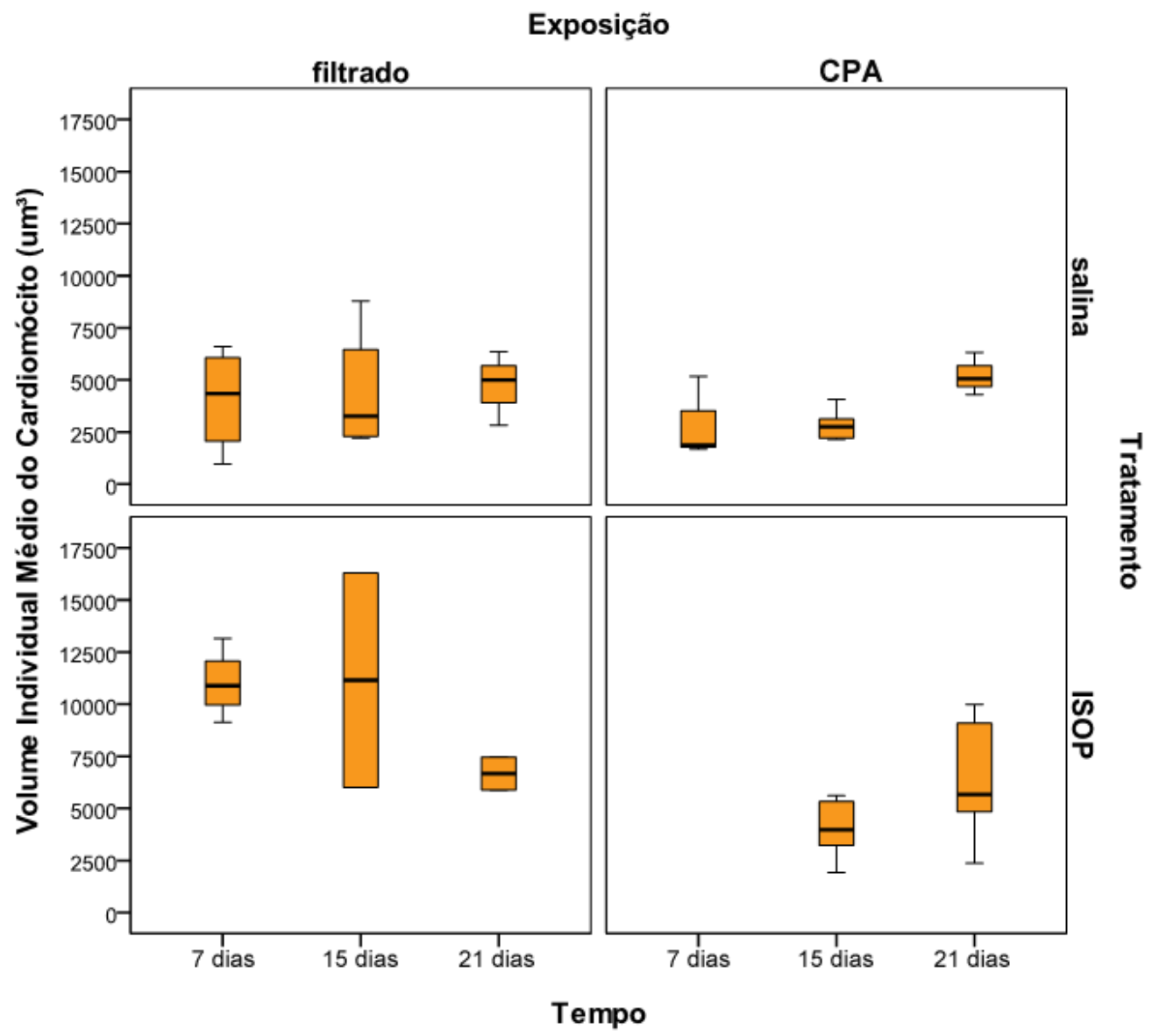

Figura 26 - Gráfico Box plot do volume individual médio do cardiomiócito nos animais dos grupos experimentais

\subsection{Avaliação eletrocardiográfica}

A análise no domínio do tempo foi realizada a partir dos índices RMSSD (ms) e SDNN (ms). A avaliação do SDNN nos mostra um claro efeito do tratamento $(p=0,03)$ e do tempo $(p=0,001)$ sobre esta variável que é um indicativo de variações de curto e longo prazo no intervalo R-R. Quando excluídos da análise os grupos tratados com isoproterenol, a exposição ao CPA $(p=0,01)$ e o tempo de exposição $(p=0,001)$ tornam-se fatores determinante para as alterações no SDNN que se apresenta aumentada no $21^{\circ}$ dia de exposição quando comparada ao grupo controle (Figura 27). 


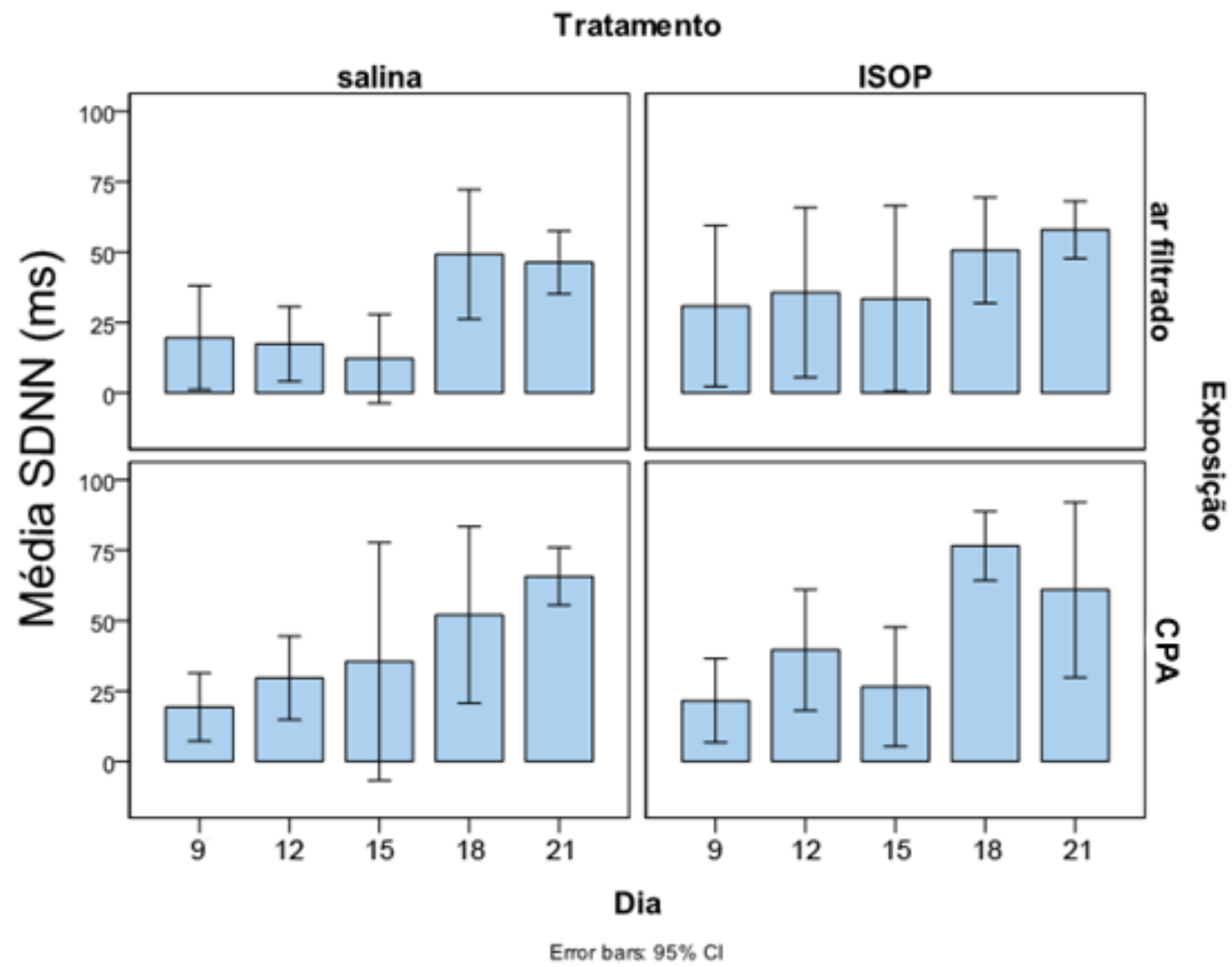

Figura 27 - Gráfico Box plot representando a média do SDNN (ms) dos animais após o tratamento (ISOP e salina) durante os dias de exposição

A avaliação do índice do controle vagal do coração (RMSSD) apresenta resultados muito semelhantes aos encontrados para o SDNN. Ou seja, o tratamento com o isoproterenol $(p=0,02)$ determina um aumento na variável que é amplificado ao longo do tempo $(p=0,001)$. Quando acrescida a exposição ao CPA, o cenário apresenta-se de forma semelhante, porém sendo a poluição por si só um fator de alteração do RMSSD $(p=0,02)$. Como pode ser visto no gráfico a seguir (Figura 28). 


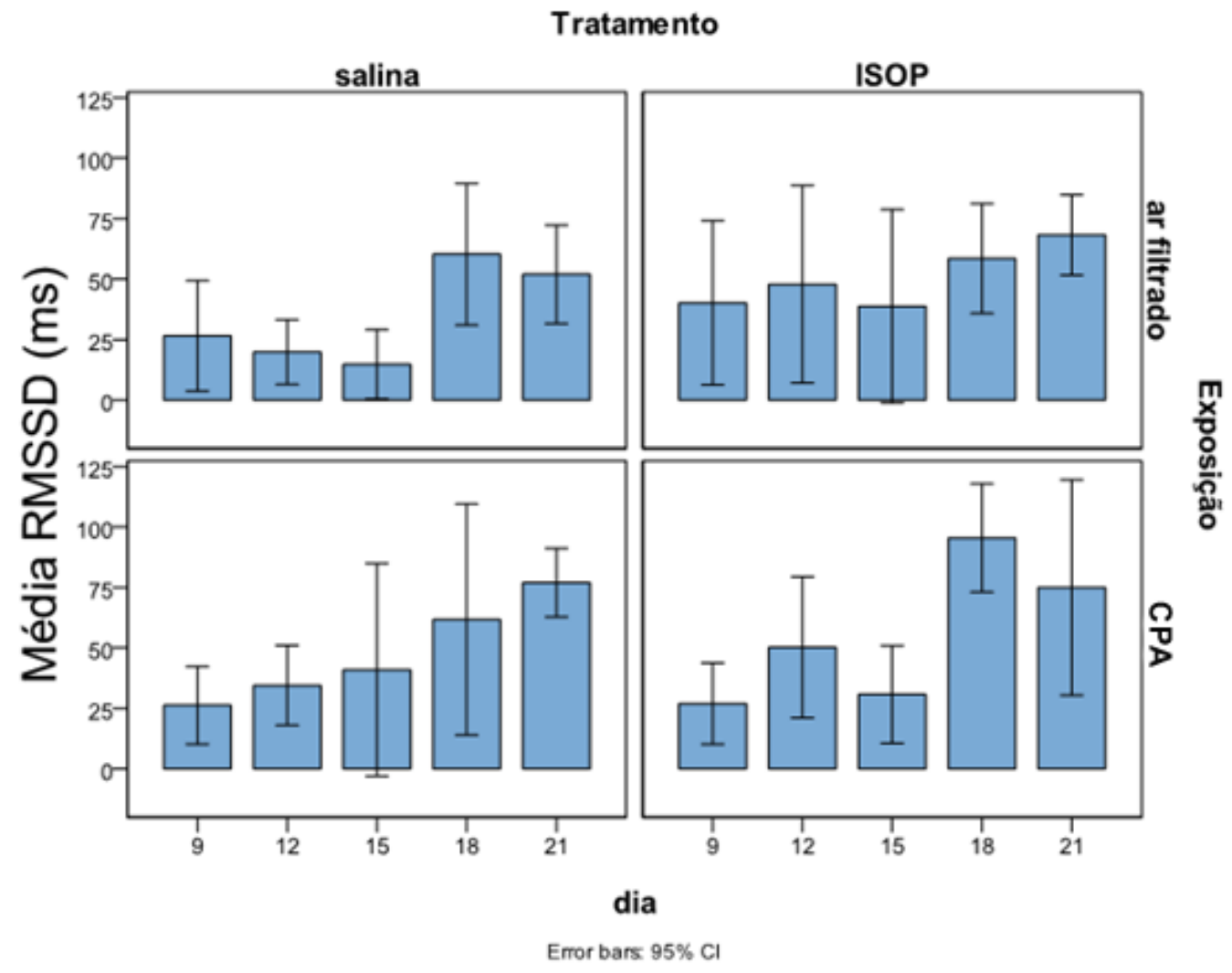

Figura 28 - Gráfico Box plot representando a média do RMSSD (ms) dos animais após o tratamento (ISOP e salina) durante os dias de exposição

A análise no domínio da frequência foi realizada a partir dos índices LF $\left(m s^{2}\right)$, HF $\left(m s^{2}\right)$ e razão LF/HF. A LF nos grupos avaliados mostrou um aumento ao longo do tempo $(p=0,001)$ com relação ao tratamento $(p=0,04)$ e a exposição ao CPA $(p=0,04)$ (Figura 29), o que representa uma alteração no controle simpático. Já a HF foi influenciada apenas pelo tempo $(p=0,001)$ e exposição ao CPA $(p=0,04)$. No gráfico (Figura 30$)$ podemos visualizar que há um aumento com relação ao tempo também nos animais que não receberam isoproterenol e que não foram expostos ao CPA. Isto pode sugerir que há também uma ação da exposição ao CPA sobre o controle parassimpático. O balanco simpato-vagal (LF/HF) não se mostra afetado pelo tratamento e exposição ao CPA (Figura 31). 


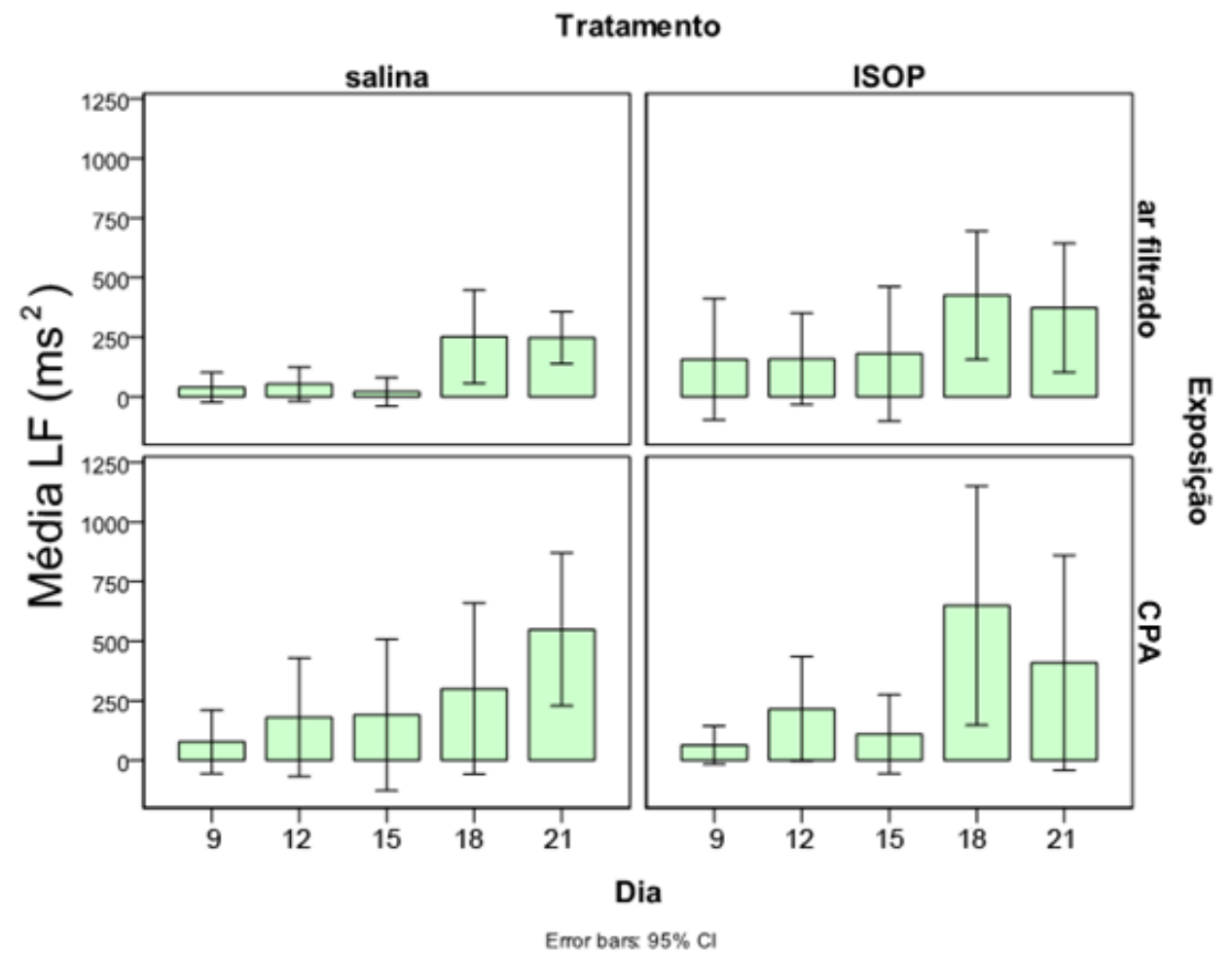

Figura 29 - Gráfico Box plot representando a média do LF $\left(\mathrm{ms}^{2}\right)$ dos animais após o tratamento (ISOP e salina) durante os dias de exposição

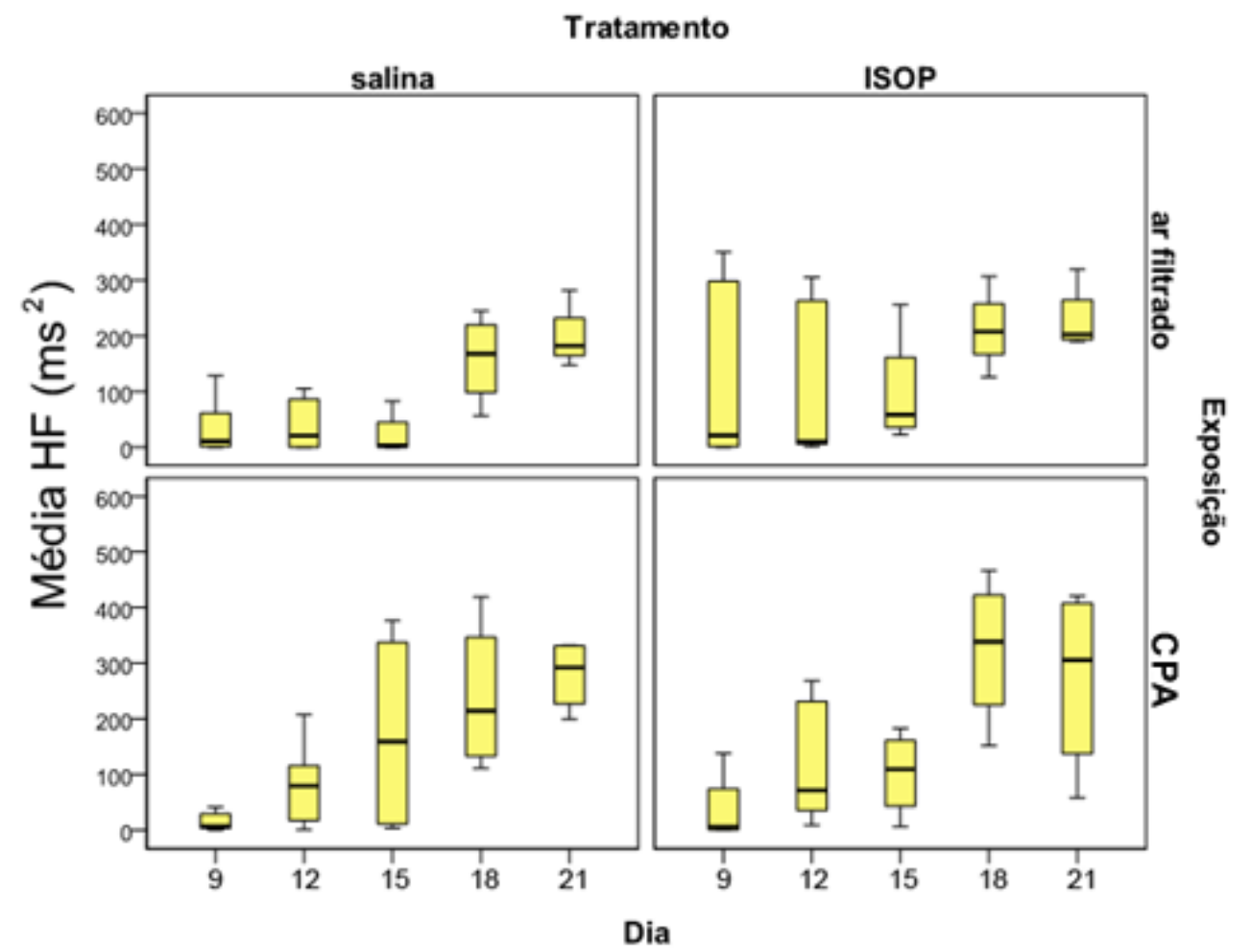

Figura 30 - Gráfico Box plot representando a média do HF $\left(\mathrm{ms}^{2}\right)$ dos animais após o tratamento (ISOP e salina) durante os dias de exposição 


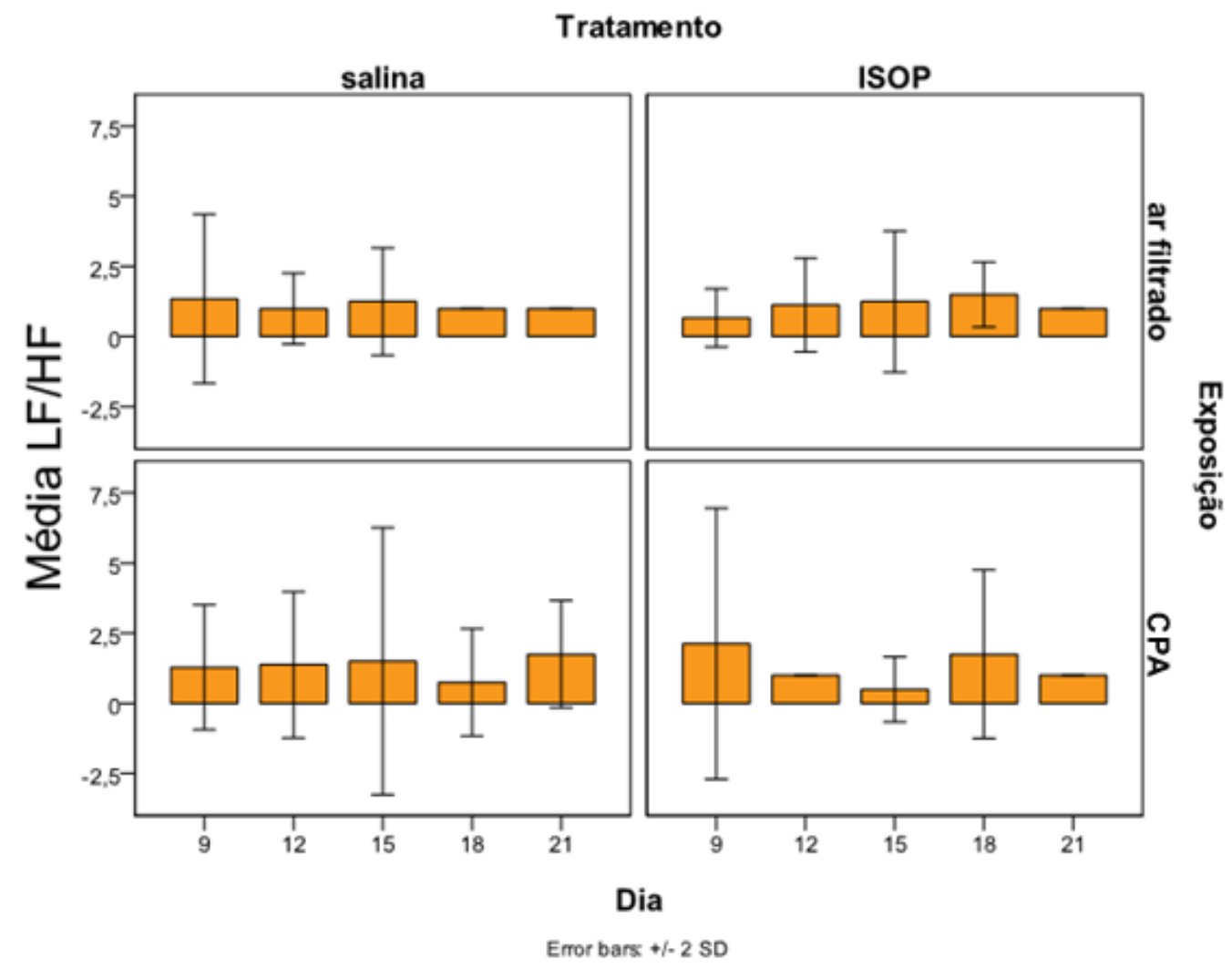

Figura 31 - Gráfico Box plot representando a média da razão LF/HF dos animais após o tratamento (ISOP e salina) durante os dias de exposição

Em relação ao número de batimentos por minuto, a exposição ao CPA ( $p=$ 0,003) foi o único fator determinante para as alterações observadas. A exposição ao CPA, tanto em animais sadios quanto com hipertrofia cardíaca, provocou uma diminuição significativa da FC (Figura 32) 


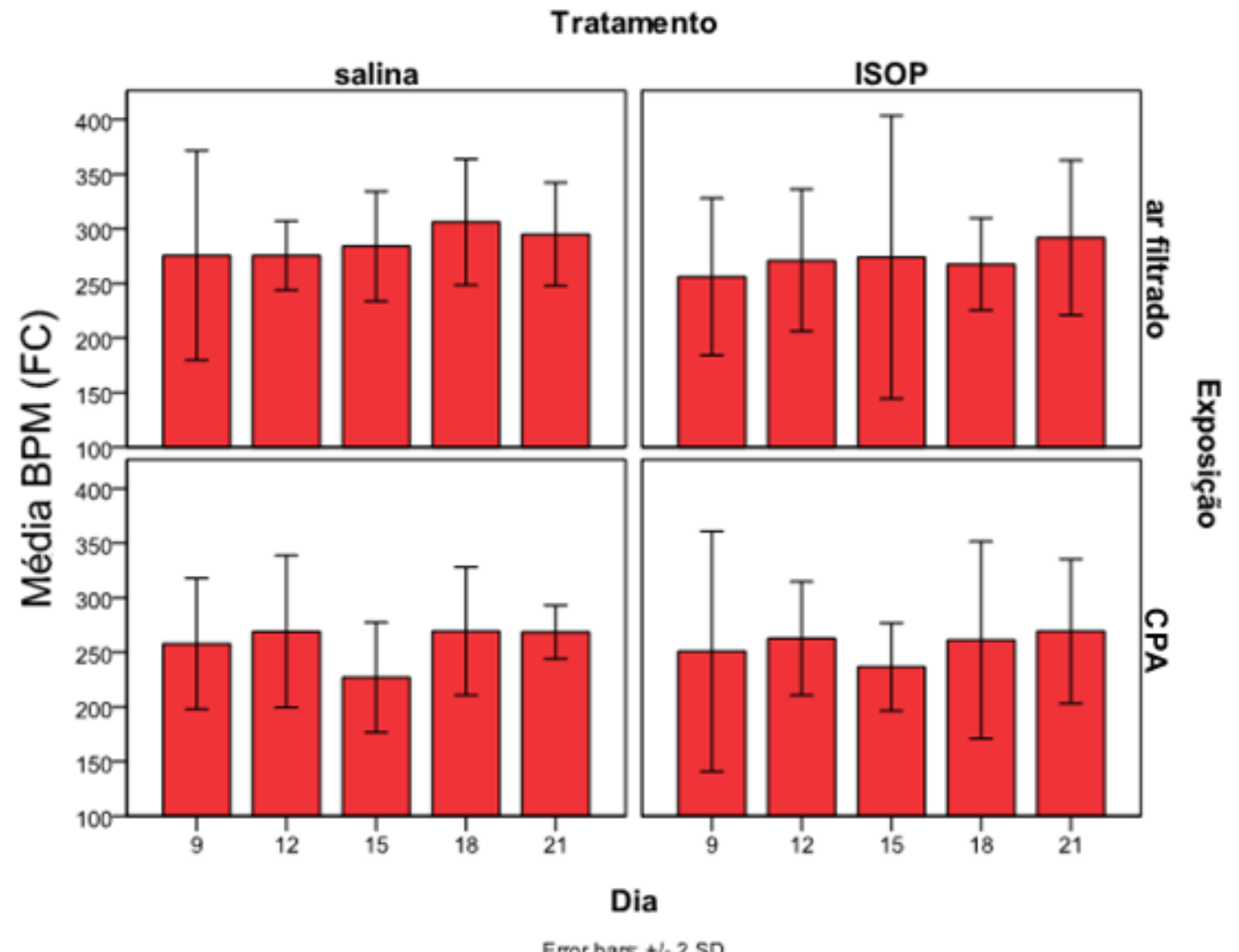

Figura 32 - Gráfico Box plot representando a média de batimentos cardíacos dos animais após o tratamento (ISOP e salina) durante os dias de exposição

A pressão arterial nos animais deste estudo quando avaliada ao longo do tempo mostrou-se influenciada principalmente pelo tratamento $(p=0,001)$ e pelo tempo $(p=0,01)$. Porém observamos uma interação sutil entre tratamento, tempo e exposição ao CPA $(p=0,05)$. Os animais que receberem as injeções de isoproterenol apresentam uma diminuição nos valores da PA (Figura 33). 
Tratamento

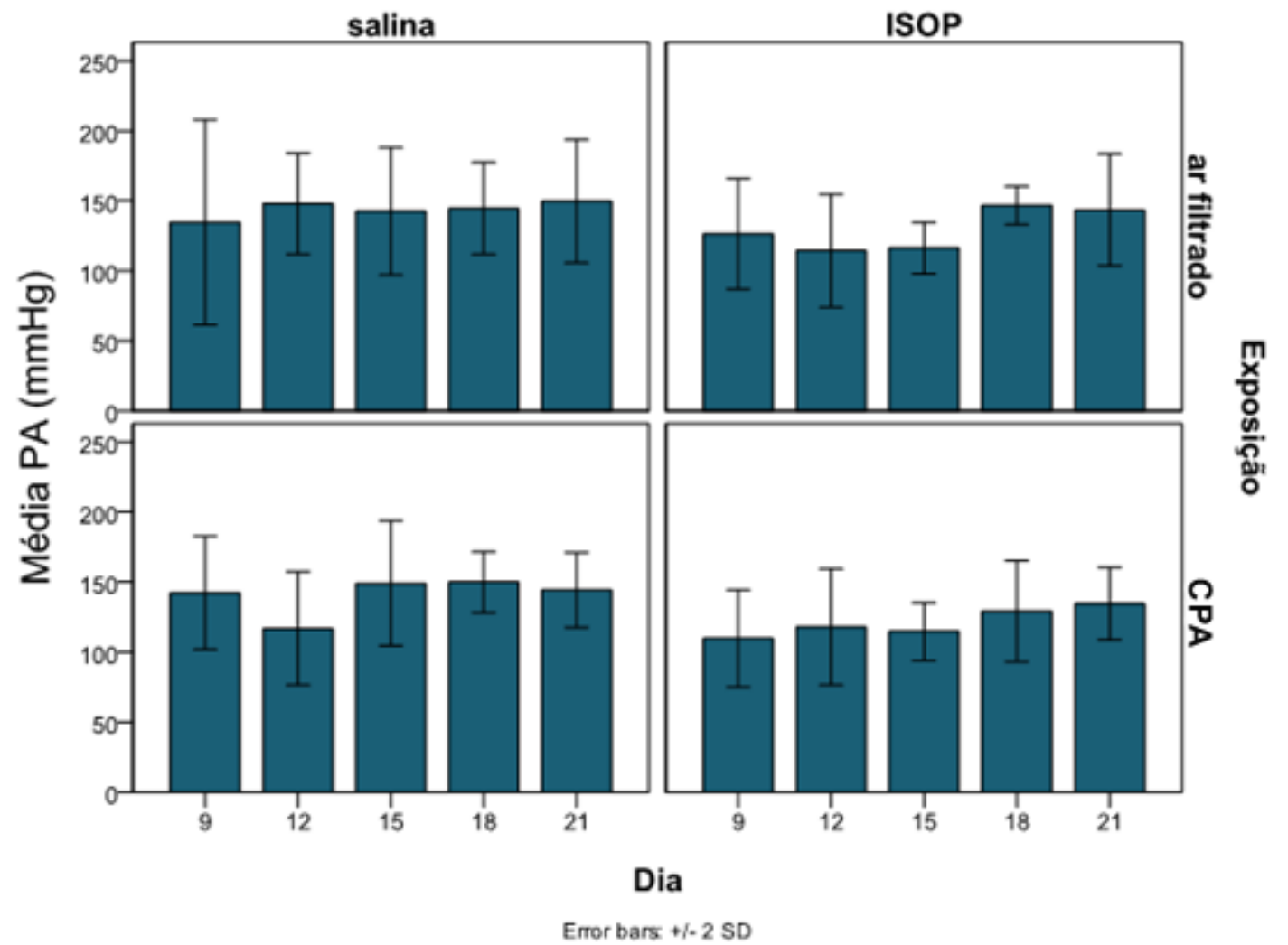

Figura 33 - Gráfico Box plot representando a média da pressão arterial $(\mathrm{mmHg})$ dos animais após o tratamento (ISOP e salina) durante os dias de exposição 


\section{DISCUSSÃO}

Neste estudo avaliamos os efeitos da exposição em curto prazo (7, 15 e 21 dias) ao $\mathrm{MP}_{2,5}$ concentrado de origem veicular sobre parâmetros funcionais e morfológicos no coração de ratos normais e com HVE induzidos por isoproterenol. Nossos resultados corroboram com achados experimentais prévios e dados epidemiológicos que apontam a poluição particulada do ar como um fator agravante de doenças cardiovasculares preexistentes bem como um fator indutor de alterações cardiovasculares. Mostramos que a dose de exposição acumulada equivalente $\left(600 \mathrm{ug} / \mathrm{m}^{3}\right)$ a dose a que pessoas comuns estão expostas diariamente na cidade de São Paulo em curto prazo já é capaz de produzir desfechos negativos sobre a estrutura e função cardíaca. Nestas mesmas condições, mostramos ainda que indivíduos portadores de uma doença cardíaca preexistente, neste caso uma HVE, apresentam sua condição agravada pela exposição.

Há mais de três décadas os efeitos da poluição do ar sobre o sistema cardiorrespiratório vêm sendo estudados e os mecanismos fisiopatológicos envolvidos desvendados. As primeiras evidências sobre os efeitos deletérios causados pela poluição do ar sobre a saúde datam mais de cinco décadas (Phalen \& Phalen, 2011). E já não há mais dúvidas da correlação positiva entre os níveis de poluição e aumentos nos índices de mortalidade e morbidade por doenças cardiorrespiratórias.

Os diferentes estudos presentes na literatura mostram, resumidamente, que a exposição à poluição do ar em centros urbanos ou derivadas da queima de combustíveis fósseis resulta em modificações em diferentes parâmetros cardiovasculares, incluindo alterações na FC e VFC, na PA, no tônus vascular e na coagulabilidade sanguínea. Alguns destes efeitos surgem agudamente como 
resposta a níveis elevados de poluição do ar. Outros desfechos, como por exemplo, a progressão de aterosclerose, aparecem em resposta a exposições mais prolongadas (crônica) a níveis elevados deste poluente (Pope III et al., 2004b). A maior parte dos estudos indica que os desfechos cardiovasculares estão associados com o $\mathrm{MP}_{2,5}$, porém as frações ultrafinas $(<0,1 \mathrm{um})$, o ozônio e óxidos de nitrogênio também podem estar associados (Samet et al., 2000).

Em nosso estudo, os animais foram expostos somente ao $\mathrm{MP}_{2,5}$, nosso sistema de exposição exclui a fração gasosa de poluentes bem como frações maiores de $\mathrm{MP}_{10}$.

Assim como nos estudos epidemiológicos e em estudos experimentais, mostramos que a poluição do ar afeta a VFC (Gold et al. ,2000; Pope III et al., 2004a; Adar et al., 2007 ). A diminuição da VFC, um marcador de controle autonômico cardíaco reduzido, tem sido frequentemente associado a polução do ar, especialmente ao $\mathrm{MP}_{2,5}$. Geralmente nestes estudos são avaliadas a relação entre VFC, obtida com base no SDNN de intervalos R-R normais, RMSSD, HF, LF e HF/LF e os níveis ambientais de MP.

Embora a maior parte dos estudos mostre que a exposição a poluição do ar está associada a um decréscimo na VFC (indicado pela diminuição no SDNN e RMSSD) nossos resultados mostram que houve um aumento na VFC (indicado por aumentos no SDNN e RMSSD). Estes aumentos mostram-se associados ao tratamento e a exposição ao CPA. Embora haja um consenso de que decréscimos no SDNN e RMSSD estejam associados a riscos aumentados de mortalidade por problemas cardíacos, hoje já se sabe que há casos em que pacientes que apresentam VFC aumentada, geralmente associada a baixos riscos, apresentam na verdade riscos aumentados de falência cardíaca (Dekker et al., 1997; Stein et al., 2005). A VFC é influenciada por diversas condições fisiológicas e patológicas, tais como, idade, respiração, doença coronariana 
cardíaca, entre outras (Liao et al., 1995; Tsuji et al., 1996; Huikuri et al., 1994).

Provavelmente, o aumento da VFC, ao contrário da VFC diminuída, não seja influenciado pelo SNA, mas pode ser devido a uma disfunção do nó sinusal (Bergfeldt et al., 1987; 1995). Estudos mostraram que o envelhecimento provoca alterações patológicas no nodulo sino-atrial, incluindo aumentos de fibras colágenas e elásticas e que há uma deteriorização da função intrínseca do nódulo que resulta em aumento no intevalo R-R e VFC aumentada (Lev, 1954; de Marneffe et al., 1993; 1995). Também pacientes com síndrome do sino doente mostram quantidades aumentadas de tecido fibroso no nódulo sino atrial (Evans e Shaw, 1977).

O aumento na VFC observado neste estudo não significa necessariamente que não há um efeito da exposição bem como do tratamento sobre o controle autonômico do coração. Provavelmente neste trabalho a avaliação da VFC foi realizada em animais sedados o que provavelmente pode ter influenciado o desfecho. Entretanto, estudos prévios conduzidos por nosso grupo, utilizando a mesma técnica para avaliação da VFC, porém utilizando camundongos também indicam aumento na VFC (Brito et al., 2010). Uma diferença que pode ser observada entre nosso trabalho e aqueles que mostram um decréscimo da VFC, diz respeito aos métodos de exposição dos animais a poluição do ar. Nós utilizamos exposições de corpo inteiro onde os animais estavam acondicionados em uma câmara onde podiam respirar e mover-se livremente, já na maior parte dos demais estudos a técnica de instilação intraqueal foi a mais empregada (Maatz et al., 2009; Rivero et al., 2005b).

O número de batimento por minuto mostra-se reduzido nos animais expostos ao CPA e a PA está reduzida apenas nos animais que receberam injeções de isoproterenol. Estudos que avaliaram os efeitos da exposição de curto prazo a poluição particulada do ar sobre a FC em humanos descrevem 
aumentos na frequência (Peters et al.,1999; Pope et al., 1999). Porem no estudo conduzido por Gold et al.(2000) em idosos, observa-se uma diminuição na FC e na PA.

Ibald-Mulli et al. (2004) avaliaram os efeitos da exposição ao MP sobre a PA e a FC em indivíduos adultos e portadores de doença coronariana e observaram que tanto a pressão sanguínea quanto a frequência apresentam-se diminuídas, principalmente em indivíduos que sofreram infarto do miocárdio previamente o que pode indicar que estes indivíduos respondem mais a exposição as partículas. Nos achados também mostram que os animais que receberam as injeções de isoproterenol, ou seja, animais com uma patologia prévia, respondem de forma mais marcante a exposição ao CPA.

Comparando nossos resultados aos achados dos diferentes tipos de estudos, experimentais e epidemiológicos, disponíveis na literatura científica observamos que há uma grande variabilidade e em alguns casos os desfechos aparecem de forma oposta. Isto talvez seja decorrente das diferentes metodologias empregadas tanto nos estudos epidemiológicos quanto a caracterização da exposição, presença de cofatores, métodos para avaliação dos desfechos bem como nos estudos experimentais no que diz respeito aos métodos de exposição, modelo animal, composição do MP, dose de exposição, entre outros.

Ainda devemos ressaltar que embora muitos avanços já tenham sido feitos no uso do VFC como um fator de prognostico de risco de cardiovascular em humanos, o uso deste parâmetro em animais de laboratório, especialmente roedores, ainda é novo (Rowan III et al., 2007). Há uma série de diferenças entre o sistema cardiovascular de mamíferos de grande porte, incluindo humanos, e pequenos mamíferos, além disto, a resposta a xenobióticos também (Swynghedauwn et al., 1997b; Kass et al., 1998; Gehrmann et al., 2000; 
Routledge et al., 2002).

A análise da VFC em roedores reflete um mecanismo de regulação cardiovascular semelhante a humanos, porém o tônus vagal ausente ou baixo em repouso nos roedores pode alterar a qualidade e grau da resposta da VFC após as exposições (Japundzic et al., 1990; Cerutti et al., 1991; Kuwahara et al., 1994; Aubert et al., 1999). Estas diferenças podem portando significar que não há necessariamente uma similaridade nos desfechos, e que o valor prognóstico da VFC que é demonstrado em diversas patologias humanas, ainda é prematuro para uso em roedores como um indicador de prognostico negativo ou toxicidade após exposições a poluentes ambientais (Rowan III et al., 2007).

Os mecanismos comumente propostos para explicar os efeitos da exposição ao MP sobre o sistema cardiovascular são toxicidade pulmonar (inflamação, estresse oxidativo) ou toxicidade cardiovascular direta (aumento da coagulabilidade sanguínea, disfunção endotelial, vasoconstrição) e estresse oxidativo sistêmico.

Baseado em nossos achados, a hipótese dos efeitos serem decorrentes de uma inflamação pulmonar não se confirma dado que os resultados da análise do LBA bem como do sangue não indicam um estado inflamatório. Kodavanti et al. (2002) também não observaram infiltrado inflamatório neutrofílico no LBA em ratos de 3 linhagens diferentes [Sprague- Dawley (SD), Wistar Kyoto normotenso (WKY) e ratos espontaneamente hipertensos (SH, SHR/NCrIBR)] expostos a diferentes concentrações e por diferentes tempos a poluição particulada. Porém, observam um aumento de macrófagos no tecido pulmonar e este aumento se mostra tempo dependente; embora não tenham sido realizadas avaliações histopatológicas no tecido pulmonar, observamos um aumento no numero de macrófagos presentes no LBA dos animais expostos ao CPA. Ressalta-se que as concentrações utilizadas por Kodavanti et al. (2002) são extremamente 
elevadas, sendo menor dose diária utilizada por eles $\left(2 \mathrm{mg} / \mathrm{m}^{3}\right) 3$ vezes maior que nossa dose diária $\left(600 \mathrm{ug} / \mathrm{m}^{3}\right)$.

Alterações de fatores sanguíneos envolvidos na coagulabilidade sanguínea também não foram detectadas. A análise do hematócrito mostra que há alterações nos animais tratados com isoproterenol, porém somente a exposição ao CPA não é capaz de provocar mudanças no hematócrito dos animais, há uma diminuição no número de eritrócitos bem como alterações em seu tamanho e concentração de hemoglobina.

Conforme apontado por Kodavanti et al. (2003) os estudos experimentais que avaliam os efeitos da exposição ao MP de origem veicular baseiam se principalmente em achados fisiológicos, muito pouco se avaliou quanto a histopatologia e bioquímica do tecido cardíaco e além disso há uma grande variabilidade quanto aos métodos e duração da exposição, composição do MP utilizado e espaço de tempo entre as exposições e avaliação dos desfechos (Vincent et al., 1997; Watkinson et al., 1998; Campen et al., 2001; Wellenius et al., 2002) dificultando comparações.

Em nosso estudo, como mencionado anteriormente utilizamos doses de exposição reais, exposições controladas de corpo inteiro e nosso sistema de exposição (CPA) garante que as características físicas e químicas do $\mathrm{MP}_{2,5}$ presente no ambiente não sejam alteradas. E para avaliar se alterações morfológicas na estrutura macro e microscópica do coração estão associadas a exposições de curto prazo ao $\mathrm{MP}_{2,5}$ conduzimos uma análise estereológica do coração.

Talvez os achados mais relevantes deste estudo sejam provenientes desta avaliação, que mostra que a exposição ao CPA provoca um aumento tanto na proporção quanto no volume absoluto de tecido conjuntivo no miocárdio, principalmente na região subendocárdia. O tempo de exposição é determinante 
para este desfecho e pode ser observado a partir de duas semanas de exposição nos animais normais. Nos animais que receberam injeções de isoproterenol, os IHCs não são influenciados pela exposição ao CPA, porém, há uma gravo devido à exposição nos parâmetros relacionados a quantidades de tecido conjuntivo no VE, aumento no diâmetro e no volume ponderado dos cardiomiócitos. Nos animais sadios, há uma tendência de aumento do diâmetro e no volume ponderado dos cardiomiócitos, porém não atingiu significância estatística. Provavelmente com a exposição continuada ou utilizando doses maiores, este desfecho poderia ser agravado.

A poluição do ar nos grandes centros urbanos deriva principalmente de emissões veiculares. A análise elementar de amostras do $\mathrm{MP}_{2,5}$ coletados na região onde foram realizadas as exposições confirma sua fonte partir de emissões veiculares (Martins, 2010). As amostras de $M_{2,5}$ são constituídas principalmente por carbono e somado a ele encontramos enxofre, alumínio, silício, cálcio, ferro, potássio, zinco, titânio, chumbo, vanádio e níquel. Entre os elementos presentes, o alumínio, ferro, zinco, cobre, titânio, níquel e vanádio são metais de transição, e a estes compostos são atribuídos diversos efeitos sobre o sistema cardiorrespiratório e imunológico (Costa e Dreher, 1997; Zelikoff et al., 2002).

Entre os metais pesados, encontramos o chumbo, que tem sua toxicidade bem conhecida. Mesmo em baixas doses o chumbo é capaz de produzir desarranjos na função cardiovascular em humanos e animais. Exposições crônicas a baixas doses de chumbo estão associadas a alterações na atividade elétrica e mecânica do coração e alterações na função da musculatura lisa (Kopp et al., 1988) bem como alterações degenerativas e bioquímicas da musculatura e vasos do coração (Asokan, 1974; Moore et al, 1975). 


\section{CONCLUSÃO}

Concluímos que a exposição em curto prazo a concentrações ambientalmente relevantes na cidade de São Paulo é capaz de produzir alterações hitopatológicas no coração de ratos normais e portadores de uma HVE, indpendentemente de alterações inflamatórias pulmonares, alterações no hematócrito e em fatores de coagulação do sangue. 


\section{ANEXOS}

Anexo A. Tabelas Análise descritiva Volume dos compartimentos

\section{cardíacos}

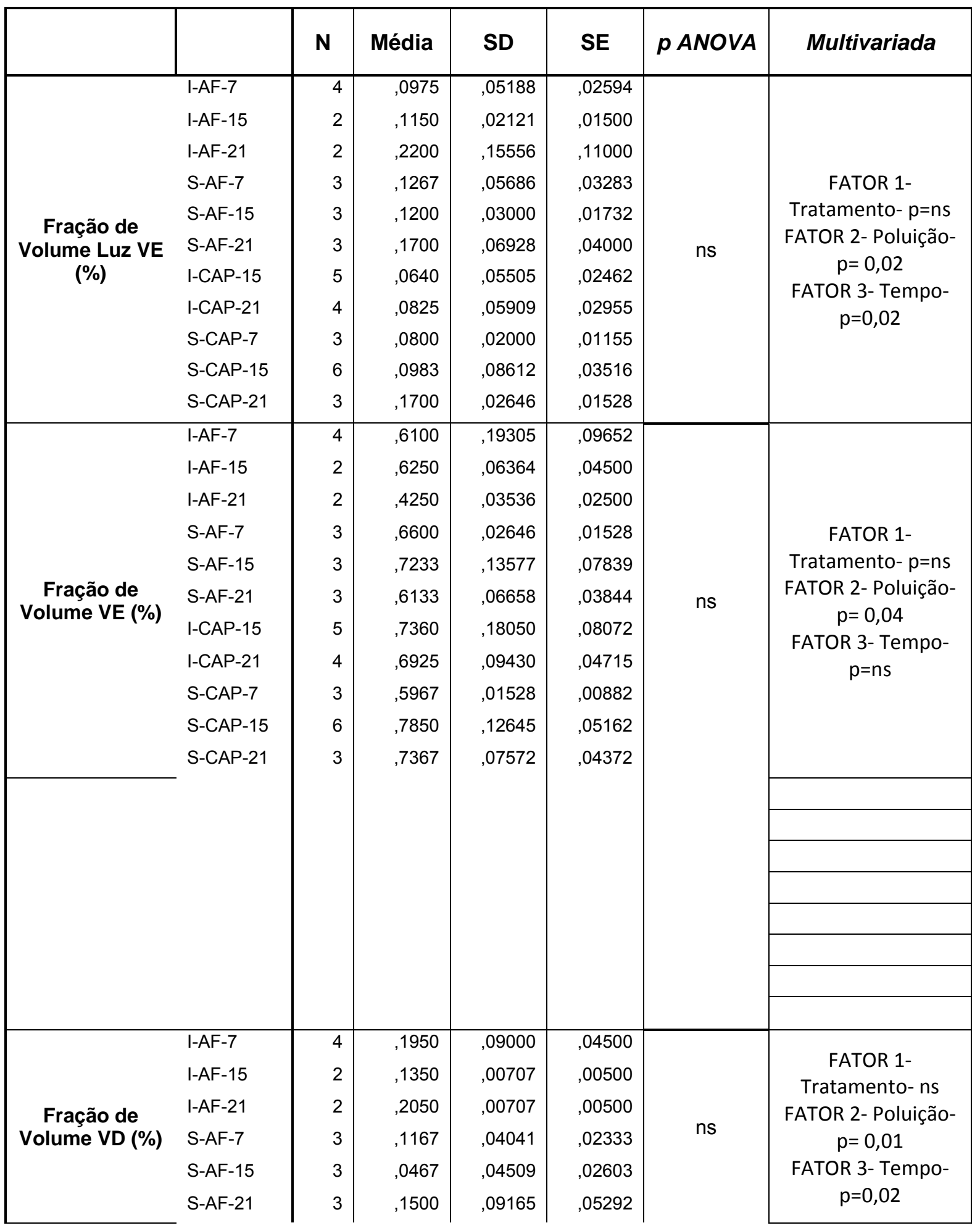




\begin{tabular}{|c|c|c|c|c|c|c|c|}
\hline & I-CAP-15 & 5 & 1040 & 10714 & ,04792 & & \\
\hline & I-CAP-21 & 4 & 1450 & ,07724 & ,03862 & & \\
\hline & S-CAP-7 & 3 & 1400 & 13115 & ,07572 & & \\
\hline & S-CAP-15 & 6 &, 0750 & ,12325 & ,05032 & & \\
\hline & S-CAP-21 & 3 & ,0667 & ,04726 & ,02728 & & \\
\hline \multirow{11}{*}{$\begin{array}{c}\text { Fração de } \\
\text { Volume Septo } \\
\text { (\%) }\end{array}$} & I-AF-7 & 4 & 1000 & ,06683 & ,03342 & \multirow{11}{*}{ ns } & \multirow{11}{*}{$\begin{array}{c}\text { FATOR 1- } \\
\text { Tratamento- ns } \\
\text { FATOR 2- Poluição- } \\
p=0,01 \\
\text { FATOR 3- Tempo- } \\
p=0,02\end{array}$} \\
\hline & I-AF-15 & 2 & , 1300 &, 04243 & ,03000 & & \\
\hline & I-AF-21 & 2 & 1550 & 12021 & ,08500 & & \\
\hline & S-AF-7 & 3 & 1000 & 07550 & 04359 & & \\
\hline & S-AF-15 & 3 & 1100 & 09644 & ,05568 & & \\
\hline & S-AF-21 & 3 & ,0700 & ,06557 & 03786 & & \\
\hline & I-CAP-15 & 5 & 1020 & ,07759 & 03470 & & \\
\hline & I-CAP-21 & 4 & ,0825 & ,07411 & 03705 & & \\
\hline & S-CAP-7 & 3 & , 1867 & 10263 & ,05925 & & \\
\hline & S-CAP-15 & 6 & ,0433 & 06743 & ,02753 & & \\
\hline & S-CAP-21 & 3 & ,0267 & ,04619 & 02667 & & \\
\hline \multirow{11}{*}{$\begin{array}{l}\text { Volume total } \\
\text { Luz VE }\left(\mathrm{cm}^{3}\right)\end{array}$} & I-AF-7 & 4 & ,0975 & ,04992 & ,02496 & \multirow{11}{*}{ ns } & \multirow{11}{*}{$\begin{array}{c}\text { FATOR 1- } \\
\text { Tratamento- ns } \\
\text { FATOR 2- Poluição- } \\
p=0,01 \\
\text { FATOR 3- Tempo- } \\
p=0,02\end{array}$} \\
\hline & I-AF-15 & 2 & 1100 & ,02828 & ,02000 & & \\
\hline & I-AF-21 & 2 & ,2150 & 16263 & 11500 & & \\
\hline & S-AF-7 & 3 & 1100 & ,06245 & ,03606 & & \\
\hline & S-AF-15 & 3 & 1033 & ,02082 & ,01202 & & \\
\hline & S-AF-21 & 3 & 1567 & 04619 & ,02667 & & \\
\hline & I-CAP-15 & 5 &, 0600 & 05099 & ,02280 & & \\
\hline & I-CAP-21 & 4 & ,0725 & 05620 & ,02810 & & \\
\hline & S-CAP-7 & 3 & ,0767 & ,02517 & 01453 & & \\
\hline & S-CAP-15 & 6 & ,0867 & ,07394 & 03018 & & \\
\hline & S-CAP-21 & 3 & 1400 & ,02646 & ,01528 & & \\
\hline \multirow{11}{*}{$\begin{array}{l}\text { Volume total } \\
\text { VE }\left(\mathrm{cm}^{3}\right)\end{array}$} & I-AF-7 & 4 & ,6125 & 19033 & ,09516 & \multirow{11}{*}{ ns } & \multirow{11}{*}{$\begin{array}{c}\text { FATOR 1- } \\
\text { Tratamento- ns } \\
\text { FATOR 2- Poluição- } \\
\text { ns } \quad \text { FATOR } \\
\text { 3- Tempo- } p=0,05\end{array}$} \\
\hline & I-AF-15 & 2 & ,6150 & ,02121 & 01500 & & \\
\hline & I-AF-21 & 2 & ,4000 & ,01414 & 01000 & & \\
\hline & S-AF-7 & 3 & ,5667 & ,08505 & 04910 & & \\
\hline & S-AF-15 & 3 & ,6367 & 18502 & ,10682 & & \\
\hline & S-AF-21 & 3 &, 5567 & ,07234 & ,04177 & & \\
\hline & I-CAP-15 & 5 & ,7060 & 13145 & 05879 & & \\
\hline & I-CAP-21 & 4 & ,6150 & ,08347 & ,04173 & & \\
\hline & S-CAP-7 & 3 &, 5633 & ,07234 & 04177 & & \\
\hline & S-CAP-15 & 6 & ,6983 & 10381 & ,04238 & & \\
\hline & S-CAP-21 & 3 & ,6067 & ,06110 & ,03528 & & \\
\hline \multirow{7}{*}{$\begin{array}{l}\text { Volume total } \\
\text { VD }\left(\mathrm{cm}^{3}\right)\end{array}$} & I-AF-7 & 4 & , 1975 & ,09570 & 04785 & \multirow{7}{*}{ ns } & \multirow{7}{*}{$\begin{array}{c}\text { FATOR 1- } \\
\text { Tratamento- } p= \\
\text { 0,03 FATOR 2- } \\
\text { Poluição- ns } \\
\text { FATOR 3- Tempo- } \\
\text { ns }\end{array}$} \\
\hline & I-AF-15 & 2 & 1300 & ,00000 & ,00000 & & \\
\hline & I-AF-21 & 2 & 1950 & ,00707 & ,00500 & & \\
\hline & S-AF-7 & 3 & 1000 & ,04000 & 02309 & & \\
\hline & S-AF-15 & 3 & ,0400 & ,04000 & ,02309 & & \\
\hline & S-AF-21 & 3 & ,1333 & ,09452 & ,05457 & & \\
\hline & I-CAP-15 & 5 & 1080 & 11432 & 05113 & & \\
\hline
\end{tabular}




\begin{tabular}{|c|c|c|c|c|c|c|c|}
\hline & I-CAP-21 & 4 & 1300 & ,07616 & ,03808 & & \\
\hline & S-CAP-7 & 3 & 1233 & 10970 & ,06333 & & \\
\hline & S-CAP-15 & 6 & ,0717 & ,12624 & 05154 & & \\
\hline & S-CAP-21 & 3 & ,0567 & ,03786 & ,02186 & & \\
\hline \multirow{11}{*}{$\begin{array}{l}\text { Volume Total } \\
\text { do Septo }\left(\mathrm{cm}^{3}\right)\end{array}$} & I-AF-7 & 4 & ,1025 & ,06946 & ,03473 & \multirow{11}{*}{ ns } & \multirow{11}{*}{$\begin{array}{c}\text { FATOR 1- } \\
\text { Tratamento- ns } \\
\text { FATOR 2- Poluição- } \\
\text { ns } \\
\text { 3- Tempo-ns }\end{array}$} \\
\hline & I-AF-15 & 2 & 1300 & 05657 & ,04000 & & \\
\hline & I-AF-21 & 2 & , 1450 & , 10607 & ,07500 & & \\
\hline & S-AF-7 & 3 & ,0767 & 05132 & ,02963 & & \\
\hline & S-AF-15 & 3 & ,0900 & ,07937 & ,04583 & & \\
\hline & S-AF-21 & 3 & ,0667 & ,06506 & ,03756 & & \\
\hline & I-CAP-15 & 5 & , 1040 & ,08735 & ,03906 & & \\
\hline & I-CAP-21 & 4 &, 0675 & ,05737 & ,02869 & & \\
\hline & S-CAP-7 & 3 & 1800 & ,11136 & ,06429 & & \\
\hline & S-CAP-15 & 6 & ,0433 & ,06976 & ,02848 & & \\
\hline & S-CAP-21 & 3 & ,0200 & ,03464 & ,02000 & & \\
\hline
\end{tabular}

Anexo B. Tabelas Análise descritiva dados do Volume total e fração

\section{do miocárdio}

\begin{tabular}{|c|c|c|c|c|c|c|c|}
\hline & & $\mathbf{N}$ & Média & SD & SE & ANOVA $p$ & $\begin{array}{c}\text { Multivariada } \\
\text { (3 WAY } \\
\text { ANOVA) }\end{array}$ \\
\hline \multirow{11}{*}{$\begin{array}{l}\text { Fração de Volume } \\
\text { Cardiomiócitos no VE (\%) }\end{array}$} & 0 & 4 & 0,578 & 0,12 & 0,059 & \multirow{11}{*}{0,001} & \multirow{11}{*}{$\begin{array}{c}\text { FATOR 1- } \\
\text { Tratamento- } \\
p=0,001 \\
\text { FATOR 2- } \\
\text { Poluição- } p= \\
\text { 0,005 } \\
\text { FATOR 3- } \\
\text { Tempo- } p=n s\end{array}$} \\
\hline & 1 & 2 & 0,675 & 0,09 & 0,065 & & \\
\hline & 2 & 2 & 0,775 & 0,11 & 0,075 & & \\
\hline & 3 & 4 & 0,935 & 0,05 & 0,023 & & \\
\hline & 4 & 4 & 0,963 & 0,02 & 0,010 & & \\
\hline & 5 & 3 & 0,933 & 0,06 & 0,032 & & \\
\hline & 6 & 5 & 0,646 & 0,12 & 0,053 & & \\
\hline & 7 & 5 & 0,586 & 0,05 & 0,022 & & \\
\hline & 8 & 4 & 0,903 & 0,04 & 0,022 & & \\
\hline & 9 & 6 & 0,808 & 0,12 & 0,050 & & \\
\hline & 10 & 3 & 0,837 & 0,08 & 0,046 & & \\
\hline \multirow{11}{*}{$\begin{array}{l}\text { Fração de Volume Tec } \\
\text { conjuntivo no VE (\%) }\end{array}$} & 0 & 4 & 0,412 & 0,11 & 0,055 & \multirow{11}{*}{0,001} & \multirow{11}{*}{$\begin{array}{c}\text { FATOR 1- } \\
\text { Tratamento- } \\
p=0,001 \\
\text { FATOR 2- } \\
\text { Poluição- } p= \\
0,01 \\
\text { FATOR 3- } \\
\text { Tempo- } p=n s\end{array}$} \\
\hline & 1 & 2 & 0,319 & 0,10 & 0,071 & & \\
\hline & 2 & 2 & 0,217 & 0,10 & 0,072 & & \\
\hline & 3 & 4 & 0,033 & 0,05 & 0,024 & & \\
\hline & 4 & 4 & 0,002 & 0,00 & 0,001 & & \\
\hline & 5 & 3 & 0,032 & 0,06 & 0,032 & & \\
\hline & 6 & 5 & 0,321 & 0,12 & 0,052 & & \\
\hline & 7 & 5 & 0,381 & 0,05 & 0,023 & & \\
\hline & 8 & 4 & 0,065 & 0,03 & 0,017 & & \\
\hline & 9 & 6 & 0,169 & 0,13 & 0,054 & & \\
\hline & 10 & 3 & 0,133 & 0,09 & 0,052 & & \\
\hline
\end{tabular}




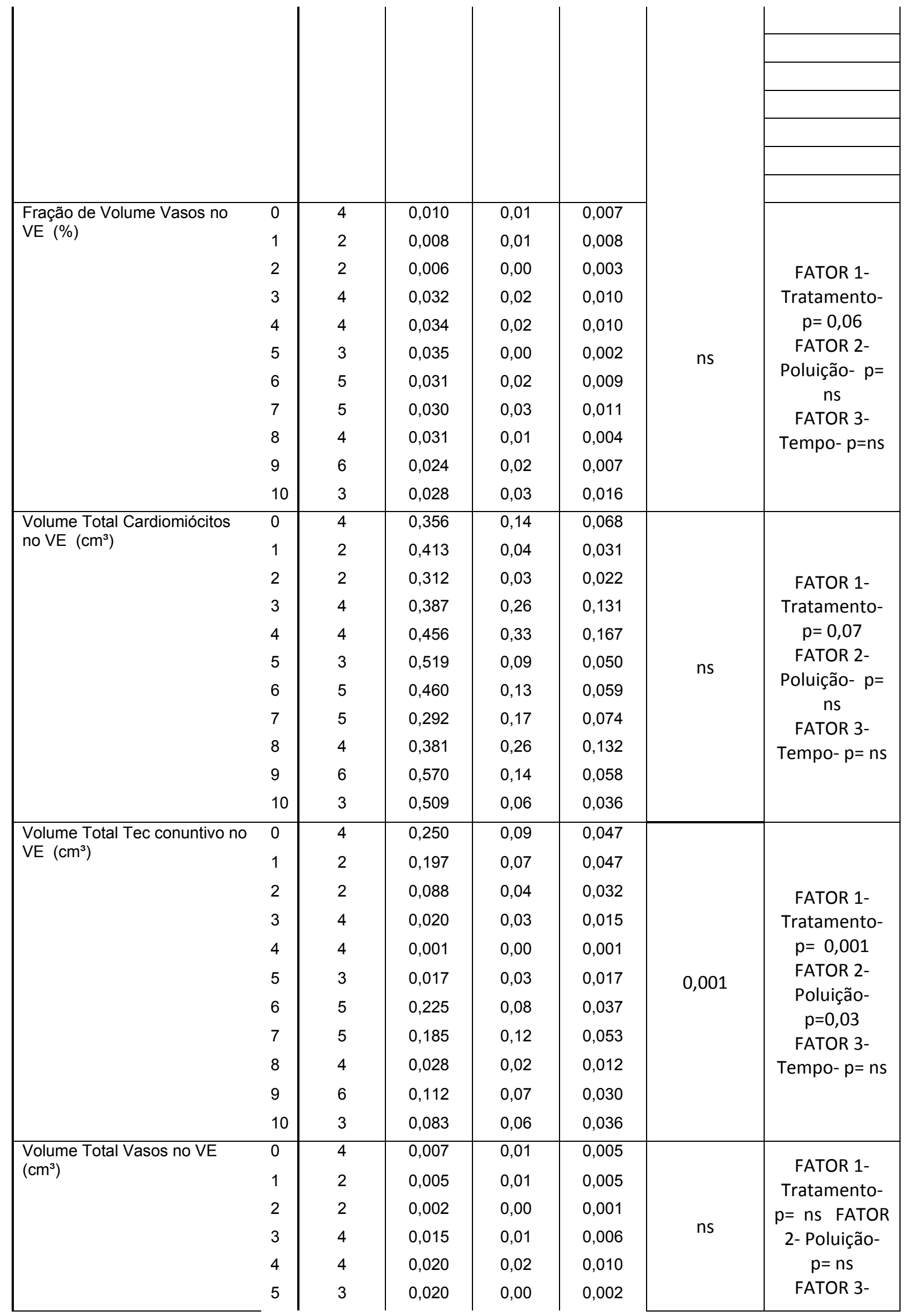




\begin{tabular}{|l|l|l|l|l|l|l|}
\hline 6 & 5 & 0,022 & 0,01 & 0,006 & Tempo- $\mathrm{p}=\mathrm{ns}$ \\
7 & 5 & 0,013 & 0,01 & 0,006 & \\
8 & 4 & 0,014 & 0,01 & 0,005 & \\
9 & 6 & 0,018 & 0,01 & 0,006 & \\
10 & 3 & 0,016 & 0,01 & 0,008 & \\
\hline
\end{tabular}

\section{Anexo C. Tabelas Análise descritiva dados do diâmetro e volume total e fração do miocárdio}

\begin{tabular}{|c|c|c|c|c|c|c|c|}
\hline & & $\mathbf{N}$ & Média & SD & SE & $\begin{array}{c}\text { ANOVA } \\
p\end{array}$ & $\begin{array}{c}\text { Multivariada } \\
\text { (3 WAY } \\
\text { ANOVA) }\end{array}$ \\
\hline \multirow{11}{*}{$\begin{array}{l}\text { Diâmetro do } \\
\text { Cardiomiócito }(\mu \mathrm{m})\end{array}$} & I-AF-7 & 4 & 21,87 & 1,09 & ,54 & \multirow{11}{*}{0,001} & \multirow{11}{*}{$\begin{array}{c}\text { FATOR 1- } \\
\text { Tratamento- } \\
p=0,0001 \\
\text { FATOR 2- } \\
\text { Poluição- } p= \\
0,03 \\
\text { FATOR 3- } \\
\text { Tempo- } p= \\
\text { NS }\end{array}$} \\
\hline & I-AF-15 & 2 & 21,44 & 4,99 & 3,53 & & \\
\hline & I-AF-21 & 2 & 18,52 & 1,03 & ,73 & & \\
\hline & S-AF-7 & 4 & 15,02 & 3,91 & 1,96 & & \\
\hline & S-AF-15 & 4 & 15,53 & 3,46 & 1,73 & & \\
\hline & S-AF-21 & 3 & 16,34 & 2,21 & 1,28 & & \\
\hline & I-CAP-15 & 5 & 15,41 & 2,15 & ,96 & & \\
\hline & I-CAP-21 & 5 & 17,82 & 3,26 & 1,46 & & \\
\hline & S-CAP-7 & 4 & 13,26 & 2,52 & 1,26 & & \\
\hline & S-CAP-15 & 6 & 13,88 & 1,11 &, 45 & & \\
\hline & S-CAP-21 & 3 & 17,05 & 1,10 & ,64 & & \\
\hline \multirow[t]{11}{*}{$\begin{array}{l}\text { Volume } \\
\text { cardiomiócito (um³) }\end{array}$} & I-AF-7 & 4 & 11013,60 & $\begin{array}{c}1648,8 \\
2\end{array}$ & 824,41 & \multirow{11}{*}{0,0001} & \multirow{11}{*}{$\begin{array}{c}\text { FATOR 1- } \\
\text { Tratamento- } \\
p=0,01 \\
\text { FATOR 2- } \\
\text { Poluição- } p= \\
0,04 \\
\text { FATOR 3- } \\
\text { Tempo- } p= \\
\text { NS FATOR } \\
2+3 p=0,03\end{array}$} \\
\hline & I-AF-15 & 2 & 11151,40 & $\begin{array}{c}7270,9 \\
0\end{array}$ & 5141,30 & & \\
\hline & I-AF-21 & 2 & 6674,45 & $\begin{array}{c}1112,3 \\
5\end{array}$ & 786,55 & & \\
\hline & S-AF-7 & 4 & 4064,03 & $\begin{array}{c}2518,2 \\
5\end{array}$ & 1259,13 & & \\
\hline & S-AF-15 & 4 & 4380,93 & $\begin{array}{c}3065,3 \\
7\end{array}$ & 1532,69 & & \\
\hline & S-AF-21 & 3 & 4730,63 & $\begin{array}{c}1785,6 \\
0\end{array}$ & 1030,92 & & \\
\hline & I-CAP-15 & 5 & 4008,34 & $\begin{array}{c}1523,5 \\
2\end{array}$ & 681,34 & & \\
\hline & I-CAP-21 & 5 & 6389,52 & $\begin{array}{c}3137,8 \\
1\end{array}$ & 1403,27 & & \\
\hline & S-CAP-7 & 4 & 2651,35 & $\begin{array}{c}1683,8 \\
8\end{array}$ & 841,94 & & \\
\hline & S-CAP-15 & 6 & 2842,07 & 705,67 & 288,09 & & \\
\hline & S-CAP-21 & 3 & 5228,13 & $\begin{array}{c}1019,4 \\
5 \\
\end{array}$ & 588,58 & & \\
\hline
\end{tabular}


Anexo D. Tabelas Análise descritiva dados do peso e volume do coração (VE)

\begin{tabular}{|c|c|c|c|c|c|c|c|c|}
\hline & & $\mathbf{N}$ & Média & SD & SE & $p$ & Pos teste & Multivariada \\
\hline \multirow[t]{11}{*}{$\begin{array}{l}\text { Peso } \\
\text { ventrículo }(\mathrm{g})\end{array}$} & I-AF-7 & 4 & 1,07 & 0,10 & \multirow{5}{*}{$\begin{array}{l}0,05 \\
0,03 \\
0,07 \\
0,05\end{array}$} & \multirow{11}{*}{ ns } & $\begin{array}{l}\mathrm{p}=0,03 \\
\text { comparado a } \\
\mathrm{S}-\mathrm{AF}-7\end{array}$ & \multirow{11}{*}{$\begin{array}{l}\text { FATOR 1- } \\
\text { Tratamento- } \\
\text { p=0,006 } \\
\text { FATOR 2- } \\
\text { Poluição- ns } \\
\text { FATOR 3- } \\
\text { Tempo- ns }\end{array}$} \\
\hline & I-AF-15 & 2 & 1,05 & 0,07 & & & & \\
\hline & I-AF-21 & 2 & 1,01 & 0,04 & & & & \\
\hline & S-AF-7 & 3 & 0,91 & 0,13 & & & & \\
\hline & S-AF-15 & 3 & 0,92 & 0,09 & & & & \\
\hline & S-AF-21 & 3 & 0,96 & 0,07 & 0,04 & & & \\
\hline & I-CAP-15 & 5 & 1,04 & 0,11 & 0,05 & & & \\
\hline & I-CAP-21 & 4 & 0,94 & 0,06 & 0,03 & & & \\
\hline & S-CAP-7 & 3 & 1,00 & 0,11 & 0,06 & & & \\
\hline & $\begin{array}{l}\text { S-CAP- } \\
15\end{array}$ & 6 & 0,95 & 0,12 & 0,05 & & & \\
\hline & $\begin{array}{l}\text { S-CAP- } \\
21\end{array}$ & 3 & 0,88 & 0,04 & 0,02 & & $\begin{array}{l}\mathrm{p}=0,01 \text { compa } \\
\text { a S-CAP-21 }\end{array}$ & \\
\hline \multirow[t]{11}{*}{$\begin{array}{l}\text { Volume } \\
\text { ventrículos } \\
\left(\mathrm{g} / \mathrm{cm}^{3}\right) \mathrm{V}=\mathrm{m} / \mathrm{d} \\
\left(\mathrm{d}=1,06 \mathrm{~g} / \mathrm{cm}^{3}\right)\end{array}$} & I-AF-7 & 4 & 1,01 & 0,09 & 0,05 & \multirow{11}{*}{ ns } & $\begin{array}{l}\mathrm{p}=0,03 \\
\text { comparado a } \\
\text { S-AF-8 }\end{array}$ & \multirow{11}{*}{$\begin{array}{c}\text { FATOR 1- } \\
\text { Tratamento- } \\
\text { p=0,01 FATOR } \\
\text { 2- Poluição- } \\
\text { ns } \\
\text { FATOR 3- } \\
\text { Tempo- ns }\end{array}$} \\
\hline & I-AF-15 & 2 & 0,99 & 0,07 & 0,05 & & & \\
\hline & I-AF-21 & 2 & 0,95 & 0,04 & 0,03 & & & \\
\hline & S-AF-7 & 3 & 0,85 & 0,12 & 0,07 & & & \\
\hline & S-AF-15 & 3 & 0,87 & 0,08 & 0,05 & & & \\
\hline & S-AF-21 & 3 & 0,91 & 0,07 & 0,04 & & & \\
\hline & I-CAP-15 & 5 & 0,98 & 0,10 & 0,04 & & & \\
\hline & I-CAP-21 & 4 & 0,89 & 0,06 & 0,03 & & & \\
\hline & S-CAP-7 & 3 & 0,94 & 0,10 & 0,06 & & & \\
\hline & $\begin{array}{l}\text { S-CAP- } \\
15\end{array}$ & 6 & 0,90 & 0,12 & 0,05 & & & \\
\hline & $\begin{array}{l}\text { S-CAP- } \\
21\end{array}$ & 3 & 0,83 & 0,03 & 0,02 & & $\begin{array}{l}\mathrm{p}=0,01 \text { compa } \\
\text { a S-CAP-22 }\end{array}$ & \\
\hline
\end{tabular}


Anexo E. Tabelas Análise descritiva dados da espessura do septo ventricular

\begin{tabular}{|c|c|c|c|c|c|c|c|c|}
\hline \multicolumn{9}{|c|}{ Descriptives } \\
\hline & & $\mathbf{N}$ & Média & SD & SE & ANOVA $p$ & Pos teste & $\begin{array}{l}\text { Multivariada (3 } \\
\text { WAY ANOVA) }\end{array}$ \\
\hline $\begin{array}{l}\text { Espessura } \\
\text { parede } \\
\text { ventricular- } \\
1\end{array}$ & $\begin{array}{l}\text { I-AF-7 } \\
\text { I-AF-15 } \\
\text { I-AF-21 } \\
\text { S-AF-7 } \\
\text { S-AF-15 } \\
\text { S-AF-21 } \\
\text { I-CAP- } \\
15 \\
\text { I-CAP- } \\
21 \\
\text { S-CAP-7 } \\
\text { S-CAP- } \\
15 \\
\text { S-CAP- } \\
21\end{array}$ & $\begin{array}{l}4 \\
2 \\
2 \\
3 \\
3 \\
3 \\
5\end{array}$ & $\begin{array}{l}2422,50 \\
2280,50 \\
2469,50 \\
1976,67 \\
1737,33 \\
2217,00 \\
2281,00 \\
2403,75 \\
2595,00 \\
2540,17 \\
2034,33\end{array}$ & $\begin{array}{l}534,52 \\
112,43 \\
142,13 \\
452,38 \\
289,84 \\
288,61 \\
164,07 \\
298,11 \\
303,16 \\
466,81 \\
292,04\end{array}$ & $\begin{array}{c}267,26 \\
79,50 \\
100,50 \\
261,18 \\
167,34 \\
166,63 \\
73,38 \\
149,05 \\
175,03 \\
190,57 \\
168,61\end{array}$ & $\begin{array}{c}21 \text { dias } \\
p=n s \\
15 \text { dias } \\
p=0,04\end{array}$ & $\begin{array}{c}15 d \\
\text { saf15 -scap15 } \\
p=0,006 \\
\text { icap15-saf15 } \\
p=0,01\end{array}$ & $\begin{array}{c}\text { FATOR 1- } \\
\text { Tratamento- } p= \\
0,05 \\
\text { FATOR 2- Poluição- } \\
\text { p }=\text { ns } \\
\text { FATOR 3- Tempo- } \\
\text { p }=\text { ns }\end{array}$ \\
\hline
\end{tabular}

Anexo F. Tabelas Análise descritiva dos dados do peso corpóreo e peso do VE (razão peso corpóreo/peso VE)

\begin{tabular}{|c|c|c|c|c|c|c|c|}
\hline & & $\mathbf{N}$ & Média & SD & SE & ANOVA $p$ & $\begin{array}{l}\text { Multivariada (3 } \\
\text { WAY ANOVA) }\end{array}$ \\
\hline \multirow{8}{*}{$\begin{array}{l}\text { Peso corporal } \\
\text { (g) }\end{array}$} & I-AF-15 & 4 & 309,8 & 6,4 & 3,2 & \multirow{8}{*}{0,01} & \multirow{8}{*}{$\begin{array}{c}\text { FATOR - } \\
\text { Tratamento- } \mathrm{p}= \\
0,009 \\
\text { FATOR - } \\
\text { Poluição- } \mathrm{p}= \\
0,006 \\
\text { FATOR - Tempo- } \\
\mathrm{p}=\mathrm{NS}\end{array}$} \\
\hline & I-CAP-15 & 6 & 302,5 & 12,2 & 5,0 & & \\
\hline & S-AF-15 & 5 & 340,1 & 19,8 & 8,9 & & \\
\hline & S-CAP-15 & 7 & 325,7 & 24,9 & 9,4 & & \\
\hline & $S-A F-30$ & 5 & 331,3 & 31,0 & 13,9 & & \\
\hline & S-CAP-30 & 6 & 310,8 & 16,3 & 6,7 & & \\
\hline & I-AF-30 & 5 & 346,9 & 30,0 & 13,4 & & \\
\hline & ICAP-30 & 5 & 313,3 & 11,5 & 5,1 & & \\
\hline \multirow{8}{*}{$\begin{array}{l}\text { Peso do } \\
\text { coração (g) }\end{array}$} & S-AF-15 & 4 & 1,0725 & 10400 & ,05200 & \multirow{8}{*}{0,09} & \multirow{8}{*}{$\begin{array}{c}\text { FATOR 1- } \\
\text { Tratamento- } \mathrm{p}= \\
0,009 \\
\text { FATOR 2- } \\
\text { Poluição- } \mathrm{p}= \\
\text { 0,07 } \\
\text { FATOR 3- } \\
\text { Tempo- } \mathrm{p}=\mathrm{NS}\end{array}$} \\
\hline & S-CAP-15 & 6 & 1,0252 & 09839 & 04017 & & \\
\hline & I-AF-15 & 5 & ,9676 & 09046 & 04046 & & \\
\hline & I-CAP-15 & 7 & ,9466 & 11297 & ,04270 & & \\
\hline & S-AF-30 & 5 & 1,0144 & ,09208 & ,04118 & & \\
\hline & S-CAP-30 & 6 & ,9605 & ,06349 & ,02592 & & \\
\hline & I-AF-30 & 5 & ,9680 & 08593 & ,03843 & & \\
\hline & ICAP-30 & 5 & ,8872 & ,03252 & ,01454 & & \\
\hline \multirow{2}{*}{$\begin{array}{l}\text { Razão Peso } \\
\text { corporal: peso } \\
\text { coração }\end{array}$} & S-AF-15 & 4 & ,003460 & ,0002889 & ,0001445 & \multirow{2}{*}{0,0001} & \multirow{2}{*}{$\begin{array}{l}\text { FATOR 1- } \\
\text { Tratamento- } \mathrm{p}=\end{array}$} \\
\hline & S-CAP-15 & 6 & ,003387 & ,0002622 & 0001071 & & \\
\hline
\end{tabular}




\begin{tabular}{|l|l|l|l|l|c|}
\hline I-AF-15 & 5 &, 002843 &, 0001813 &, 0000811 & 0,0001 \\
I-CAP-15 & 7 &, 002901 &, 0001742 &, 0000658 & FATOR 2- \\
S-AF-30 & 5 &, 003066 &, 0001457 &, 0000652 & Poluição- p= NS \\
S-CAP-30 & 6 &, 003089 &, 0000756 &, 0000309 & FATOR 3- \\
I-AF-30 & 5 &, 002799 &, 0002586 &, 0001157 & Tempo- $\mathrm{p}=$ \\
ICAP-30 & 5 &, 002835 &, 0001401 &, 0000627 & 0,002 \\
\hline
\end{tabular}

Anexo G. Tabelas Análise descritiva dos pesos dos órgãos

\begin{tabular}{|c|c|c|c|c|c|c|c|}
\hline & & $\mathbf{N}$ & Média & SD & SE & ANOVA $p$ & $\begin{array}{c}\text { Multivariada } \\
\text { (3 WAY } \\
\text { ANOVA) }\end{array}$ \\
\hline \multirow{11}{*}{ Peso Figado (g) } & I-AF-7 & 6 & 9,93 & 0,75 & 0,31 & \multirow{11}{*}{0,0001} & \multirow{11}{*}{$\begin{array}{c}\text { FATOR 1- } \\
\text { Tratamento- } \\
p=0,05 \\
\text { FATOR 2- } \\
\text { Poluição- } p= \\
0,05 \\
\text { FATOR 3- } \\
\text { Tempo- } p= \\
\text { NS } \\
\text { FATOR 1+2= } \\
0,002\end{array}$} \\
\hline & S-AF-7 & 6 & 10,78 & 0,82 & 0,33 & & \\
\hline & S-CAP-7 & 5 & 12,78 & 1,76 & 0,79 & & \\
\hline & I-AF-15 & 4 & 11,62 & 0,44 & 0,22 & & \\
\hline & I-CAP-15 & 6 & 11,98 & 1,15 & 0,47 & & \\
\hline & S-AF-15 & 5 & 12,53 & 0,49 & 0,22 & & \\
\hline & S-CAP-15 & 7 & 12,33 & 1,21 & 0,46 & & \\
\hline & I-AF-30 & 5 & 11,77 & 1,47 & 0,66 & & \\
\hline & I-CAP-30 & 6 & 12,18 & 1,11 & 0,45 & & \\
\hline & S-AF-30 & 5 & 13,57 & 1,24 & 0,56 & & \\
\hline & S-CAP-30 & 5 & 11,81 & 1,20 & 0,54 & & \\
\hline \multirow[t]{11}{*}{ Peso Baço(g) } & I-AF-7 & 6 & 0,64 & 0,08 & 0,03 & \multirow{11}{*}{ NS } & \multirow{11}{*}{$\begin{array}{c}\text { FATOR 1- } \\
\text { Tratamento- } \\
\mathrm{p}= \\
\text { FATOR 2- } \\
\text { Poluição- } \mathrm{p}= \\
\text { FATOR 3- } \\
\text { Tempo- } \mathrm{p}=\end{array}$} \\
\hline & S-AF-7 & 6 & 0,69 & 0,05 & 0,02 & & \\
\hline & S-CAP-7 & 5 & 0,74 & 0,09 & 0,04 & & \\
\hline & $\mathrm{I}-\mathrm{AF}-15$ & 4 & 0,72 & 0,15 & 0,07 & & \\
\hline & I-CAP-15 & 6 & 0,61 & 0,09 & 0,04 & & \\
\hline & S-AF-15 & 5 & 0,75 & 0,12 & 0,05 & & \\
\hline & S-CAP-15 & 7 & 0,69 & 0,05 & 0,02 & & \\
\hline & $\mathrm{I}-\mathrm{AF}-30$ & 5 & 0,75 & 0,09 & 0,04 & & \\
\hline & I-CAP-30 & 6 & 0,66 & 0,09 & 0,04 & & \\
\hline & S-AF-30 & 5 & 0,75 & 0,05 & 0,02 & & \\
\hline & S-CAP-30 & 5 & 0,73 & 0,10 & 0,04 & & \\
\hline \multirow[t]{11}{*}{ Peso Rim (g) } & I-AF-7 & 6 & 1,00 & 0,04 & 0,02 & \multirow{11}{*}{0,001} & \multirow{11}{*}{$\begin{array}{c}\text { FATOR 1- } \\
\text { Tratamento- } \\
\mathrm{p}=0,04 \\
\text { FATOR 2- } \\
\text { Poluição- } \mathrm{p}= \\
\text { FATOR 3- } \\
\text { Tempo- } \mathrm{p}=\end{array}$} \\
\hline & S-AF-7 & 6 & 1,19 & 0,09 & 0,04 & & \\
\hline & S-CAP-7 & 5 & 1,30 & 0,13 & 0,06 & & \\
\hline & $\mathrm{I}-\mathrm{AF}-15$ & 4 & 1,18 & 0,12 & 0,06 & & \\
\hline & I-CAP-15 & 6 & 1,18 & 0,15 & 0,06 & & \\
\hline & S-AF-15 & 5 & 1,33 & 0,09 & 0,04 & & \\
\hline & S-CAP-15 & 7 & 1,28 & 0,16 & 0,06 & & \\
\hline & I-AF-30 & 5 & 1,27 & 0,13 & 0,06 & & \\
\hline & I-CAP-30 & 6 & 1,20 & 0,12 & 0,05 & & \\
\hline & S-AF-30 & 5 & 1,39 & 0,12 & 0,06 & & \\
\hline & S-CAP-30 & 5 & 1,30 & 0,20 & 0,09 & & \\
\hline Peso Rim 2 (g) & I-AF-7 & 6 & 0,97 & 0,03 & 0,01 & 0,0001 & FATOR 1- \\
\hline
\end{tabular}




\begin{tabular}{|c|c|c|c|c|c|c|c|}
\hline & S-AF-7 & 6 & 1,19 & 0,09 & 0,04 & & Tratamento- \\
\hline & S-CAP-7 & 5 & 1,24 & 0,08 & 0,04 & & $p=0,001$ \\
\hline & I-AF-15 & 4 & 1,23 & 0,13 & 0,07 & & FATOR 2- \\
\hline & I-CAP-15 & 6 & 1,18 & 0,13 & 0,05 & & Poluição- $p=$ \\
\hline & S-AF-15 & 5 & 1,33 & 0,09 & 0,04 & & Temno- $n=$ \\
\hline & S-CAP-15 & 7 & 1,32 & 0,15 & 0,06 & & 0,001 \\
\hline & I-AF-30 & 5 & 1,26 & 0,09 & 0,04 & & \\
\hline & I-CAP-30 & 6 & 1,19 & 0,13 & 0,05 & & \\
\hline & S-AF-30 & 5 & 1,35 & 0,14 & 0,06 & & \\
\hline & S-CAP-30 & 5 & 1,30 & 0,23 & 0,10 & & \\
\hline Cérebro $(\mathrm{g})$ & I-AF-7 & 6 & 1,90 & 0,09 & 0,04 & & \\
\hline & S-AF-7 & 6 & 1,91 & 0,10 & 0,04 & & \\
\hline & S-CAP-7 & 5 & 1,89 & 0,16 & 0,07 & & FATOR 1- \\
\hline & I-AF-15 & 4 & 1,90 & 0,06 & 0,03 & & Tratamento- \\
\hline & I-CAP-15 & 6 & 1,68 & 0,29 & 0,12 & & $p=0,0001$ \\
\hline & S-AF-15 & 5 & 1,97 & 0,08 & 0,03 & 0,001 & FATOR 2- \\
\hline & S-CAP-15 & 7 & 1,89 & 0,15 & 0,06 & & $\begin{array}{l}\text { Polulçao- } p= \\
\text { FATOR 3- }\end{array}$ \\
\hline & I-AF-30 & 5 & 2,06 & 0,04 & 0,02 & & Tempo- $p=$ \\
\hline & I-CAP-30 & 6 & 1,93 & 0,07 & 0,03 & & 0,001 \\
\hline & S-AF-30 & 5 & 2,01 & 0,04 & 0,02 & & \\
\hline & S-CAP-30 & 5 & 2,06 & 0,06 & 0,03 & & \\
\hline Peso Pulmão (g) & I-AF-7 & 6 & 1,66 & 0,27 & 0,11 & & \\
\hline & S-AF-7 & 6 & 1,54 & 0,12 & 0,05 & & \\
\hline & S-CAP-7 & 5 & 1,70 & 0,28 & 0,13 & & \\
\hline & I-AF-15 & 3 & 1,62 & 0,05 & 0,03 & & FATOR 1- \\
\hline & I-CAP-15 & 6 & 1,76 & 0,21 & 0,09 & & $p=$ \\
\hline & S-AF-15 & 5 & 1,62 & 0,13 & 0,06 & NS & FATOR 2- \\
\hline & S-CAP-15 & 7 & 1,59 & 0,04 & 0,02 & & Poluição- $p=$ \\
\hline & I-AF-30 & 5 & 1,64 & 0,14 & 0,06 & & FATOR 3- \\
\hline & I-CAP-30 & 6 & 1,59 & 0,10 & 0,04 & & lempo- $p=$ \\
\hline & S-AF-30 & 5 & 1,58 & 0,06 & 0,03 & & \\
\hline & S-CAP-30 & 5 & 1,56 & 0,12 & 0,05 & & \\
\hline
\end{tabular}


Anexo H. Tabelas Análise descritiva dos dados do LBA

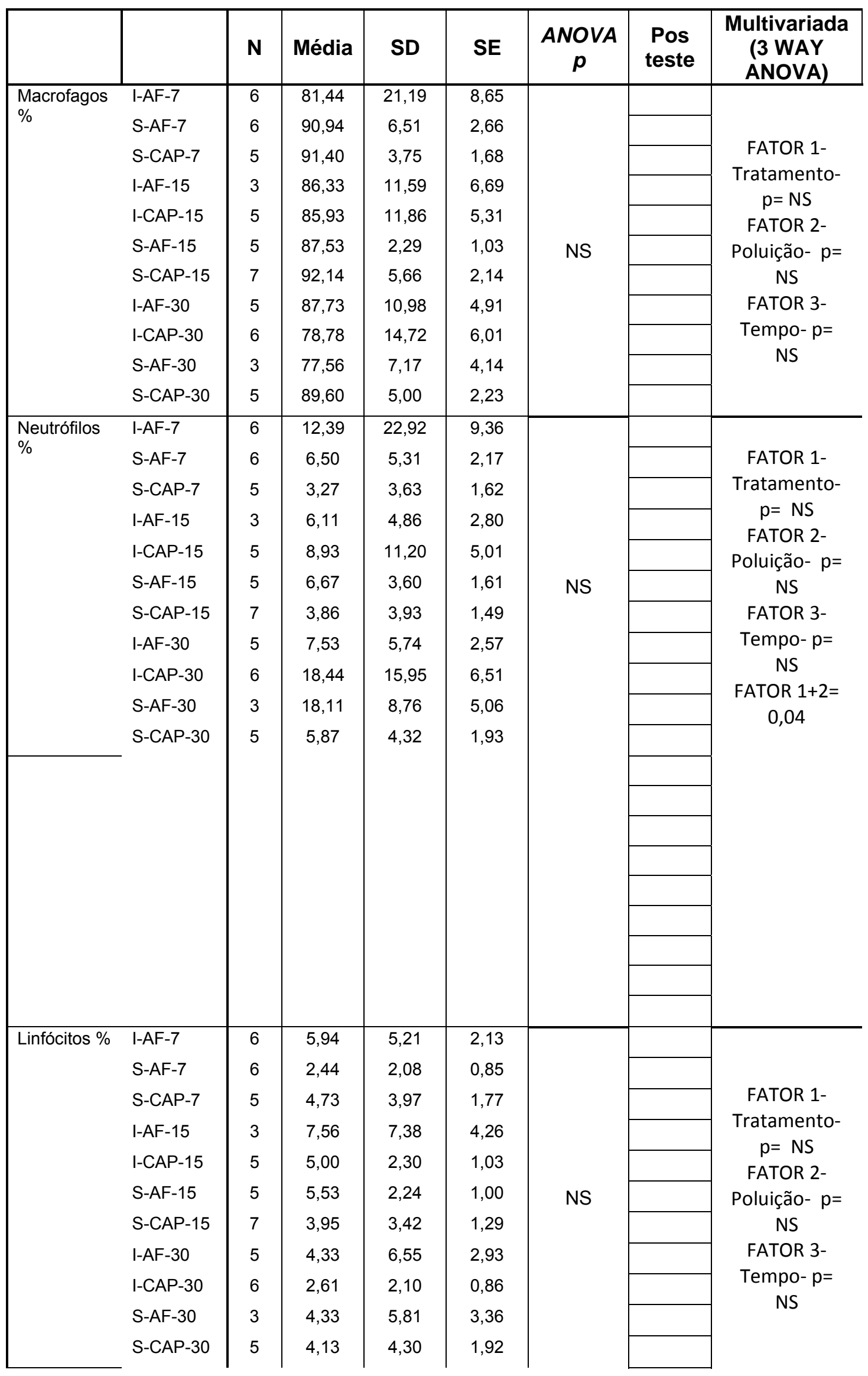




\begin{tabular}{|c|c|c|c|c|c|c|c|}
\hline \multirow{11}{*}{$\begin{array}{l}\text { Eosinófilos } \\
\%\end{array}$} & I-AF-7 & 6 & 0,22 & 0,40 & 0,16 & \multirow{11}{*}{ NS } & \multirow{11}{*}{$\begin{array}{c}\text { FATOR 1- } \\
\text { Tratamento- } \\
p=\text { NS } \\
\text { FATOR 2- } \\
\text { Poluição- } p= \\
\text { NS } \\
\text { FATOR 3- } \\
\text { Tempo- } p= \\
\text { NS }\end{array}$} \\
\hline & S-AF-7 & 6 & 0,11 & 0,17 & 0,07 & & \\
\hline & S-CAP-7 & 5 & 0,60 & 0,68 & 0,31 & & \\
\hline & I-AF-15 & 3 & 0,00 & 0,00 & 0,00 & & \\
\hline & I-CAP-15 & 5 & 0,13 & 0,18 & 0,08 & & \\
\hline & S-AF-15 & 5 & 0,27 & 0,43 & 0,19 & & \\
\hline & S-CAP-15 & 7 & 0,05 & 0,13 & 0,05 & & \\
\hline & I-AF-30 & 5 & 0,40 & 0,43 & 0,19 & & \\
\hline & I-CAP-30 & 6 & 0,17 & 0,41 & 0,17 & & \\
\hline & S-AF-30 & 3 & 0,00 & 0,00 & 0,00 & & \\
\hline & S-CAP-30 & 5 & 0,40 & 0,72 & 0,32 & & \\
\hline \multirow{11}{*}{$\begin{array}{l}\text { Macrofágos } \\
\mathrm{cel} / \mathrm{mL} \text { x105 }\end{array}$} & I-AF-7 & 6 & 0,72 & 0,52 & 0,21 & \multirow{11}{*}{0,001} & \multirow{11}{*}{$\begin{array}{c}\text { FATOR 1- } \\
\text { Tratamento- } \\
\mathrm{p}=\mathrm{ns} \\
\text { FATOR 2- } \\
\text { Poluição- } \mathrm{p}= \\
0,002 \\
\text { FATOR 3- } \\
\text { Tempo- } \mathrm{p}= \\
0,002 \\
\text { FATOR 3+2= } \\
0,01\end{array}$} \\
\hline & S-AF-7 & 6 & 1,14 & 0,70 & 0,28 & & \\
\hline & S-CAP-7 & 5 & 1,39 & 0,80 & 0,36 & & \\
\hline & I-AF-15 & 4 & 0,65 & 0,50 & 0,25 & & \\
\hline & I-CAP-15 & 5 & 2,11 & 1,22 & 0,54 & & \\
\hline & S-AF-15 & 5 & 0,54 & 0,33 & 0,15 & & \\
\hline & S-CAP-15 & 7 & 1,51 & 0,52 & 0,20 & & \\
\hline & I-AF-30 & 5 & 0,44 & 0,22 & 0,10 & & \\
\hline & I-CAP-30 & 6 & 0,65 & 0,37 & 0,15 & & \\
\hline & S-AF-30 & 3 & 0,55 & 0,39 & 0,23 & & \\
\hline & S-CAP-30 & 5 & 0,54 & 0,35 & 0,16 & & \\
\hline \multirow{11}{*}{$\begin{array}{l}\text { Neutrófilos } \\
\mathrm{cel} / \mathrm{mL} \times 105\end{array}$} & I-AF-7 & 6 & 17,78 & 26,36 & 10,76 & \multirow{11}{*}{ NS } & \multirow{11}{*}{$\begin{array}{c}\text { FATOR 1- } \\
\text { Tratamento- } \\
p=\text { NS } \\
\text { FATOR 2- } \\
\text { Poluição- } p= \\
\text { NS } \\
\text { FATOR 3- } \\
\text { Tempo- } p= \\
\text { NS FATOR } \\
1+2=0,01\end{array}$} \\
\hline & S-AF-7 & 6 & 16,91 & 13,17 & 5,38 & & \\
\hline & S-CAP-7 & 5 & 8,81 & 9,47 & 4,23 & & \\
\hline & I-AF-15 & 4 & 11,10 & 11,75 & 5,87 & & \\
\hline & I-CAP-15 & 5 & 19,90 & 22,06 & 9,87 & & \\
\hline & S-AF-15 & 5 & 16,17 & 9,44 & 4,22 & & \\
\hline & S-CAP-15 & 7 & 10,20 & 10,02 & 3,79 & & \\
\hline & $\mathrm{I}-\mathrm{AF}-30$ & 5 & 18,55 & 12,90 & 5,77 & & \\
\hline & I-CAP-30 & 6 & 37,76 & 27,42 & 11,19 & & \\
\hline & S-AF-30 & 3 & 41,20 & 16,56 & 9,56 & & \\
\hline & S-CAP-30 & 5 & 15,43 & 11,23 & 5,02 & & \\
\hline \multirow{11}{*}{$\begin{array}{l}\text { Linfócitos } \\
\text { cel/mL x105 }\end{array}$} & I-AF-7 & 6 & 0,83 & 0,76 & 0,31 & \multirow{11}{*}{ NS } & \multirow{11}{*}{$\begin{array}{c}\text { FATOR 1- } \\
\text { Tratamento- } \\
\mathrm{p}=\mathrm{NS} \\
\text { FATOR 2- } \\
\text { Poluição- } \mathrm{p}= \\
\text { NS } \\
\text { FATOR 3- } \\
\text { Tempo- } \mathrm{p}= \\
\text { NS }\end{array}$} \\
\hline & S-AF-7 & 6 & 0,61 & 0,58 & 0,24 & & \\
\hline & S-CAP-7 & 5 & 0,30 & 0,19 & 0,09 & & \\
\hline & I-AF-15 & 4 & 1,46 & 2,27 & 1,14 & & \\
\hline & I-CAP-15 & 5 & 1,42 & 1,89 & 0,85 & & \\
\hline & S-AF-15 & 5 & 0,84 & 0,21 & 0,09 & & \\
\hline & S-CAP-15 & 7 & 0,51 & 0,78 & 0,29 & & \\
\hline & I-AF-30 & 5 & 1,41 & 2,70 & 1,21 & & \\
\hline & I-CAP-30 & 6 & 0,82 & 0,54 & 0,22 & & \\
\hline & S-AF-30 & 3 & 1,76 & 1,82 & 1,05 & & \\
\hline & S-CAP-30 & 5 & 0,67 & 0,62 & 0,28 & & \\
\hline Eosinófilos & I-AF-7 & 6 & 0,05 & 0,10 & 0,04 & NS & FATOR 1- \\
\hline
\end{tabular}




\begin{tabular}{|c|c|c|c|c|c|c|}
\hline \multirow[t]{10}{*}{$\mathrm{cel} / \mathrm{mL} \times 105$} & S-AF-7 & 6 & 0,01 & 0,02 & 0,01 & \multirow{10}{*}{$\begin{array}{c}\text { Tratamento- } \\
p=\text { NS } \\
\text { FATOR 2- } \\
\text { Poluição- } p= \\
\text { NS } \\
\text { FATOR 3- } \\
\text { Tempo- } p= \\
\text { NS }\end{array}$} \\
\hline & S-CAP-7 & 5 & 0,07 & 0,09 & 0,04 & \\
\hline & $\mathrm{I}-\mathrm{AF}-15$ & 4 & 0,00 & 0,00 & 0,00 & \\
\hline & I-CAP-15 & 5 & 0,02 & 0,03 & 0,01 & \\
\hline & S-AF-15 & 5 & 0,04 & 0,06 & 0,03 & \\
\hline & S-CAP-15 & 7 & 0,00 & 0,01 & 0,00 & \\
\hline & $\mathrm{I}-\mathrm{AF}-30$ & 5 & 0,10 & 0,21 & 0,09 & \\
\hline & I-CAP-30 & 6 & 0,01 & 0,02 & 0,01 & \\
\hline & S-AF-30 & 3 & 0,00 & 0,00 & 0,00 & \\
\hline & S-CAP-30 & 5 & 0,01 & 0,01 & 0,01 & \\
\hline
\end{tabular}

\section{Anexo I. Tabelas Análise descritiva dos dados do Hemograma}

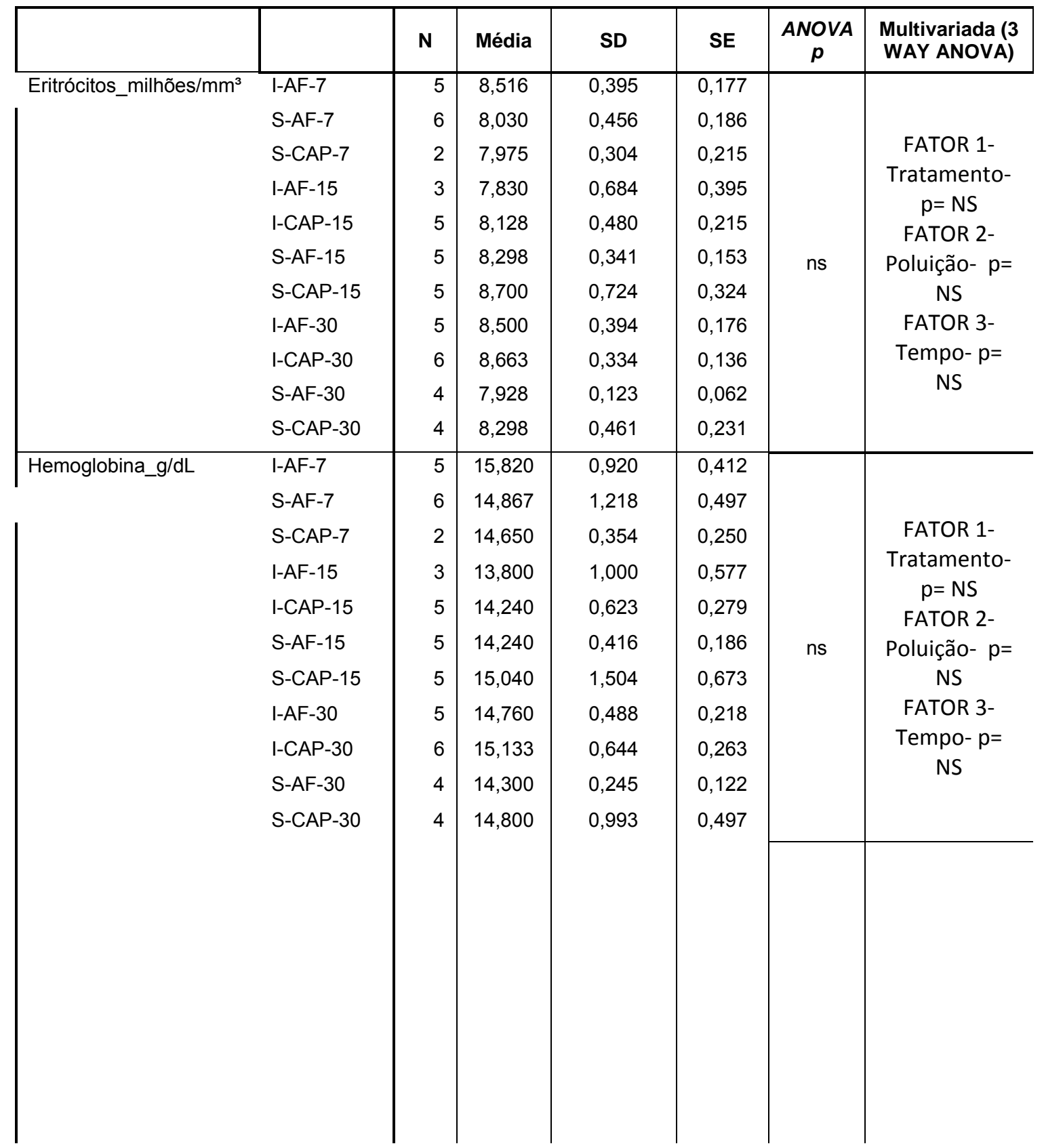




\begin{tabular}{|c|c|c|c|c|c|c|c|}
\hline \multirow[t]{11}{*}{ Hematócrito_\% } & I-AF-7 & 5 & 47,680 & 2,847 & 1,273 & \multirow{11}{*}{,017 } & \multirow{11}{*}{$\begin{array}{c}\text { FATOR 1- } \\
\text { Tratamento- } \\
\mathrm{p}=\mathrm{NS} \\
\text { FATOR 2- } \\
\text { Poluição- } \mathrm{p}= \\
\text { NS } \\
\text { FATOR 3- } \\
\text { Tempo- } \mathrm{p}= \\
0,02 \quad \text { FATOR } \\
2+3=0,02\end{array}$} \\
\hline & S-AF-7 & 6 & 43,733 & 2,990 & 1,221 & & \\
\hline & S-CAP-7 & 2 & 44,700 & 1,273 & 0,900 & & \\
\hline & I-AF-15 & 3 & 41,067 & 2,113 & 1,220 & & \\
\hline & I-CAP-15 & 5 & 43,000 & 1,684 & 0,753 & & \\
\hline & S-AF-15 & 5 & 42,400 & 1,185 & 0,530 & & \\
\hline & S-CAP-15 & 5 & 44,460 & 3,807 & 1,703 & & \\
\hline & $\mathrm{I}-\mathrm{AF}-30$ & 5 & 45,240 & 2,476 & 1,108 & & \\
\hline & I-CAP-30 & 6 & 45,850 & 2,104 & 0,859 & & \\
\hline & S-AF-30 & 4 & 42,075 & 0,624 & 0,312 & & \\
\hline & S-CAP-30 & 4 & 43,725 & 2,959 & 1,480 & & \\
\hline \multirow[t]{11}{*}{ VCM_fL } & I-AF-7 & 5 & 56,060 & 0,709 & 0,317 & \multirow{11}{*}{,002 } & \multirow{11}{*}{$\begin{array}{c}\text { FATOR 1- } \\
\text { Tratamento- } \\
p=0,04 \\
\text { FATOR 2- } \\
\text { Poluição- } p= \\
\text { NS } \\
\text { FATOR 3- } \\
\text { Tempo- } p= \\
0,001\end{array}$} \\
\hline & S-AF-7 & 6 & 54,483 & 2,718 & 1,110 & & \\
\hline & S-CAP-7 & 2 & 56,050 & 0,495 & 0,350 & & \\
\hline & I-AF-15 & 3 & 52,567 & 1,888 & 1,090 & & \\
\hline & I-CAP-15 & 5 & 52,980 & 2,306 & 1,031 & & \\
\hline & S-AF-15 & 5 & 51,140 & 0,948 & 0,424 & & \\
\hline & S-CAP-15 & 5 & 51,080 & 0,817 & 0,365 & & \\
\hline & I-AF-30 & 5 & 53,260 & 2,399 & 1,073 & & \\
\hline & I-CAP-30 & 6 & 52,900 & 1,114 & 0,455 & & \\
\hline & S-AF-30 & 4 & 53,100 & 1,564 & 0,782 & & \\
\hline & S-CAP-30 & 4 & 52,725 & 2,287 & 1,143 & & \\
\hline \multirow[t]{11}{*}{ HCM_pg } & I-AF-7 & 5 & 18,600 & 0,235 & 0,105 & \multirow{11}{*}{, 000} & \multirow{11}{*}{$\begin{array}{c}\text { FATOR 1- } \\
\text { Tratamento- } \\
p=N S \\
\text { FATOR 2- } \\
\text { Poluição- } p= \\
\text { NS } \\
\text { FATOR 3- } \\
\text { Tempo- } p= \\
0,001 \\
\text { FATOR 1+3 } \\
\text { P=0,04 }\end{array}$} \\
\hline & S-AF-7 & 6 & 18,517 & 0,924 & 0,377 & & \\
\hline & S-CAP-7 & 2 & 18,400 & 0,283 & 0,200 & & \\
\hline & I-AF-15 & 3 & 17,633 & 0,306 & 0,176 & & \\
\hline & I-CAP-15 & 5 & 17,540 & 0,568 & 0,254 & & \\
\hline & S-AF-15 & 5 & 17,200 & 0,255 & 0,114 & & \\
\hline & S-CAP-15 & 5 & 17,280 & 0,517 & 0,231 & & \\
\hline & I-AF-30 & 5 & 17,380 & 0,449 & 0,201 & & \\
\hline & I-CAP-30 & 6 & 17,433 & 0,103 & 0,042 & & \\
\hline & S-AF-30 & 4 & 18,025 & 0,562 & 0,281 & & \\
\hline & S-CAP-30 & 4 & 17,850 & 0,557 & 0,278 & & \\
\hline \multirow[t]{11}{*}{ CHCM_d/dL } & I-AF-7 & 5 & 33,180 & 0,239 & 0,107 & \multirow{11}{*}{, 011} & \multirow{11}{*}{$\begin{array}{c}\text { FATOR 1- } \\
\text { Tratamento- } \\
p=0,0001 \\
\text { FATOR 2- } \\
\text { Poluição- } p= \\
\text { NS } \\
\text { FATOR 3- } \\
\text { Tempo- } p= \\
\text { NS }\end{array}$} \\
\hline & S-AF-7 & 6 & 33,983 & 0,741 & 0,303 & & \\
\hline & S-CAP-7 & 2 & 32,800 & 0,141 & 0,100 & & \\
\hline & I-AF-15 & 3 & 33,567 & 0,777 & 0,448 & & \\
\hline & I-CAP-15 & 5 & 33,120 & 0,444 & 0,198 & & \\
\hline & S-AF-15 & 5 & 33,600 & 0,283 & 0,126 & & \\
\hline & S-CAP-15 & 5 & 33,800 & 0,959 & 0,429 & & \\
\hline & $\mathrm{I}-\mathrm{AF}-30$ & 5 & 32,660 & 0,838 & 0,375 & & \\
\hline & I-CAP-30 & 6 & 33,000 & 0,607 & 0,248 & & \\
\hline & S-AF-30 & 4 & 34,000 & 0,316 & 0,158 & & \\
\hline & S-CAP-30 & 4 & 33,850 & 0,480 & 0,240 & & \\
\hline RDW-CV_\% & I-AF-7 & 5 & 18,760 & 0,611 & 0,273 & ,000 & FATOR 1- \\
\hline
\end{tabular}




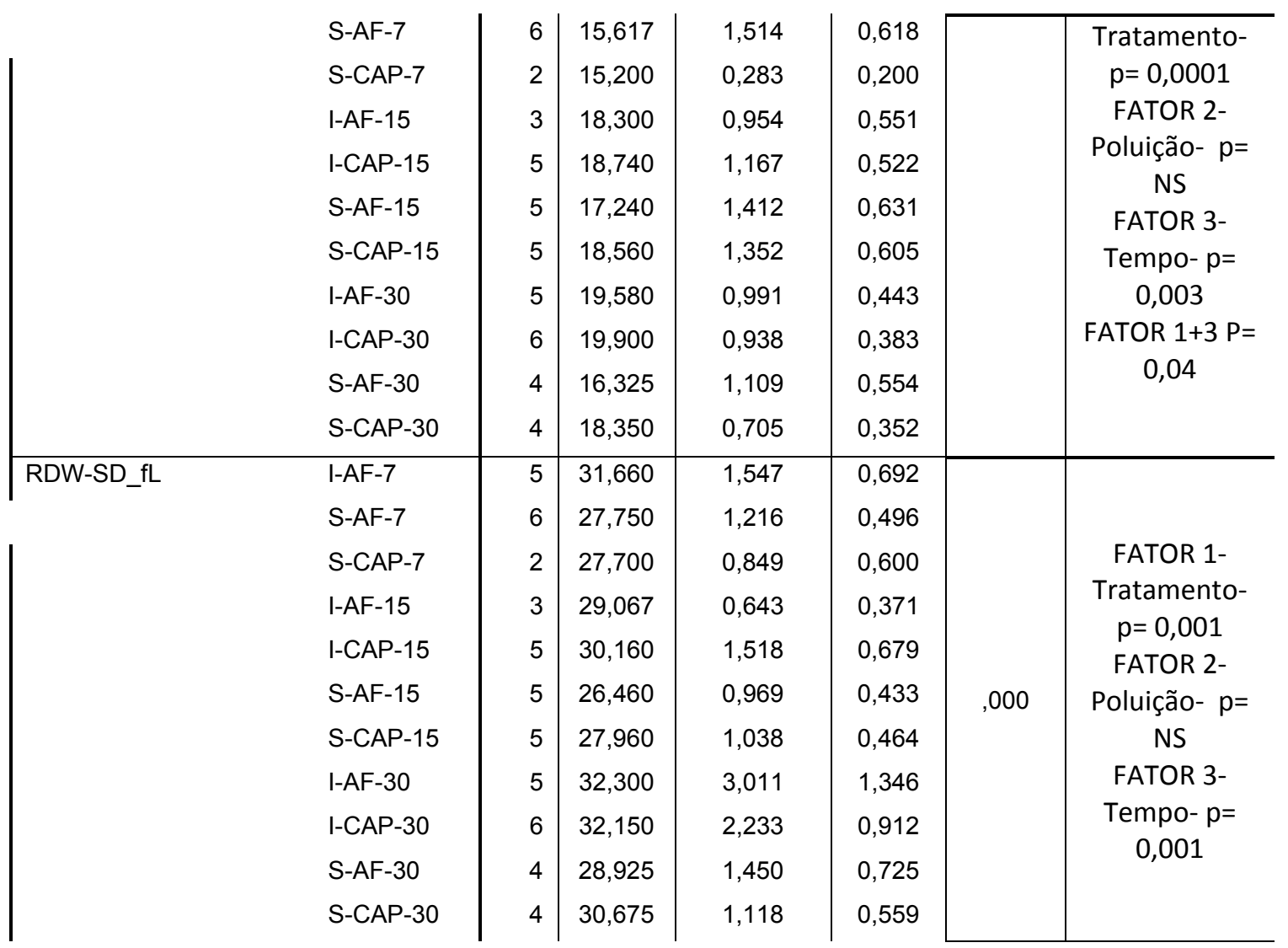

Anexo J. Tabelas Análise descritiva dos dados eletrocardiográficos

Dependent Variable:SDNN (ms)
\begin{tabular}{|cc|c|c|c|}
\hline Exposição & Tratamento & Média & SD & N \\
\hline \multirow{2}{*}{ ar filtrado } & salina & 28,54 & 20,366 & 57 \\
& ISOP & 23,90 & 25,398 & 72 \\
\hline \multirow{2}{*}{ CAP } & salina & 34,53 & 22,831 & 70 \\
& ISOP & 32,95 & 25,485 & 64 \\
\hline
\end{tabular}

Tests of Between-Subjects Effects

Dependent Variable:SDNN (ms)

\begin{tabular}{|l|r|r|r|r|r|}
\hline Source & $\begin{array}{c}\text { Type III Sum } \\
\text { of Squares }\end{array}$ & df & Mean Square & \multicolumn{1}{c|}{ F } & \multicolumn{1}{c|}{ Sig. } \\
\hline Corrected Model & $25746,826^{\text {a }}$ & 4 & 6436,707 & 13,290 &, 000 \\
Intercept & 41227,544 & 1 & 41227,544 & 85,123 &, 000 \\
dia & 20956,562 & 1 & 20956,562 & 43,270 &, 000 \\
poluição & 3532,386 & 1 & 3532,386 & 7,293 &, 007 \\
trat & 620,222 & 1 & 620,222 & 1,281 &, 259 \\
poluição * trat & 87,800 & 1 & 87,800 &, 181 &, 671 \\
Error & 124956,201 & 258 & 484,326 & & \\
Total & 386444,000 & 263 & & & \\
Corrected Total & 150703,027 & 262 & & & \\
\hline
\end{tabular}


Dependent Variable:RMSSD (ms)

\begin{tabular}{|ll|c|c|c|}
\hline \multicolumn{1}{|c|}{ Exposição } & Tratamento & Média & SD & N \\
\hline ar filtrado & salina & 34,37 & 24,087 & 57 \\
& ISOP & 29,74 & 31,174 & 72 \\
\hline CAP & salina & 41,70 & 27,462 & 70 \\
& ISOP & 40,69 & 31,591 & 64 \\
\hline
\end{tabular}

Tests of Between-Subjects Effects

Dependent Variable:RMSSD (ms)

\begin{tabular}{|l|r|r|r|r|r|}
\hline Source & $\begin{array}{c}\text { Type III Sum } \\
\text { of Squares }\end{array}$ & df & Mean Square & \multicolumn{1}{|c|}{ F } & \multicolumn{1}{c|}{ Sig. } \\
\hline Corrected Model & $35913,448^{\mathrm{a}}$ & 4 & 8978,362 & 12,384 &, 000 \\
Intercept & 63617,663 & 1 & 63617,663 & 87,747 &, 000 \\
dia & 29347,497 & 1 & 29347,497 & 40,479 &, 000 \\
poluição & 5229,361 & 1 & 5229,361 & 7,213 &, 008 \\
trat & 508,960 & 1 & 508,960 &, 702 &, 403 \\
poluição * trat & 122,238 & 1 & 122,238 &, 169 &, 682 \\
Error & 187052,202 & 258 & 725,009 & & \\
Total & 575065,000 & 263 & & & \\
Corrected Total & 222965,650 & 262 & & & \\
\hline
\end{tabular}


Dependent Variable:LF $\left(\mathrm{ms}^{2}\right)$

\begin{tabular}{|ll|c|r|r|}
\hline poluição & trat & Mean & $\begin{array}{c}\text { Std. } \\
\text { Deviation }\end{array}$ & \multicolumn{1}{c|}{$\mathrm{N}$} \\
\hline ar filtrado & salina & 129,04 & 149,5 & 57 \\
& ISOP & 131,17 & 200,3 & 72 \\
\hline CAP & salina & 188,54 & 211,5 & 70 \\
& ISOP & 180,02 & 235,8 & 64 \\
\hline
\end{tabular}

Tests of Between-Subjects Effects

Dependent Variable:LF $\left(\mathrm{ms}^{2}\right)$

\begin{tabular}{|l|r|r|r|r|r|}
\hline Source & $\begin{array}{c}\text { Type III Sum } \\
\text { of Squares }\end{array}$ & df & Mean Square & \multicolumn{1}{c|}{ F } & Sig. \\
\hline Corrected Model & $1,917 \mathrm{E}+06$ & 4 & 479252,8 & 13,788 &, 000 \\
Intercept & 413506,741 & 1 & 413506,7 & 11,896 &, 001 \\
dia & $1,721 \mathrm{E}+06$ & 1 & 1721032,4 & 49,514 &, 000 \\
poluição & 181461,660 & 1 & 181461,7 & 5,221 &, 023 \\
trat & 578,607 & 1 & 578,6 &, 017 &, 897 \\
poluição * trat & 4935,898 & 1 & 4935,9 &, 142 &, 707 \\
Error & $8,968 \mathrm{E}+06$ & 258 & 34758,7 & & \\
Total & $1,744 \mathrm{E}+07$ & 263 & & & \\
Corrected Total & $1,088 \mathrm{E}+07$ & 262 & & & \\
\hline
\end{tabular}

Dependent Variable:HF $\left(\mathrm{ms}^{2}\right)$
\begin{tabular}{|ll|r|r|r|}
\hline \multirow{2}{*}{ poluição } & trat & \multicolumn{1}{c|}{ Mean } & \multicolumn{1}{c|}{$\begin{array}{c}\text { Std. } \\
\text { Deviation }\end{array}$} & \multicolumn{1}{c|}{$\mathrm{N}$} \\
\hline ar filtrado & salina & 89,16 & 109,694 & 57 \\
& ISOP & 84,21 & 129,001 & 72 \\
\hline CAP & salina & 130,46 & 135,000 & 70 \\
& ISOP & 121,36 & 147,107 & 64 \\
\hline
\end{tabular}


Tests of Between-Subjects Effects

Dependent Variable:HF $\left(\mathrm{ms}^{2}\right)$

\begin{tabular}{|l|r|r|r|r|r|}
\hline Source & $\begin{array}{c}\text { Type III Sum } \\
\text { of Squares }\end{array}$ & df & Mean Square & \multicolumn{1}{c|}{ F } & \multicolumn{1}{c|}{ Sig. } \\
\hline Corrected Model & $773547,328^{\mathrm{a}}$ & 4 & 193386,832 & 13,096 &, 000 \\
Intercept & 238967,067 & 1 & 238967,067 & 16,182 &, 000 \\
dia & 666323,663 & 1 & 666323,663 & 45,122 &, 000 \\
poluição & 95840,797 & 1 & 95840,797 & 6,490 &, 011 \\
trat & 3093,155 & 1 & 3093,155 &, 209 &, 648 \\
poluição * trat & 1134,887 & 1 & 1134,887 &, 077 &, 782 \\
Error & 3809905,896 & 258 & 14767,077 & & \\
Total & 7573818,000 & 263 & & & \\
Corrected Total & 4583453,224 & 262 & & & \\
\hline
\end{tabular}

Dependent Variable:LF/HF
\begin{tabular}{|ll|r|r|r|}
\hline \multirow{2}{*}{ poluição } & trat & Mean & $\begin{array}{c}\text { Std. } \\
\text { Deviation }\end{array}$ & \multicolumn{1}{c|}{$\mathrm{N}$} \\
\hline ar filtrado & salina & 1,35 & 1,737 & 57 \\
& ISOP & 1,14 & 1,052 & 72 \\
\hline CAP & salina & 1,21 & 1,203 & 70 \\
& ISOP & 1,11 & 1,129 & 64 \\
\hline
\end{tabular}

Tests of Between-Subjects Effects

Dependent Variable:LF/HF

\begin{tabular}{|c|c|c|c|c|c|}
\hline Source & $\begin{array}{l}\text { Type III Sum } \\
\text { of Squares }\end{array}$ & df & Mean Square & $F$ & Sig. \\
\hline Corrected Model & $5,497^{a}$ & 4 & 1,374 &, 836 &, 503 \\
\hline Intercept & 124,870 & 1 & 124,870 & 75,942 &, 000 \\
\hline dia & 3,392 & 1 & 3,392 & 2,063 & ,152 \\
\hline poluição & ,472 & 1 & ,472 & ,287 &, 593 \\
\hline trat & 1,631 & 1 & 1,631 & ,992 & ,320 \\
\hline poluição * trat & , 155 & 1 & , 155 & ,094 & ,759 \\
\hline Error & 424,221 & 258 & 1,644 & & \\
\hline Total & 807,000 & 263 & & & \\
\hline Corrected Total & 429,719 & 262 & & & \\
\hline
\end{tabular}


Descriptive Statistics

Dependent Variable:BPM (FC)
\begin{tabular}{|ll|r|r|r|}
\hline \multirow{2}{*}{ poluição } & trat & Mean & $\begin{array}{c}\text { Std. } \\
\text { Deviation }\end{array}$ & \multicolumn{1}{c|}{ N } \\
\hline ar filtrado & salina & 288,91 & 31,684 & 56 \\
& ISOP & 278,74 & 29,594 & 72 \\
\hline CAP & salina & 277,17 & 36,112 & 70 \\
& ISOP & 267,36 & 35,339 & 64 \\
\hline
\end{tabular}

Tests of Between-Subjects Effects

Dependent Variable:BPM (FC)

\begin{tabular}{|l|r|r|r|r|r|}
\hline Source & $\begin{array}{c}\text { Type III Sum } \\
\text { of Squares }\end{array}$ & df & Mean Square & \multicolumn{1}{c|}{$\mathrm{F}$} & \multicolumn{1}{c|}{ Sig. } \\
\hline Corrected Model & $30175,603^{\mathrm{a}}$ & 4 & 7543,901 & 7,184 &, 000 \\
Intercept & $9,014 \mathrm{E}+06$ & 1 & $9,014 \mathrm{E}+06$ & 8584,191 &, 000 \\
dia & 16197,289 & 1 & 16197,289 & 15,425 &, 000 \\
poluição & 8413,784 & 1 & 8413,784 & 8,013 &, 005 \\
trat & 6466,249 & 1 & 6466,249 & 6,158 &, 014 \\
poluição * trat & 14,794 & 1 & 14,794 &, 014 &, 906 \\
Error & 269859,928 & 257 & 1050,039 & & \\
Total & $2,051 \mathrm{E}+07$ & 262 & & & \\
Corrected Total & 300035,531 & 261 & & & \\
\hline
\end{tabular}


Descriptive Statistics

Dependent Variable:PA (mmHg)
\begin{tabular}{|ll|c|r|r|}
\hline \multirow{2}{*}{ poluição } & trat & Mean & $\begin{array}{c}\text { Std. } \\
\text { Deviation }\end{array}$ & \multicolumn{1}{c|}{ N } \\
\hline ar filtrado & salina & 144,75 & 23,768 & 57 \\
& ISOP & 136,10 & 48,908 & 71 \\
\hline CAP & salina & 137,40 & 22,256 & 70 \\
& ISOP & 124,94 & 25,068 & 64 \\
\hline
\end{tabular}

Tests of Between-Subjects Effects

Dependent Variable:PA (mmHg)

\begin{tabular}{|l|r|r|r|r|r|}
\hline Source & $\begin{array}{c}\text { Type III Sum } \\
\text { of Squares }\end{array}$ & df & Mean Square & F & Sig. \\
\hline Corrected Model & $12314,369^{a}$ & 4 & 3078,592 & 2,900 &, 023 \\
Intercept & 2005764,390 & 1 & 2005764,390 & 1889,398 &, 000 \\
dia & 17,072 & 1 & 17,072 &, 016 &, 899 \\
poluição & 5577,532 & 1 & 5577,532 & 5,254 &, 023 \\
trat & 7243,579 & 1 & 7243,579 & 6,823 &, 010 \\
poluição * trat & 238,421 & 1 & 238,421 &, 225 &, 636 \\
Error & 272828,349 & 257 & 1061,589 & & \\
Total & 5102848,000 & 262 & & & \\
Corrected Total & 285142,718 & 261 & & & \\
\hline
\end{tabular}




\section{REFERÊNCIAS BIBLIOGRÁFICAS}

Acharya, U.R.; Joseph, K.P.; Kannathal, N.; Lim, C.M.; Suri, J.S. Heart rate variability: a review. Med. Bio. Eng. Comput. 2006. 44:1031-1051.

Achten, J.; Jeukendrup, A.E. Heart rate monitoring: applications and limitations. Sports Med. 2003. 33(7):517-38.

Adar, S.D.; Gold, D.R.; Coull, B.A.; Schwartz, J. Stone, P.H.; Suh, H. Focused exposures to airborne traffic particles and heart rate variability in the elderly. Epidemiology. 2007. 18(1):95-103.

Albanesi, F.M. Cardiomiopatia Hipertrófica. Conceito e Classificação. Arq. Bras. Cardiol. 1996. Vol. 66 ( $\left.n^{\circ} 2\right)$.

Anderson, J.O.; Thundiyil, J.G.; Stolbach, A. Clearing the air: a review of the effects of particulate matter air pollution on human health. J. Med. Toxicol. 2012. 8:166-175.

Anselme, F.; Loriot, S.; Henry, J.P.; Dionnet, F.; Napoleoni, J.G; Thuillez, C.; Morin, J.P. Inhalation of diluted diesel engine emission impacts heart rate variability and arrhythmia occurrence in a rat model of chronic ischemic heart failure. Arch. Toxicol. 2007. 81:299-307.

Asokan, S.K. Experimental lead cardiomyopathy: myocardial structural changes in rats given small amounts of lead. J. Lab. Clin. Med. 1974. Jul;84(1):20-5.

Aubert, A.E.; Ramaekers, D.; Beckers, F.; Breem, R.; Denef, C.; Van de Werf, F.; Ector, $\mathrm{H}$. The analysis of heart rate variability in unrestrained rats. Validation of method and results. Comput. Methods Programs Biomed. 1999. Nov;60(3):197213.

Ayres, J.G. Cardiovascular Disease and Air Pollution - A report by the Commitee on the Medical Effects of Air Pollutants. 2006. Disponível em: http//:www.Advisory bodies.doh.gov.uk/comeap//CardioDisease.pdf. Acesso em 07 de Junho de 2012. 
Azevedo, F.A.; Chasin, A.A.M. As bases toxicológicas da ecotoxicologia. RIMA São Carlos ISBN - 85-86552-64-x. Intertox - São Paulo. 2003. p:173-181.

Ballester, F.; Medina, S.; Boldo, E.; Goodman, P.; Neuberger, M.; Iñiguez, C.; Künzli, N. Reducing ambient levels of fine particulates could substantially improve health: a mortality impact assessment for 26 European cities. J. Epidemiol. Community Health; 2008. Vol. 62, p:98-105.

Bergfeldt, B.L.; Edhag, K.O.; Solders, G.; Vallin, H.O. Analysis of sinus cycle variation: a new method for evaluation of suspected sinus node dysfunction. Am. Heart J. 1987 Aug;114(2):321-7.

Bergfeldt, L.; Rosenqvist, M.; Vallin, H.; Nordlander, R.; Aström, H. Screening for sinus node dysfunction by analysis of short-term sinus cycle variations on the surface electrocardiogram. Am. Heart J. 1995 Jul;130(1):141-7.

Bohachick, P.; Rongaus, A. M. Hypertrophic Cardiomyopathy. The American Journal of Nursing, 1984. Vol. 84, No. 3, pp. 320-326.

Braga, A.L.F.; Zanobetti, A.; Schwartz, J. The lag structure between particulate air pollution and respiratory and cardiovascular deaths in 10 US cities. J. Occup. Environ. Med. 2001. Vol. 43. p: 927-933.

Braga, A.L.F.; Pereira, L.A.A.; Procópio, M.; André, P.A.; Saldiva P.H. Associação entre poluição atmosférica e doenças respiratórias e cardiovasculares na cidade de Itabira, Minas Gerais, Brasil. Cad. Saúde pública, Rio de Janeiro, 2007. 23 Sup 4:S570-S578.

Brasileiro Filho, G.; Bogliolo, L. Bogliolo patologia. 8. ed. Rio de Janeiro : Guanabara Koogan. 2011. 457-467p.

Braun, S.; Appel, L.G.; Schmal, M. A Poluição gerada por máquinas de combustão interna movidas a diesel - A questão dos particulados. Estratégias atuais para a redução e controle das emissões e tendências futuras. Quim. Nova, 2003. Vol. 27, No. 3, 472-482. 
Braunwald, E.; Douglas, P.; Zipes, P.L.; Robert, O.B. Braunwald's heart disease: a textbook of cardiovascular medicine. 7ed. W.B. Saunders Company. 2005. 1659-1682p.

Brito, J.M.; Belotti, L.; Toledo, A.C.; Antonangelo, L.; Silva, F.S.; Alvim, D.S.; Andre, P.A.; Saldiva, P.H.; Rivero, D.H. Acute cardiovascular and inflammatory toxicity induced by inhalation of diesel and biodiesel exhaust particles. Toxicol. Sci. 2010. Jul;116(1):67-78.

Brook, R. D. Cardiovascular effects of air pollution. Clinical Science, 2008. 115, 175-187.

Brook, R.D.; Rajagopalan, S.; Pope, C.A. 3rd; Brook, J.R.; Bhatnagar, A.; DiezRoux, A.V.; Holguin, F.; Hong, Y.; Luepker, R.V.; Mittleman, M.A.; Peters, A.; Siscovick, D.; Smith, S.C. Jr.; Whitsel, L.; Kaufman, J.D. Particulate Matter Air Pollution and Cardiovascular Disease: An Update to the Scientific Statement from the American Heart Association. Circulation. 2010. 1;121(21):2331-78.

Brüel, A.; Oxlund, H.; Nyengaard, J.R. Growth hormone increases the total number of cardiac myocyte nuclei in young rats but not in old rats. Mech. Ageing. Dev. 2002; 123:1353-1362.

Brüel A, Oxlund H, Nyengaard JR. The total length of myocytes and capillaries, and total number of myocyte nuclei in the rat heart are time-dependently increased by growth hormone. Growth Horm, IGF. Res. 2005; 15: 256-264.

Brunekreef, B.; Holgate, S.T. Air pollution and health. Lancet. 2002. 360: 1233-42

Brunton, L.L.; Lazo, J.S.; Parker, K.L. Goodman \& Gilman: As bases Farmacológicas da Terapêutica. 11ed. AMGH. 2010. 127-160p.; 215-226p.

Burgan, O.; Smargiassi, A.; Perron. S.; Kosatsky, T. Cardiovascular effects of sub-daily levels of ambient fine particles: a systematic review. Environ. Health. 2010. 15;9:26. 
Cadle, S.H.; Mulawa, P.H.; Ball, J.; Donase, C.; Weibel, A.; Sagebiel, J.C.; Knapp, K.; Snow, R. Particulate Emission Rates from In-Use High-Emitting Vehicles Recruited in Orange County, California. Environ Sci Technol.; 1997. 31(12):340512.

Campen, M.J.; Nolan, J.P.; Schladweiler, M.C.; Kodavanti, U.P.; Evansky, P.A.; Costa, D.L.; Watkinson, W.P. Cardiovascular and thermoregulatory effects of inhaled PM-associated transition metals: a potential interaction between nickel and vanadium sulfate. Toxicol. Sci. 2001. Dec;64(2):243-52.

Cançado, J.E.D.; Braga, A.; Pereira, L.A.A.; Arbex, M.A.; Saldiva, P.H.; Santos, U.P. Repercussões clínicas da exposição à poluição atmosférica. J. Bras. Pneumol.; 2006. 32 (Supl. 1):S5-S11.

Caplain, I; Cazier, F.; Nouali, H.; Mercier, A.; Déchaux, J.; Nollet, V.; Joumard, R.; André, J.; Vidon, R. Emissions of unregulated pollutants from European gasoline and diesel passenger cars. Atmospheric Environment. 2006. 40:5954-5966

Carmo, W.B.; Almeida, S.C.; Rezende, F.C.M.; Oliveira, V.K.; Henriques, D.M.N.; Andrad, L.C.; Alves, M.J.M.; Bastos, M.G.; Paula, R.B. Hipertensão arterial e hipertrofia ventricular esquerda em pacientes renais crônicos em tratamento hemodialítico. J. Bras. Nefrol.; 2003. 25(1):1-9.

Cerutti, C.; Gustin, M.P.; Paultre, C.Z.; Lo, M.; Julien, C.; Vincent, M.; Sassard, J. Autonomic nervous system and cardiovascular variability in rats: a spectral analysis approach. Am. J. Physiol. 1991. Oct;261(4 Pt 2):H1292-9.

Cetesb. Material Particulado Inalável Fino $\left(\mathrm{MP}_{2,5}\right)$ e Grosso $\left(\mathrm{MP}_{2,5}-{ }_{10}\right)$ na Atmosfera da Região Metropolitana de São Paulo (2000 - 2006). 2008a. Disponível em: http://www.cetesb.sp.gov.br/ar/qualidade-do-ar/31-publicacoes-erelatorios (outros relatórios). p.17. Acesso em 10 de Abril de 2010.

Cetesb. Relatório de qualidade do ar no estado de São Paulo 2007 - São Paulo : CETESB, 2008b. Série Relatórios / CETESB, ISSN 0103-4103. 40-50 p.: il. color. 
Cetesb. Relatório de qualidade do ar no estado de São Paulo 2008/ CETESB. São Paulo : CETESB, 2009. Série Relatórios / CETESB, ISSN 0103-4103. 290 p. : il. color.

Cetesb. Relatório de qualidade do ar no estado de São Paulo 2009/ CETESB. São Paulo : CETESB, 2010. Série Relatórios / CETESB, ISSN 0103-4103. 290 p. : il. color.

Cetesb. Relatório de qualidade do ar no estado de São Paulo 2010/ CETESB. São Paulo : CETESB, 2011. Série Relatórios / CETESB, ISSN 0103-4103. 67 p. : il. color.

Cetesb. Relatório de qualidade do ar no estado de São Paulo 2011/ CETESB. São Paulo : CETESB, 2012. Série Relatórios / CETESB, ISSN 0103-4103. 37-40p

Chang, L.T.; Tang, C.S.; Pan, Y.Z.; Chan, C.C. Association of Heart Rate Variability of the Elderly with Personal Exposure to PM1, PM1-2.5, and PM2.510. Bull. Environ. Contam. Toxicol. 2007 Nov;79(5):552-6.

Charpentier, F.; Baudet, S.; Le Marec, H. Triggered activity as a possible mechanism for arrhythmias in ventricular hypertrophy. Pacing. Clin. Electrophysiol. 1991. 14:1735-41.

CONAMA N. ${ }^{\circ}$ 18, de 6 de Maio de 1986. http://www.mma.gov.br/port/conama/res /res86/res1886.html. Acesso em 02 de Fevereiro de 2009.

CONAMA N. ${ }^{\circ}$ 3, de 28 de Junho de 1990. http://www. mma.gov.br/port/conama/r es/res90/res0390.html. Acesso em 02 de Fevereiro de 2009.

CONAMA n 418, de 25 de Novembro de 2009. http://www.mma.gov.br/port/cona ma/legiabre.cfm?codlegi=618. Acesso em 01 de Agosto de 2011.

Controlar - Programa de Inspeção e Manutenção de Veículos em Uso. 2010. http://www.controlar.com.br/OPrograma_SobreOPrograma.aspx. Acesso em 11 de Maio de 2011. 
Costa, E. A. S.; Luna, B. Fo; Póvoa, R.; Ferreira, C. Fo; Murad, N.; Ferreira, M.; Ferreira, C. Enalaprilato na Prevenção da Hipertrofia Ventricular Esquerda Induzida pelo Isoproterenol Arq. Bras. Cardiol. 1997. Vol.69 n.1 São Paulo.

Costa, D.L.; Dreher, K.L. Bioavailable transition metals in particulate matter mediate cardiopulmonary injury in healthy and compromised animal models. Environ. Health Perspect. 1997. Sep;105 Suppl 5:1053-60.

Courtois, A.; Andujar, P.; Ladeiro, Y.; Baudrimont, I.; Delannoy, E.; Leblais, V.; Begueret, H.; Galland, M.A.B. ; Brochand, P.; Marano, F. Impairament of $\mathrm{NO}$ - dependent relaxation in intralobar pulmonary arteries: comparison of urban particulate matter and manufactured nanoparticles. Environmental Health Perspectives. 2008. Vol. 116, No 10, P. 1294-1299.

Craig, L.; Brook, J.R.; Chiotti, Q.; Croes, B.; Gower, S.; Hedley, A.; Krewski, D.; Krupnick, A.; Krzyzanowski, M.; Moran, M.D.; Pennell, W.; Samet, J.M.; Schneider, J.; Shortreed, J.; Williams, M. Air pollution and public health: a guidance document for risk managers. J. Toxicol. Environ. Health. 2008. A. ;71(910): page 589; 588-698.

Danielsen, P.H.; Risom, L.; Wallin, H.; Autrup, H.; Vogel, U.; Loft, S.; Moller, P. DNA damage in rats after a single oral exposure to diesel exhaust particles. Elsevier - Mutation Research, 2008. 637 p:49-55.

Datasus - Caderno de Informação de Saúde - Município de São Paulo. 2007. Disponível em: http://tabnet.datasus.gov.br/tabdata/cadernos/sp.htm. Acesso em 27 de fevereiro de 2009.

Davies, B.; Morris, T. Physiological Parameters in Laboratory Animals and Humans. Pharmaceutical Research, 1993. Vol.10, № 7. p: 1093-95. 
de Hartog, J.J.; Lanki, T.; Timonen, K.L.; Hoek, G.; Janssen, N.A.H.; Ibald- Mulli, A.; Peters, A.; Heinrich, J.; Tarkiainen, T.H.; van Grieken, R.; van Wijnen, J.H.; Brunekreef, B.; Pekkanen, J. Associations between PM 2.5 and Heart Rate Variability Are Modified by Particle Composition and Beta-Blocker Use in Patients with Coronary Heart Disease. Environmental Health Perspectives, 2009. Vol. 117, N. $^{\circ} 1, \mathrm{p}: 105-111$.

Decreto Municipal $N^{\circ}$ 37.085, de 03 de Outubro de 1997. Disponível em: http://cetsp1.cetsp.com.br/pdfs/rodizio/Decreto37085.pdf. Acesso em 25 de Julho de 2011.

Decreto Estadual n 47.397, de 4 de Dezembro de 2002. Disponível em: http://ww w.ambiente.sp.gov.br/destaque/Decreto\%20n_47397_02.pdf. Acesso em 11 de Maio de 2011.

Decreto Estadual $n^{0} 50.753$, de 28 de Abril de 2006. Disponível em: http://www.al. .sp.gov.br/repositorio/legislacao/decreto/2006/decreto\%20n.50.753,\%20de\%2028 .04.2006.htm. Acesso em 01 de Maio de 2011.

Dekker JM, Schouten EG, Klootwijk P, Pool J, Swenne CA, Kromhout D. Heart rate variability from short electrocardiographic recordings predicts mortality from all causes in middle-aged and elderly men. The Zutphen Study. Am. J. Epidemiol. 1997.145:899-908.

de Marneffe, M.; Gregoire, J.M.; Waterschoot, P.; Kestemont, M.P. The sinus node and the autonomic nervous system in normals and in sick sinus patients. Acta Cardiol. 1995;50(4):291-308.

de Marneffe, M.; Gregoire, J.M.; Waterschoot, P.; Kestemont, M.P. The sinus node function: normal and pathological. Eur. Heart J. 1993 May;14(5):649-54.

Dockery, D.W. Health Effects of Particulate Air Pollution. Ann. Epidemiol. 2009. 19:257-263. 
Enomoto, M.; Tierney, W.J.; Nozaki, K. Risk of human health by particulate matter as a source of air pollution - comparison with tobacco smoking. The Journal of Toxicological Sciences. 2008. Vol. 33, 251-267.

EPA - U.S. Environmental Protection Agency. Particulate Matter (PM) Basic Information. 2011 Disponível em: http://www.epa.gov/airquality/particlepollution/b asic.html. Acesso em 25 de Julho de 2011.

EPA - U.S. Environmental Protection Agency. Clean Air Act - History of the Clean Air Act. 2012. Disponível em: http://epa.gov/air/caa/caa_history.html. Acesso em 27 de Agosto de 2012.

Escudero, E.M.; Pinilla, O.A. Paradigmas y paradojas de la hipertrofia ventricular izquierda: desde el laboratório de investigación a la consulta clínica. Arch. Cardiol. Méx. 2007. Vol.77 n.3.

Evans, R.; Shaw, D.B. Pathological studies in sinoatrial disorder (sick sinus syndrome). Br. Heart J. 1977 Jul;39(7):778-86.

Fang, S.C.; Cassidy, A.; Christiani, D.C. A systematic review of occupational exposure to particulate matter and cardiovascular disease. Int. J. Environ. Res. Public Health. 2010. Apr;7(4):1773-806.

Farraj, A.K.; Hazari, M.S.; Cascio, W.E. The utility of the small rodent electrocardiogram in toxicology. Toxicol. Sci. 2011 May;121(1):11-30.

Feng, J.; Yang, W. Effects of particulate air pollution on cardiovascular health: a population health risk assessment. PLoS One.; 2012. 7(3):e33385.

Franchini, K.G. Hipertrofia cardíaca: mecanismos moleculares. Rev. Bras. Hipertens., 2001. Vol.8, p:125-142.

Franchini, M.; Mannucci, P.M. Air pollution and cardiovascular disease. Thromb Res.; 2012. 129(3):230-4. 
Gehrmann, J.; Hammer, P.E.; Maguire, C.T.; Wakimoto, H.; Triedman, J.K.; Berul, C.I. Phenotypic screening for heart rate variability in the mouse. Am J Physiol Heart Circ Physiol. 2000 Aug;279(2):H733-40.

Gold, D.R., Litonjua, A., Schwartz, J., Lovett, E., Larson, A., Nearing, B., Allen, G., Verrier, M., Cherry, R., Verrier, R. Ambient pollution and heart rate variability. Circulation. 2000. 101 (11), 1267-1273.

Gottipolu, R.R.; Wallenborn, J.G.; Karoly, E.D.; Schladweiler, M.C.; Ledbetter, A.D.; Krantz, T.; Linak, W.P.; Nyska, A.; Johnson, J.A.; Thomas, R.; Richards, J.E.; Jaskot, R.H.; Kodavanti, U.P. One-Month Diesel Exhaust Inhalation Produces Hypertensive Gene Expression Pattern in Healthy Rats. Environmental Health Perspectives. 2009. Vol. 117, N. ${ }^{\circ} 1$.

Gouveia, N.; Freitas, C.U.; Martins, L.C.; Marcilio, I.O. Hospitalizações por causa respiratórias e cardiovasculares associadas à contaminação atmosférica no Município de São Paulo, Brasil. Cad. Saúde Pública, Rio de Janeiro, 2006. 22(12): 2669-2677.

Grahame, T.J.; Schlesinger, R.B. Health Effects of Airborne Particulate Matter: Do We Know Enough to Consider Regulating Specific Particle Types or Sources? Inhalation Toxicology, 2007. 19:457-481.

Grahame, T.J.; Schlesinger, R.B. Oxidative Stress-Induced Telomeric Erosion as a Mechanism Underlying Airborne Particulate Matter-Related Cardiovascular Disease. Part. Fibre. Toxicol. 2012. 19;9(1):21.

Gundersen HJ. Stereology of arbitrary particles. A review of unbiased number and size estimators and the presentation of some new ones, in memory of William R. Thompson J. Microsc. 1986;143:3-45.

Hartz, A.M.S.; Bauer, B.; Block, M.L.; Hong, J.S.; Miller, D.S. Diesel exhaust particles induce oxidative estresse, proinflammatory signaling, and $\mathrm{P}$ - glycoprotein up-regulation at the blood-brain barrier. FASEB J. 2008. Vol. 22, p:2723-2733. 
Harvey, P.A.; Leinwand, L.A. The cell biology of disease: cellular mechanisms of cardiomyopathy. Cell Biol. 2011. Aug 8;194(3):355-65.

Hedley, A.J. Air Pollution and Public Health - The current avoidable burden of health problems, community costs and harm to future generations. 2009. Disponível em: http://www.legco.gov.hk/yr08-09/english/panels/ea/ea_iaq/papers/ ea_iaq0212cb1-733-2-e.pdf. Acesso em 07 de Junho de 2012.

Howard, C.V.; Reed, M.G. Unbiased Stereology. 2nd Edition Garland Science/BIOS Scientific Publishers, 2005.p:

Hoyer, L.W. The Factor VIII Complex: Structure and Function. Blood. 1981. Jul;58(1):1-13.

Hu, L.W.; Benvenuti, L.A.; Liberti, E.A.; Carneiro-Ramos, M.S.; Barreto-Chaves, M.L.M. Thyroxine-induced cardiac hypertrophy: influence of adrenergic nervous system versus renin-angiotensin system on myocyte remodeling. Am. J. Physiol. Regul. Integr. Comp. Physiol. 2003. 285: R1473-R1480.

Huikuri, H.V.; Niemelä, M.J.; Ojala, S.; Rantala, A.; Ikäheimo, M.J.; Airaksinen, K.E. Circadian rhythms of frequency domain measures of heart rate variability in healthy subjects and patients with coronary artery disease. Effects of arousal and upright posture. Circulation. 1994 Jul;90(1):121-6.

Ibald-Mulli, A.; Timonen, K.L.; Peters, A.; Heinrich, J.; Wölke, G.; Lanki, T.; Buzorius, G.; Kreyling, W.G.; de Hartog, J.; Hoek, G.; ten Brink, H.M.; Pekkanen, J. Effects of particulate air pollution on blood pressure and heart rate in subjects with cardiovascular disease: a multicenter approach. Environ. Health Perspect. 2004 Mar;112(3):369-77. 
Ito, K.; Mathes, R.; Ross, Z.; Nádas, A.; Thurston, G.; Matte, T. Fine particulate matter constituents associated with cardiovascular hospitalizations and mortality in New York City. Environ Health Perspect.; 2011. 119(4):467-73.

Jia, X.; Song, X.; Shima, M.; Tamura, K.; Deng, F.; Guo, X. Effects of fine particulate on heart rate variability in Beijing: a panel study of healthy elderly subjects. Int. Arch. Occup. Environ. Health. 2012. 85:97-107.

Japundzic, N.; Grichois, M.L.; Zitoun, P.; Laude, D.; Elghozi, JL. Spectral analysis of blood pressure and heart rate in conscious rats: effects of autonomic blockers. J. Auton. Nerv. Syst. 1990. Jun;30(2):91-100.

Kampa, M.; Castanas, E. Human health effects of air pollution. Environmental Pollution. 2008. 151, 362-367.

Kass, D.A.; Hare, J.M.; Georgakopoulos, D. Murine cardiac function: a cautionary tail. Circ. Res. 1998 Mar 9;82(4):519-22.

Kinney, P.L. Climate Change, Air Quality, and Human Health. American Journal of Preventive Medicine, 2008. 35(5):459-467.

Kodavanti, U.P.; Schladweiler, M.C.; Ledbetter, A.D.; Hauser, R.; Christiani, D.C.; Samet, J.M.; McGee, J.; Richards, J.H.; Costa, D.L. Pulmonary and systemic effects of zinc-containing emission particles in three rat strains: multiple exposure scenarios. Toxicol. Sci. 2002. Nov;70(1):73-85.

Kodavanti, U.P.; Moyer, C.F.; Ledbetter, A.D.; Schladweiler, M.C.; Costa, D.L.; Hauser, R.; Christiani, D.C.; Nyska A. Inhaled environmental combustion particles cause myocardial injury in the Wistar Kyoto rat. Toxicol. Sci. 2003. Feb;71(2):23745.

Kopp, S.J.; Barron, J.T.; Tow, J.P. Cardiovascular actions of lead and relationship to hypertension: a review. Environ. Health Perspect. 1988. Jun;78:91-9. 
Knuckles, T.L.; Lund, A.K.; Lucas, S.N.; Campen, M.J. Diesel exhaust exposure enhances venoconstriction via uncoupling of eNOS. Toxicology and Applied Pharmacology. 2008. 230: 346-351.

Kuwahara, M.; Yayou, K.; Ishii, K.; Hashimoto, S.; Tsubone, H.; Sugano, S. Power spectral analysis of heart rate variability as a new method for assessing autonomic activity in the rat. J. Electrocardiol. 1994. Oct;27(4):333-7.

Laks, D.; Oliveira, R.C.; André, P.A.; Macchione, M.; Lemos, M.; Faffe, D.; Saldiva, P.H.; Zin, W.A. Composition of Diesel Particles Influences Acute Pulmonary Toxicity: An Experimental Study in MICE. Inhalation Toxicol. , 2008. Vol. 20 p: 1037-1042.

Langrish, J.P.; Bosson, J.; Unosson, J.; Muala, A.; Newby, D.E.; Mills, N.L.; Blomberg, A.; Sandström, T. Cardiovascular effects of particulate air pollution exposure: time course and underlying mechanisms. J. Intern. Med. 2012 Sep; 272(3):224-39. doi: 10.1111/j.1365-2796.2012.02566.x

Laumbach, R.; Tong, J.; Zhang, L.; Ohman-Strickland, P.; Stern, A.; Fiedler, N.; Kipen, H.; Kelly-McNeil, K.; Lioya, P.; Zhang, J. Quantification of 1- aminopyrene in human urine after a controlled exposure to diesel exhaust. Journal of Environmental Monitoring - The Royal Society of Chemistry, 2009. Vol.11, p: 153-159.

Leenen, F.H.H.; White, R.; Yuan, B. Isoproterenol-induced cardiac hypertrophy: role of circulatory versus cardiac renin-angiotensin system. Am. J. Physiol. Heart Circ. Physiol. 2001. 281: H2410-H2416.

Lei Municipal n 11.733 de 27 de março de 1995. Disponível em: http://www.tjsp.j us.br/Handlers/FileFetch.ashx?id_arquivo=19486. Acesso em 24 de Julho de 2011. 
Lei Municipal n¹2.157 de 09 de agosto de 1996. Disponível em: http://www3.pre feitura.sp.gov.br/cadlem/secretarias/negocios_juridicos/cadlem/integra.asp?alt=1 0081996L\%20121570000. Acesso em 24 de Julho de 2011.

Lei Municipal 12.490, de 03 de Outubro de 1997. Disponível em: http://www3.pref eitura.sp.gov.br/cadlem/secretarias/negocios_juridicos/cadlem/integra.asp?alt=04 101997L\%20124900000. Acesso em 25 de Julho de 2011.

Lei $n^{\circ}$ 11.097, de 13 de setembro de 2005. Disponível em: http://www.planalto. gov.br/ccivil_03/_ato2004-2006/2005/Lei/L11097.htm. Acesso em 11 de Março de 2008.

Lei Municipal no 14.717 de 17 de abril de 2008. Disponível em: http://www3.prefeit ura.sp.gov.br/cadlem/secretarias/negocios_juridicos/cadlem/integra.asp?alt=180 42008L\%20147170000. Acesso em 24 de Julho de 2011.

Lev, M. Aging changes in the human sinoatrial node. J. Gerontol. 1954 Jan;9(1):1-9.

Levy, D.; Anderson, K.M.; Savage, D.D.; Balkus, S.A.; Kannel, W.B.; Castelli W.P. Risk of ventricular arrhythmias in left ventricular hypertrophy: the Framingham Study. Am. J. Cardiol. 1987. 60:560-5.

Li, R.; Ning, Z.; Cui, J.; Khalsa, B.; Ai, L.; Takabe, W.; Beebe, T.; Majumdar, R.; Sioutas, C.; Hsiai, T. Ultrafine particles from diesel engines induce vascular oxidative estresse via JNK activation. Free Radic. Biol. Med. 2009. Mar 15;46(6):775-82.

Liao, D.; Barnes, R.W.; Chambless, L.E.; Simpson, R.J. Jr.; Sorlie, P.; Heiss, G. Age, race, and sex differences in autonomic cardiac function measured by spectral analysis of heart rate variability-The ARIC Study. Am. J. Cardiol. 1995;76:906-12. 
Lichtenfels, A.J.; Gomes, J.B.; Pieri, P.C.; El Khouri Miraglia, S.G.; Hallak, J.; Saldiva, P.H. Increased levels of air pollution and a decrease in the human and mouse male-to-female ratio in São Paulo, Brazil. Fertil Steril. 2007. Jan;87(1):2302.

Lorenzi, T.F. Manual de hematologia: propedêutica e clínica. Rio de Janeiro: $4^{\circ}$. Ed. Guanabara Koogan; 2006. p.44-83: Fisiologia das Células do Sangue e da Hemostasia.

Mammarella, A.; Paradiso, M.; Basili. S. Morphologic left ventricular patterns and prevalence of high-grade ventricular arrhythmias in the normotensive and hypertensive elderly. Adv. Ther. 2000. 17:222-9.

Maron, B.J. Hypertrophic cardiomyopathy. Lancet; 1997. 350: 127-33

Maron, B.J. Hypertrophic Cardiomyopathy: A Systematic Review. JAMA. 2002. Vol 287 , No. 10 , pp. $1308-20$

Martins, M.C.H.; Fatigati, F.L.; Véspoli,T.C.; Martins, L.C.; Pereira, L.A.A.; Martins, M.A.; Saldiva, P.H.; Braga, A.L.F. Influence of socioeconomic conditions on air pollution adverse health effects in elderly people: an analysis of six regions in São Paulo, Brazil. J. Epidemiol. Community Health. 2004. 58:41-46.

Martins, M.A.G. Variação da composição e toxicidade do material particulado ao longo do dia na cidade de São Paulo. 2010. USP/FM/DBD-233/10, p: 28 - 37.

Mills, N.L.; Donaldson, K.; Hadoke, P.W.; Boon, N.A.; MacNee, W.; Cassee, F.R.; Sandström, T.; Blomberg, A.; Newby, D.E. Adverse Cardiovascular effects of air pollution. Nature Clinical practice cardiovascular medicine. 2009. Vol. 06, № 1, p. 36-44.

Møller, P.; Folkmann, J.K.; Forchhammer, L.; Bräuner, E.V.; Danielsen, P.H.; Risom, L.; Loft, S. Air pollution, oxidative damage to DNA, and carcinogenesis. Cancer Lett. 2008 Jul. 18;266(1):84-97. 
Monteiro, L. Valores de referência do RDW-CV e do RDW-SD e sua relação com o VCM entre os pacientes atendidos no ambulatório do Hospital Universitário Oswaldo Cruz - Recife, PE. Rev. Bras. Hematol. Hemoter. 2010.

Mühlfeld, C.; Nyengaard, J.R.; Mayhew, T.M. A review of state-of-the-art stereology for better quantitative 3D morphology in cardiac research. Cardiovasc. Pathol. 2010; 19:65-82.

Moore, M.R.; Meredith, P.A.; Goldberg, A.; Carr, K.E.; Toner, P.G.; Lawrie, T.D. Cardiac effects of lead in drinking water of rats. Clin. Sci. Mol. Med. 1975. Oct;49(4):337-41.

Murad, N.; de Franco, M.F.; Tucci, P.J.F. Caracterização Funcional da Hipertrofia Miocárdica Induzida pelo Isoproterenol e de sua Regressão. Arq. Bras. Cardiol. 2001. volume $77\left(n^{\circ} 1\right), 51-8$.

Nakajima-Takenaka, C.; Zhang, G.X.; Obata, K.; Tohne, K.; Matsuyoshi, H.; Nagai, Y.; Nishiyama, A.; Takaki, M. Left ventricular function of isoproterenolinduced hypertrophied rat hearts perfused with blood: mechanical work and energetic. Am. J. Physiol. Heart Circ. Physiol. 2009. 297: H1736-H1743.

Nemmar, A.; Al-Maskari, S.; Ali, B.H.; Al-Amri; I.S. Cardiovascular and lung inflammatory effects induced by systemically administered diesel exhaust particles in rats. Am. J. Physiol. Lung Cell. Mol. Physiol. 2007. 292: L664-L670.

Nishimura, M.; Tokoro, T; Nishida, M.; Hashimoto, T.; Kobayashi, H.; Yamazaki, S.; Imai, R.; Okino, K.; Iwamoto, N.; Takahashi, H.; Ono, T. Sympathetic overactivity and sudden cardiac death among hemodialysis patients with left ventricular hypertrophy. Int. J. Cardiol. 2010. Jun. 25;142(1):80-6.

Oberdörster, G.; Oberdörster, E.; Oberdörster, J. Nanotoxicology: An Emerging Discipline Evolving from Studies of Ultrafine Particles. Environmental Health Perspectives. 2005. Vol. 113, N. ${ }^{\circ}$ 7, p: 823-839. 
Okayama, Y.; Kuwahara, M.; Suzuki, A.K.; Tsubone, H. Role of reactive oxygen species on diesel exhaust particle-induced cytotoxicity in rat cardiac myocytes. J. Toxicol. Environ. Health A. 2006. Sep;69(18):1699-710.

Oliveira, M.R.A.A. Hematologia Básica: fisiopatologia e estudo laboratorial. $2^{\circ}$ Ed. São Paulo: American Med; 1998. p. 39-45. Morfologia e Função dos Leucócitos.

Ommen, S.R.; Nishimura, R.A. Hypertrophic Cardiomyopathy. Curr. Probl. Cardiol.; 2004. 29:233-91.

Ommen, S.R.; Nishimura, R.A.; Tajik, A.J.; Hypertrophic Cardiomyopathy. 2011. Disponível em: www.cardiotext.com/pdf/fuster33.pdf. Acesso em 25 de Julho de 2011.

Park, S.K.; O'Neill, M.S.; Vokonas, P.S.; Sparrow, D.; Schwartz, J. Effects of Air Pollution on Heart Rate Variability: The VA Normative Aging Study. Environ. Health Perspect.; 2005. 113:304-309.

Peretz, A.; Sullivan, J.H.; Leotta, D.F.; Trenga, C. A.; Sands, F.N.; Allen, J.; Carlsten, C.; Wilkinson, C.W.; Gill, E.A.; Kaufman, J.D. Diesel Exhaust Inhalation Elicits Acute Vasoconstriction in vivo. Environmental Health Perspectives. 2008. Vol. 116, No 7, P. 937-942.

Peters, A.; Perz, S.; Döring, A.; Stieber, J.; Koenig, W.; Wichmann, HE. Increases in heart rate during an air pollution episode. Am. J. Epidemiol. 1999 Nov 15;150(10):1094-8.

Phalen, R.F.; Phalen, R.N. Introduction To Air Pollution Science: A Public Health Perspective. 2011. Jones \& Bartlett Learning. $1^{\circ}$ edição. http://samples.jbp ub.com/9780763780449/80449_Ch01_001_rev.pdf. Acesso em 02 de Julho de 2012.

Poliac, L.C.; Barron, M.E.; Maron, B.J. Hypertrophic Cardiomyopathy. Anesthesiology; 2006. 104:183-92. 
Pope III, C.A.; Verrier, R.L.; Lovett, E.G.; Larson, A.C.; Raizenne, M.E.; Kanner, R.E.; Schwartz, J.; Villegas, G.M.; Gold, D.R.; Dockery, D.W. Heart rate variability associated with particulate air pollution. Am. Heart J. 1999 Nov;138(5 Pt 1):890-9.

Pope III, C.A.; Burnett, R.T.; Thun, M.J.; Calle, E.E.; Krewski, D.; Ito, K.; Thurston, G.D. Lung cancer, cardiopulmonary mortality, and long-term exposure to fine particulate air pollution. JAMA. 2002. Vol. 287, Nº9, P.1132-1141

Pope III, C.A.; Hansen, M.L.; Long, R.W.; Nielsen, K.R.; Eatough, N.L.; Wilson, W.E.; Eatough, D.J. Ambient Particulate Air Pollution, Heart Rate Variability, and Blood Markers of Inflammation in a Panel of Elderly Subjects . Environ. Health Perspect. 2004a. 112:339-345.

Pope III, C.A.; Burnett, R.T.; Thurston, G.D.; Thun, M.J.; Calle, E.E.; Krewski, D.; Godleski, J.J. Cardiovascular mortality and long-term exposure to particulate air pollution: epidemiological evidence of general pathophysiological pathways of disease. Circulation. 2004b. Jan. 6;109(1):71-7.

Rang, H.P.; Dale, M.M.; Ritter, J.M.; Flower, R.J. Rang \& Dale Farmacologia. Tradução. $6^{\circ}$ Edição. Elsevier. 2007. 168-188p. 277-297p.

Rivero, D.H.R.F. Alterações eletrocardiográficas, hematológicas e histológicas induzidas pelo material particulado fino da cidade de São Paulo. 2005. USP/FM/SBD-163/05, 2 - 7.

Rivero, D.H.R.F; Sassaki, C.; Lorenzi-Filho, G.; Saldiva, P.H. PM 2.5 induces acute electrocardiographic alterations in healthy rats. Enviroment Research, 2005a. Vol. 99, p: 262-266.

Rivero, D.H.R.F; Soares, SRC; Lorenzi-Filho, G.; Saiki, M.; Godleski, J.J.; Antonangelo, L.; Dolnikoff, M; Saldiva, P.H. Acute cardiopulmonary alterations induced by fine particulate matter of São Paulo, Brazil. Toxicological Sciences. 2005b. 85, 898-905. 
Routledge, H.C.; Chowdhary, S.; Townend, J.N. Heart rate variability--a therapeutic target? J. Clin. Pharm. Ther. 2002. Apr;27(2):85-92

Rowan III, W.H.; Campen, M.J.; Wichers, L.B.; Watkinson, W.P. Heart rate variability in rodents: uses and caveats in toxicological studies. Cardiovasc. Toxicol. 2007.;7(1):28-51.

Saldiva, P.H.; Lichtenfels, A.J.; Paiva, P.S.; Barone, I.A.; Martins, M.A.; Massad, E.; Pereira, J.C.; Xavier, V.P.; Singer, J.M.; Böhm, G.M. Association between air pollution and mortality due to respiratory diseases in children in São Paulo, Brazil: a preliminary report. Environ. Res.; 1994. 65(2):218-25.

Saldiva, P.H.; Pope, C.A.; Schwartz, J.; Dockery, D.W.; Lichtenfels, A.J.; Salge, J.M; Barone, I.; Bohm, G.M. Air pollution and mortality in elderly people: a timeseries study in Sao Paulo, Brazil. Environ. Health. 1995. 50(2),p: 159-163.

Saldiva, P.H. - Air pollution and our lung disease patients. J. Bras. Pneumol. 2008.;34(1):1.

Samesina, N.; Amodeo, C. Hipertrofia ventricular esquerda. Ver. Bras. Hipertens. 2001. Vol. 8, p:316-320.

Santos, U.P.; Terra-Filho, M.; Lin, C.A.; Pereira, L.A.; Vieira, T.C.; Saldiva P.H.; Braga, A.L. Cardiac arrhythmia emergency room visits and environmental air pollution in Sao Paulo, Brazil. J. Epidemiol. Community Health; 2008. 62(3): 26772.

Samet, J.M.; Dominici, F.; Curriero, F.C.; Coursac, I.; Zeger, S.L. Fine particulate air pollution and mortality in 20 U.S. cities, 1987-1994. New Eng. J. Med. 2000 343, pp. 1742-1749

Schulz, H.; Harder, V.; Ibald-Mulli, A.; Khandoga, A.; Koenig, W.; Krombach, F.; Radykewicz, R.; Stampfl, A.; Thorand, B.; Peters, A. Cardiovascular Effects of Fine and Ultrafine Particles. J. Aerosol Med. 2005. Spring;18(1):1-22. 
SEBRAE - Cartilha de Biodiesel. 2007. Disponível em: http://www.biblioteca.sebr ae.com.br/. Acesso em 02 de fevereiro de 2008.

Seidman, J.G.; Seidman, C. Genetic Basis for Cardiomyopathy - from Mutation Identification to Mechanistic Paradigms. Cell, 2001. Vol. 104, 557-567.

Shrey, K.; Suchit, A.; Deepika, D.; Shruti, K; Vibha, R. Air pollutants: the key stages in the pathway towards the development of cardiovascular disorders. Environ. Toxicol. Pharmacol.; 2011. 31(1):1-9.

Sierra-Vargas, M.P.; Teran, L.M. Air Pollution: Clinical Impact and Prevention. Respirology. 2012. Jun 22. doi: 10.1111/j.1440-1843.2012.02213.x.

Soor, G. S.; Luk, A.; Ahn, E.; Abraham, J.R.; Woo, A.; Ralph-Edwards, A.; Butany, J. Hypertrophic cardiomyopathy: current understanding and treatment objectives. J. Clin. Pathol.; 2008. 62: 226-235

Spirito, P.; Seidman, C.E.; McKenna, W.J.; Maron, B.J. The Management of Hypertrophic Cardiomyopathy. N. Engl. J. Med.; 1997. 336:775-785.

Stein, P.K.; Domitrovich, P.P.; Hui, N.; Rautaharju, P. Gottdiener, J. Sometimes higher heart rate variability is not better heart rate variability: results of graphical and nonlinear analyses. J. Cardiovasc. Electrophysiol. 2005 Sep;16(9):954-9

Swanson, K.J.; Madden, M.C.; Ghio, A.J. Biodiesel Exhaust: The Need for Health Effects Research. Environmental Health Perspectives. 2007. Vol.115. № 4. p: 496-499.

Swynghedauw, B.; Chevalier, B.; Charlemagne, D.; Mansier, P.; Carré, F. Cardiac hypertrophy, arrhythmogenicity and the new myocardial phenotype.II. The cellular adaptational process Cardiovasc. 1997a. Res; 35: 6-12.

Swynghedauw, B.; Jasson, S.; Clairambault, J.; Chevalier, B.; Heymes, C.; Medigue, C.; Carré, F.; Mansier, P. Myocardial determinants in regulation of the heart rate. J. Mol. Med. (Berl). 1997b. Nov-Dec;75(11-12):860-6. 
Takeshita, D.; Shimizu, J.; Kitagawa, Y.; Yamashita, D.; Tohne, K.; NakajimaTakenaka, C.; Ito, H.; Takaki, M. Isoproterenol-Induced Hypertrophied Rat Hearts: Does Short-Term Treatment Correspond to Long-Term Treatment? J. Physiol. Sci. 2008. Vol. 58, No. 3; pp. 179-188.

Taylor, P.B.; Tang, Q. Development of isoproterenol - induced cardiac hypertrophy. Can. J. Physiol. Pharmacol. 1984. 62(4):384-389.

Thorpe, A.; Harrison, R. M. Sources and properties of non-exhaust particulate matter from road traffic: A review. Sci. Total Environ. 2008. 1;400(1-3):270-82.

Tsuji, H.; Venditti, F.J. Jr.; Manders, E.S.; Evans, J.C.; Larson, M.G.; Feldman, C.L.; Levy, D. Determinants of heart rate variability. J. Am. Col.I Cardiol. 1996 Nov 15;28(6):1539-46.

Twigg, M.V.; Phillips, P.R. Cleaning the Air We Breathe - Controlling Diesel Particulate Emissions from Passenger Cars. Platinum Metals Review. 2009. Volume 53, Number 1, pp. 27-34(8).

Urch, B.; Silverman, F.; Corey, P.; Brook, J.R.; Lukic, K. Z.; Rajagopalan, S.; Brook, R.D. Acute Blood Pressure Responses in Healthy Adults During Controlled Air Pollution Exposures. Environ. Health Perspect. 2005. 113:1052-1055.

Vallada E.P. Manual de técnicas hematológicas. São Paulo: Atheneu; 2002. p.201-6: Testes para fragilidade e resistência capilar. (Série Manuais práticos de exames de laboratório clínico Prof. E. Vallada).

van Berlo, D.; Albrecht, C.; Knaapen, A.M.; Cassee, F.R.; Gerlofs-Nijland, M.E.; Kooter, I.M.; Palomero-Gallagher, N.; Bidmon, H.J.; van Schooten, F.J.; Krutmann, J.; Schins, R.P. Comparative evaluation of the effects of short-term inhalation exposure to diesel engine exhaust on rat lung and brain. Arch. Toxicol. 2010. Jul;84(7):553-62. 
Vanderlei, L.C.M.; Pastre, C.M.; Hoshi, R.A.; Carvalho, T.D.; Godoy, M.F. Noções básicas de variabilidade da frequência cardíaca e sua aplicabilidade clínica. Rev. Bras. Cir. Cardiovasc. 2009. 24(2): 205-217.

Veras, M.M. Efeitos da poluição do ar da cidade de São Paulo sobre o processo reprodutivo de camundongos com ênfase no desenvolvimento da placenta e cordão umbilical. 2008. Universidade de São Paulo - Biblioteca digital teses e dissertações. Disponível em: http://www.teses.usp.br/teses/disponiveis/5/5160/tde -311102008-12 55138/. Acesso em 12 de Fevereiro de 2009.

Vincent, R.; Bjarnason, S.G.; Adamson, I.Y.; Hedgecock, C.; Kumarathasan, P.; Guénette, J.; Potvin, M.; Goegan, P.; Bouthillier, L. Acute pulmonary toxicity of urban particulate matter and ozone. Am. J. Pathol. 1997. Dec;151(6):1563-70.

Wang, J.; Xie, P.; Kettrup, A.; Schramm, K.W. Inhibition of progesterone receptor activity in recombinant yeast by soot from fossil fuel combustion emissions and air particulate materials. Sci. Total Environ. 2005. Oct 15;349(1-3):120-8.

Watkinson, W.P.; Campen, M.J.; Costa D.L. Cardiac arrhythmia induction after exposure to residual oil fly ash particles in a rodent model of pulmonary hypertension. Toxicol. Sci. 1998. Feb;41(2):209-16.

Wellenius, G.A.; Saldiva, P.H.; Batalha, J.R.; Krishna Murthy, G.G.; Coull, B.A.; Verrier, R.L.; Godleski, J.J. Electrocardiographic changes during exposure to residual oil fly ash (ROFA) particles in a rat model of myocardial infarction. Toxicol. Sci. 2002. Apr;66(2):327-35.

WHO - Air quality guidelines for particulate matter, ozone, nitrogen dioxide and sulfur dioxide - Global update 2005 - Summary of risk assessment. 2005. Disponível em: http://whqlibdoc.who.int/hq/2006/WHO_SDE_PHE_OEH_06.02_e ng.pdf. Acesso em 30 de Maio de 2011.

WHO - Particulate matter air pollution: how it harms health. 2005a. Fact sheet EURO/04/05 Berlin, Copenhagen, Rome. Disponível em: http://www.chaseireland. org/Documents/WHOParticulateMatter.pdf. Acesso em 30 de Maio de 2011. 
WHO - Heath topics - Air pollution. 2011. Disponível em: http://www.who.int/topics lair_pollution/en /. Acesso em 30 de Maio de 2011.

Wichmann, H.E. Diesel exhaust particles. Inhal. Toxicol.; 2007. 19 Suppl. 1:241-4.

Wold, L.E.; Ying, Z.; Hutchinson, K.R.; Velten, M.; Gorr, M.W.; Velten, C.; Youtz, D.J.; Wang, A.; Lucchesi, P.A.; Sun, Q.; Rajagopalan, S. Cardiovascular remodeling in response to long-term exposure to fine particulate matter air pollution. Circ. Heart Fail. 2012. 1;5(4):452-61.

Wong, C.M.; Ou, C.Q.; Chan, K.P.; Chau, Y.K.; Thach, T.Q.; Yang, L.; Chung, R.Y.N.; Thomas, G. N.; Peiris, J.S.M.; Wong, T.W.; Hedley, A.J.; Lam, T.H. The Effects of Air Pollution on Mortality in Socially Deprived Urban Areas in Hong Kong, China. Environmental Health Perspectives. 2008. Vol. 116, № 9.

Yan, Y.H.; Huang, C.H.; Chen, W.J.; Wu, M.F.; Cheng, T.J. Effects of Diesel Exhaust Particles on Left Ventricular Function in Isoproterenol-Induced Myocardial Injury and Healthy Rats. Inhalation Toxicology. 2008. 20:2,199-203.

Yeatts, K.; Svendsen, E.; Creason, J.; Alexis, N.; Herbst, M.; Scott, J.; Kupper, L.; Williams, R.; Neas, L.; Cascio, W.; Devlin, R. B.; Peden, D.B. Coarse Particulate Matter (PM2.5-10) Affects Heart Rate Variability, Blood Lipids, and Circulating Eosinophils in Adults with Asthma. Environ. Health Perspect. 2007. 115:709-714.

Zanchi, A.C.; Saiki, M.; Saldiva, P.H.; Barros, H.M.; Rhoden, C.R. Hippocampus lipid peroxidation induced by residual oil fly ash intranasal instillation versus habituation to the open field. Inhal. Toxicol. 2010. Jan;22(1):84-8.

Zanobetti, A.; Canner, M.J.; Stone, P.H.; Schwartz, J.; Sher, D.; Eagan- Bengston, E. ; Gates, K.A.; Hartley, L.H.; Suh, H.; Gold, D.R. Ambient Pollution and Blood Pressure in Cardiac Rehabilitation Patients. Circulation. 2004. 110:2184-2189. 
Zareba, W.; Nomura, A.; Couderc, J.P. Cardiovascular Effects of Air Pollution: What to Measure in ECG? Environ. Health Perspect. 2001. 109 Suppl. 4:533-8.

Zelikoff, J.T.; Schermerhorn, K.R.; Fang, K.; Cohen, M.D.; Schlesinger, R.B. A role for associated transition metals in the immunotoxicity of inhaled ambient particulate matter. Environ. Health Perspect. 2002. Oct;110 Suppl 5:871-5. 